\title{
DIE SUBURBANE ZONE VON ZÜRICH
}

\section{WALTER Schärer}

\section{E I N L E IT U N G}

Im Laufe der letzten hundert Jahre hat sich die Stadt Zürich von einer mittelalterlichen Kleinstadt zu einer Großstadt entwickelt. Als Kennzeichen dieser Wandlung seien die starke räumliche Ausdehnung und die bedeutende Zunahme der Funktionen als Zentrum erwähnt.

Mit dem räumlichen Wachstum ist die ehemalige scharfe Abgrenzung des baulichen Stadtgebietes durch die Fortifikationen verloren gegangen. An Stelle des sozusagen linearen Stadtrandes finden wir heute eine mehr oder weniger breite Zone, die den Übergang zur ländlichen Umgebung vermittelt. In dieser sind städtische und ländliche Elemente vermischt. Der Prozeß der Vermischung, bei dem die ländlichen Elemente eine offensichtlich passive Rolle zu spielen scheinen, dauert an. Die erwähnte Zone ist deshalb in bezug auf ihre Zusammensetzung, ihre Ausdehnung und ihre Lage ständigen Veränderungen unterworfen. Besonders eindrücklich ist dabei, wie sie sich unaufhaltsam weiter in die ländliche Umgebung der Stadt hinaus verschiebt. Die Notwendigkeit zweimaliger Eingemeindungen hat im Falle von Zürich nicht nur die direkt betroffene Bevölkerung, sondern weite Volkskreise mindestens des ganzen Kantons auf diese Erscheinung am Rande der wachsenden Stadt aufmerksam gemacht.

Übergangszonen sind noch bei vielen andern Städten $\mathrm{zu}$ finden. Ihre Existenz scheint sogar für alle größeren Städte mindestens der westlichen Welt bezeichnend zu sein. Jedenfalls zeugen auch eine Anzahl allgemein gebräuchliche Begriffe wie 《Vorort», 《Vorortszone», «Vorstadt», «Bannmeile», «Banlieu», 《Suburban Zone» und andere davon, daß es am Rande größerer Städte Gebiete gibt, die weder ohne weiteres zur Stadt selbst noch zu ihrer ländlichen Umgebung gerechnet werden können. Eine eindeutige Definition oder gar eine allgemein anerkannte Abgrenzung dieser Übergangszone gibt es nicht, was aus zahlreichen Arbeiten verschiedener Autoren, wie Bonnoure (2), Chatelin (10), Clozier (13), Dickinson (14), Carol (9), Martin (18a), um nur einige zu nennen, hervorgeht. Vielmehr sind die Auffassungen ebenso zahlreich wie die Gesichtspunkte der Betrachter. So können die oben erwähnten Begriffe recht unterschiedliche Deutungen erhalten, und zwar je nach dem Gesichtspunkt des Betrachters, der ein politischer, wirtschaftlicher, soziologischer, verkehrstechnischer, verwaltungsmäßiger oder allgemein landschaftskundlicher sein kann.

Diese Übergangszone kann auf der Grundlage der Definition des Landschaftsbegriffes von CAROL (8) untersucht werden: «Das Objekt der Geographie ist die Erdhülle, die Geosphäre. Sie ist ein sach-raum-zeitliches Gebilde, dessen besondere Wesensart in einer spezifischen Korrelation von Lithosphäre, Hydrosphäre, Atmosphäre, meist ergänzt durch Biosphäre und Anthroposphäre, liegt. Landschaft nun ist ein beliebig begrenzbarer (vertikaler) Ausschnitt der Geosphäre.» Man kann also willkürlich Ausschnitte aus dem Bereich der Erdhülle auswählen, etwa ein Stück eines Waldes, die Fläche eines Gemeindebannes, einen Kontinent oder irgend einen Ausschnitt in irgend einer Form; bei allen handelt es sich um Landschaft, wenn nur immer alle Sphären und ihr Zusammenwirken berücksichtigt werden. Diese Sphären überlagern und durchdringen sich gegenseitig und sind in verschiedenster Art und Weise und stärker oder schwächer miteinander verknüpft. «Wobei sich», immer nach CAROL, «der Mensch zwar nie völlig, aber doch weitgehend von einer zwingenden Bindung zur Natur lösen kann. Er allein vermag über das kausale Verwobensein hinauszutreten, die außermenschliche Natur zweckgerichtet, final sich dienstbar zu machen.» Es sind somit verschiedenartige, mindestens zum Teil voneinander unabhängige 
Kräfte bei der Gestaltung der Landschaft am Werk. Wir wollen dabei namentlich zwischen den Kräften unterscheiden, die physischen oder biologischen Gesetzmäßigkeiten folgen und den Kräften des Menschen, die zwar auch im Physischen und Biologischen wurzeln, darüber hinaus aber doch ganz anders geartet sind. Diese Kräfte sind es, die der Kulturlandschaft das Gepräge geben, die überhaupt erst die Naturlandschaft zur Kulturlandschaft umgestalten.

Wenn sich in den letzten 150 Jahren die Kulturlandschaft im Bereiche der Übergangszone am Rande der Stadt Zürich stark verändert hat, dann ist das fast ausschließlich dem Wirken der menschlichen Kräfte zuzuschreiben. Wo ehemals die Limmat nach natürlichen Gesetzen einen mäanderreichen Lauf durch das Tal wählte, folgt heute ein gezähmter Wasserlauf dem ihm vom Menschen vorgezeichneten Bett; wo einfache Fähren den Verkehr über den Fluß besorgten, spannen sich heute feste Brücken; wo Fahrwege und Fußpfade sich durch das Gelände wanden, ziehen breite asphaltierte Straßen und Eisenbahnen; wo sich Wiesen-, Acker- und Weideland um stille Bauerndörfer breitete, stehen Wohnquartiere und Fabriken, und wo einst die Bauern auf ihren Feldern selber pflanzten, was für die Bedürfnisse der Dorfbevölkerung notwendig war, sorgen jetzt weitreichende Organisationen für die Beschaffung und Verteilung von Lebens- und Genußmitteln. Die Menschen haben wahrlich mit starken Kräften gestaltend in das Gefüge der Landschaft eingegriffen. Freilich konnten sie dies nicht ganz unbekümmert um die Kräfte der andern, außermenschlichen, Sphären tun. Diese haben in mancher Beziehung, aber durchaus nicht überall, auf das Gestaltungswerk des Menschen einen mitbestimmenden Einfluß ausgeübt. Auf jeden Fall sind Komponenten vorhanden, die, wie etwa das Relief, an der Gestaltung dieser Kulturlandschaft einen durchaus realen und wesentlichen Anteil haben.

Betrachten wir nun diese Kulturlandschaft von einem bestimmten Gesichtspunkt aus, zum Beispiel von dem des Bauern oder des Verkehrsfachmannes, so ist damit die Auswahl von bestimmten Merkmalen verbunden. Diese werden von den hinter ihnen stehenden Kräften in besonderen Strukturen geordnet. Ändern wir den Gesichtspunkt, richten wir also unser Augenmerk auf andere Merkmale und damit auf andere Kräfte, dann ändern sich auch die Formen der Strukturen. Aus dieser Tatsache ist auch die oben erwähnte vielfältige Deutung der Begriffe «Vorort», 《Vorstadt»u. a. zu erklären. Weil die durchgehende kausale Abhängigkeit zwischen den verschiedenen Kräften fehlt, brauchen sich die von ihnen erzeugten Strukturen nicht unbedingt zu decken. Es kann deshalb auch nicht gelingen, ein Strukturbild zu finden, das sämtliche Merkmale berücksichtigt und somit eine Funktion aller in der Landschaft wirksamen Kräfte darstellen würde. Dies steht im Gegensatz zu den sachlich-räumlichen Definitionen des Landschaftsbegriffes, in denen Landschaft ein einheitlich integriertes Stück der Erdhülle, ein Landschaftsindividuum ist und damit zur Auffassung, daß es möglich ist, individuelle landschaftliche Ganzheiten, die alle Gesichtspunkte berücksichtigen und sich von ihrer Umgebung - andern solchen Ganzheiten - unterscheiden, zu bestimmen und abzugrenzen ${ }^{1}$.

Ich schließe mich der Auffassung von Hettner ${ }^{2}$ an, daß Landschaft nicht aus einem Prinzip, sondern nur aus mehreren, völlig verschiedenen erklärbar ist. Nach CArol läßt sich die Landschaft nur aus einer Reihe zweckmäßig auszuwählenden und genau zu definierenden Betrachtungsweisen erfassen. Diese Reihe ausgewählter, definierter und mit der Zeit allgemein anerkannter Betrachtungsweisen liegt noch nicht vor, wie es nach BoEscH ${ }^{3}$ überhaupt noch kein akzeptiertes oder akzeptierbares System der Geographie gibt. In seiner neuesten Publikation «Zur Diskussion um Landschaft und Geographie» macht nun CARoL dafür einen Vorschlag. In einer Gliederung der Kulturgeographie stellt er den kulturlandschaftlichen Elementarsphären die entspre-

\footnotetext{
1 Vergl. Carol (8).

2 ebenda.

3 ebenda.
} 
chenden kulturlandschaftlichen Betrachtungssysteme als Hauptdisziplinen der Anthropogeographie gegenüber. Da selbst für die einzelnen Betrachtungssysteme, wie etwa das anthropogeographische, das sozialgeographische, das wirtschaftsgeographische oder das agrargeographische, die geographischen Inhalte noch zu umfassend sind, um als solche zweckmäßig untersucht und dargestellt werden zu können, ist eine weitere Unterteilung der Gesichtspunkte notwendig. Innerhalb eines Betrachtungssystems ist deshalb noch eine «formale» und eine «funktionale» Betrachtungsrichtung zu unterscheiden. Beide können in aktueller Sicht und historisch-genetisch behandelt werden ${ }^{4}$.

Welches sind nun aber die Gesichtspunkte, von denen aus die Betrachtung des Stadtrandgebietes zu erfolgen hat, damit ein weitgehendes Verständnis dieser Kulturlandschaft möglich wird? Wie bereits früher gesagt, vermischen sich hier städtische und ländliche Elemente. Hier treffen zwei ganz verschiedene Welten aufeinander: die des Städters und die des Bauern. In der einen sind es die wirtschaftenden Städter, in der andern die wirtschaftenden Bauern, die der Kulturlandschaft das besondere Gepräge geben. Die Unterschiede sind dabei so offensichtlich, da $\beta$ wir geradezu von einer «städtischen» und einer «ländlichen Kulturlandschaft» sprechen können. Wollen wir also von unserem Untersuchungsobjekt ein einigermaßen zutreffendes Bild erhalten, müssen wir es mindestens einerseits unter dem Gesichtswinkel des Städters und anderseits unter demjenigen des Bauern betrachten. Dabei ist zu beachten, daß die Kräfte, welche die städtische Kulturlandschaft konstituieren, äußerst vielgestaltig sind, im Gegensatz zu den relativ einfachen Kräften, welche die ländliche Kulturlandschaft schaffen.

Diese allgemeinen theoretischen Ausführungen waren notwendig, um darzulegen, welche grundsätzlichen Voraussetzungen bei der Problemstellung gemacht werden müssen. Folgende Auffassungen betrachte ich für die vorliegende Arbeit als wesentlich:

1. Die Kulturlandschaft ist ein höchst komplexes Gebilde.

2. Die bei der Gestaltung der Kulturlandschaft wirksamen Kräfte stehen nicht unbedingt durchwegs in kausalem Zusammenhang. Die Kulturlandschaft - als komplexeste Ausprägung der Landschaft - ist deshalb nicht aus einem, sondern nur aus mehreren, völlig verschiedenen Prinzipien zu verstehen.

3. Ein vollumfängliches Verständnis der Kulturlandschaft wäre nur bei Anwendung aller möglichen Gesichtspunkte denkbar. Bei zweckmäßiger Auswahl vermögen auch wenige Gesichtspunkte zu einem weitgehenden Verständnis zu verhelfen. Für die Kulturlandschaft des Stadtrandes sind der agrargeographische und der stadtgeographische wesentlich.

\section{PROBLEMSTELLUNG}

Ausgehend von den in der Einleitung erwähnten allgemeinen Voraussetzungen und der Tatsache, daß mit dem neuzeitlichen raschen Hinauswachsen der Stadt in die ländliche Umgebung eine Kulturlandschaft von besonderer Prägung entstanden ist, über die weder nach Inhalt, Struktur und Verbreitung Klarheit herrscht, sind für meine Arbeit folgende Probleme zu stellen :

1. Welches sind Veränderungen der Kulturlandschaft im Randgebiet der Stadt Zürich, das im Laufe der Entwicklung in den städtischen Kulturlandschaftsbereich hineingeraten ist?

2. Welches ist heute in formaler Hinsicht der Übergang von der Stadt zur ländlichen Umgebung?

3. Wie weit reicht heute die städtische Kulturlandschaft und eine allenfalls zu unterscheidende Übergangszone in formaler Hinsicht?

+ Vergl. auch Carol. (7) S. 21. 
Das erste moderne Wachstum der Stadt Zürich beginnt in der ersten Hälfte des 19. Jahrhunderts. Da schon zu dieser Zeit in ihrer Umgebung Veränderungen eintreten können, muß hier die Untersuchung ebensoweit zurückreichen. Es kann sich aber nicht darum handeln, die Untersuchung auf das ganze Gebiet, das seit damals von der städtischen Siedlungsentwicklung berührt worden ist, auszudehnen. Das wäre ein umfangreiches und nicht durchwegs notwendiges Unterfangen, da an vielen Orten die Veränderungen gleich oder ähnlich sein werden. Wir beschränken uns deshalb auf einen ausgewählten Ausschnitt.

Der Untersuchung des Überganges von der Stadt zur ländlichen Umgebung soll eine Feldkartierung zugrunde gelegt werden. Sie wird ebenfalls räumlich beschränkt und zwar auf einen sektorförmigen Ausschnitt. Die Ergebnisse dieser Arbeiten müssen die Grundlage für die Behandlung der dritten Frage liefern.

Auf Grund der Problemstellung ergibt sich eine Gliederung der Arbeit in drei Teile. Da sie sich räumlich und in bezug auf die berücksichtigten Gesichtspunkte be- schränkt, kann es sich nur um einen Beitrag zur Untersuchung der städtischen Kulturlandschaft von Zürich handeln.

Die Beschränkung auf die mehr formalen Gesichtspunkte läßt sich auch deswegen befürworten, weil die funktionalen Gesichtspunkte gegenwärtig von anderer Seite bearbeitet werden.

I. Teil

\section{Veränderungen der Kulturlandschaft im Raume Schlieren-Urdorf seit Anfang des 19. Jahrhunderts}

\section{A. ARBEITSGRUNDLAGEN}

\section{Umfang und Lage des Untersuchungsgebietes}

Für die Untersuchung der im Laufe der städtischen Entwicklung erfolgten Veränderungen ist das Gebiet von Schlieren - Urdorf ausgewählt worden. Aus dem gleichen bäuerlichen Ursprung hervorgehend, ist in Schlieren eine ausgesprochene Industriesiedlung, in Urdorf aber eine Wohnsiedlung entstanden. Es dürften somit in diesem Ausschnitt wesentliche und verschiedenartige Veränderungen erfaßt werden.

Die Abgrenzung des Untersuchungsgebietes fällt mit den politischen Grenzen der Gemeinden Schlieren und Urdorf zusammen. Die Wahl der politischen Gemeindeeinheit war notwendig und praktisch, weil sich vieles, namentlich statistisches Unterlagematerial auf diese Flächen bezieht.

Die Fläche des Untersuchungsgebietes hat auf Grund der Arealstatistik für 1952 folgendes Ausmaß:

\begin{tabular}{lcc} 
Gemeinde & Fläche & davon Wald \\
\hline Schlieren & 655,45 ha & 178,75 ha \\
Urdorf & 761,23 ha & 222,66 ha \\
\hline Total & 1416,68 ha & 401,41 ha
\end{tabular}

Die Gemeinde Urdorf besteht erst seit 1931 in diesem Umfang. In diesem Jahr schlossen sich die beiden bisher politisch selbständigen und nur in Schul-, Kirchenund Armensachen vereinten Gemeinden Niederurdorf und Oberurdorf zu einer politischen Gemeinde zusammen. Grund zur Vereinigung boten vor allem die Schwierigkeiten, denen sich das kleine Gemeinwesen Niederurdorf gegenübergestellt sah, als eine moderne Entwicklung neue und umfangreiche Aufgaben an Verwaltung und Finanzkraft der Gemeinde stellten.

Die Fläche der Gemeinde Schlieren liegt zur Hauptsache südlich der Limmat im breiten Talraum des Limmattales. Sie grenzt auf der ganzen Länge ihrer Ostseite an die politische Stadtgemeinde. 
Die Fläche der Gemeinde Urdorf nimmt fast den ganzen Raum eines flachen und breiten Seitentales, das zwischen Schlieren und Dietikon von Süden in das Limmattal mündet, ein. Sie reicht auch noch westwärts hinüber ins Reppischtal. Auf der Ostseite grenzt sie an die Gemeinde Schlieren und trifft nur an einem Punkt innerhalb des Waldes auf die politische Stadtgrenze.

\title{
2. Die Elemente der Kulturlandschaft
}

Da wir die Kulturlandschaft im Raume Schlieren-Urdorf vom stadtgeographischen und vom agrargeographischen Gesichtspunkt aus zu betrachten haben, müssen wir nach den Komponenten fragen, die von diesen Gesichtspunkten aus die Kulturlandschaft konstituieren.

Für den agrargeographischen Gesichtspunkt nennt CAROL in seinem agrargeographischen Betrachtungssystem (7) bei gleichzeitiger Unterscheidung von formalen und funktionalen Elementen die folgenden:

Formale Elemente
Untergrund
Relief
Klima
Wasser
Boden
Naturvegetation
Kulturvegetation
Kulturbauten

\author{
Funktionale Elemente \\ Landwirtschaftliche Bevölkerung \\ Stand von Kultur und Technik \\ Betrieb \\ Markt \\ Organisation zur Versorgung der bäuer- \\ lichen Bevölkerung mit wirtschaftlichen \\ und kulturellen Gütern \\ Verkehr
}

Dabei haben die formalen Elemente bei der Gestaltung der agrarischen Kulturlandschaft ausschlaggebenden Anteil.

Für den anthropogeographischen Gesichtspunkt müssen die gleichen formalen Elemente gelten. Bei der Gestaltung der städtischen Kulturlandschaft treten sie aber an Bedeutung stark hinter die funktionalen Elemente zurück.

Funktionale Elemente der städtischen Kulturlandschaft sind:

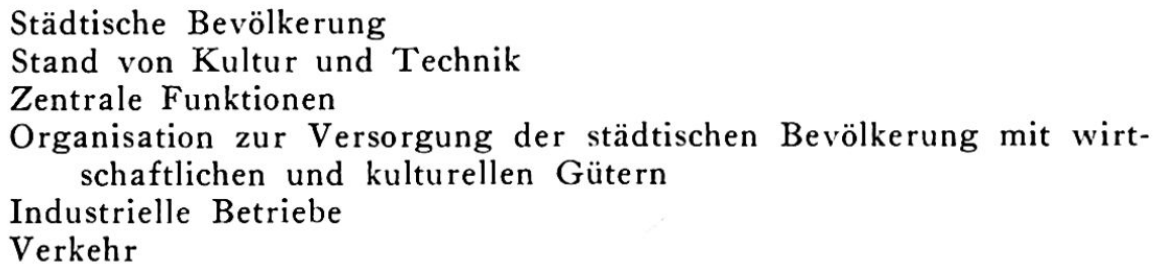

Von den formalen Elementen spielen in der städtischen Kulturlandschaft die Bauten eine ausschlaggebende Rolle. Diese Komponente ist am ausgeprägtesten Ausdruck menschlichen Wirkens und ist deshalb viel mehr als alle andern unabhängig von den übrigen Elementen. Jedenfalls viel mehr als die Kulturvegetation, die etwa als Hauptkomponente der ländlichen Kulturlandschaft zu bezeichnen ist. Auch diese kann allerdings vom Menschen wesentlich beeinflußt werden.

Die an der Konstituierung der städtischen Kulturlandschaft am stärksten beteiligten Komponenten sind aber die funktionalen Elemente, voran die zentralen Funktionen ${ }^{5}$.

\section{Arbeitstechnisches}

Die Art der Aufgabenstellung für diesen Teil bringt mit sich, daß die Beschaffung des Materials auf verschiedenste Weise zu erfolgen hatte.

Die formalen Gegebenheiten der Gegenwart wurden durch Feldkartierungen gewonnen, die funktionalen durch Feldkartierung, Statistik und persönliche Befragung.

Formale und funktionale Gegebenheiten der Vergangenheit mußten auf Grund von Statistiken und Beschreibungen, von Karten und Plänen, von Archivschriften und Protokollen und für die Zeit von 1900 an auch von persönlichen Befragungen rekonstruiert werden. Ohne letz-

5 Vergl. Boesch (5), Christaller (12). 
tere wäre eine zuverlässige Darstellung der formalen und funktionalen Verhältnisse der Besiedlung um 1900 schwerlich möglich gewesen. Sie hat außerdem zahlreiche Einzelheiten namentlich wirtschaftlicher Art zu Tage gefördert, die nirgends aufgezeichnet sind. Viele solche Details aus der Zeit vor 1900 sind deshalb verloren gegangen.

\section{Die Naturgrundlagen}

\section{B. DIE UNTERSUCHUNG}

Der Untergrund wird wie im ganzen Mittelland durch die Molasse, im speziellen die obere Süßwassermolasse gebildet, die größtenteils von einem diluvialen Schuttmantel bedeckt ist. Im Raume des Untersuchungsgebietes bestehen die Talebenen des Limmattales und des Urdorfer Seitentales aus Schottern der niederen Terrassen. Mit Ausnahme einiger Partien an den Hängen südlich von Schlieren, östlich und westlich von Urdorf und im Reppischtal, wo die Molasse den unmittelbaren Untergrund bildet, bedecken an allen andern Orten Moränen der Würmvergletscherung in wechselnder Mächtigkeit den Molasseuntergrund ${ }^{6}$.

Die Böden sind durchwegs als mittel- bis tiefgründige Braunerdeböden zu bezeichnen. Im besondern treten auf den Talsohlen trockene, durchlässige Schotterböden, im Molasse- und Moränenmaterial mehr lehmige, zum Teil nasse Böden auf. Von diesen letztern zeugen zahlreiche Flurnamen: Naßäcker, im Moos, Moosmatt, Moosäcker, im Letten, Bergermoos, Iltismoos, Taubenmoos.

Durch Bodenverbesserungen, die namentlich in Urdorf anläßlich der Güterzusammenlegung durchgeführt worden sind, hat man die meisten dieser nassen Partien trokken gelegt. Auch die Schotterflächen des Limmattales können dort, wo der Grundwasserspiegel hoch steht, sumpfig sein. Dies war früher, vor allem vor der Flußkorrektion an vielen Stellen der Fall. Solche Verhältnisse finden wir heute noch nördlich von Schönenwerd, gerade westlich des Gemeindebannes von Schlieren, wohl als Folge des Limmatstaues bei Dietikon.

Das Relief weist große Unterschiede auf. Der weitaus größte Teil des Untersuchungsgebietes ist jedoch flach oder schwach geneigt. Man vergleiche dazu die Böschungskarte des oberen Limmattales (Kartenbeilage I).

Das differenzierende Element des Klimas ist die Exposition, welche ebenfalls aus der Böschungskarte ersichtlich ist. Dabei sind die Differenzen innerhalb der Gemeinden Schlieren und Urdorf weniger groß als zu der unmittelbaren Umgebung, vor allem dem windgeschützten, süd- bis südwestexponierten rechtsseitigen Talhang des Limmattales, wo bei Weiningen ausgedehnte Rebberge einen quantitativ und qualitativ befriedigenden Ertrag liefern. Schlieren ist an den linksseitigen, schattigen Talhang gelehnt und wie das von Süden nach Norden verlaufende Urdorfer Tal gegen die Nordwinde ungeschützt. Obwohl heute weder in Schlieren noch in Urdorf Rebbau zu finden ist, sind die Verhältnisse nicht derart, daß dieser nicht möglich wäre. Vor hundert bis hundertfünfzig Jahren haben in Urdorf und in Schlieren umfangreiche Rebpflanzungen bestanden ${ }^{7}$.

Die Niederurdorfer pflanzten ihre Reben in Ermangelung einer andern Gelegenheit am linksseitigen schattigen Hang des Urdorfer Tales und aus betrieblichen Gründen nicht in der günstiger exponierten Ebene. Die Oberurdorfer wählten den südwestexponierten Hang im Reppischtal und den rechtsseitigen westexponierten Talhang bei Oberurdorf. Dieser ist etwas milder als der Gegenhang bei Niederurdorf und steht vor allem im ausgiebigen Genuß der Mittags- und Abendsonne. Diese Seite ist heute auch bevorzugtes Wohnbaugebiet, wobei allerdings die Lage der Bahnstation weit mehr als die klimatischen Vorzüge den Ausschlag geben.

Die geringe Wirtschaftlichkeit des Weinbaues veranlaßte die Bauern mit der im Verlaufe des 19. Jahrhunderts erfolgenden Intensivierung des Anbaues und der Um-

${ }^{6}$ Vergl. Suter (27).

${ }^{7}$ Vergl. Tabellen auf Seiten 9 und 11. Verteilung des Kulturlandes. 
stellung von der Selbstversorgungs- auf die Marktwirtschaft, den Rebbau immer mehr einzuschränken. Einige schlechte Jahre und den Rebstock befallende Krankheiten brachten schließlich in den ersten Jahrzehnten des 20. Jahrhunderts die letzten Reste zum verschwinden.

\section{Die Bevölkerung}

Die Bevölkerung von Schlieren und Urdorf hat sich seit der ersten Hälfte des 19. Jahrhunderts bis heute stark verändert, was aus der Tabelle über die Bevölkerungsbewegung hervorgeht.

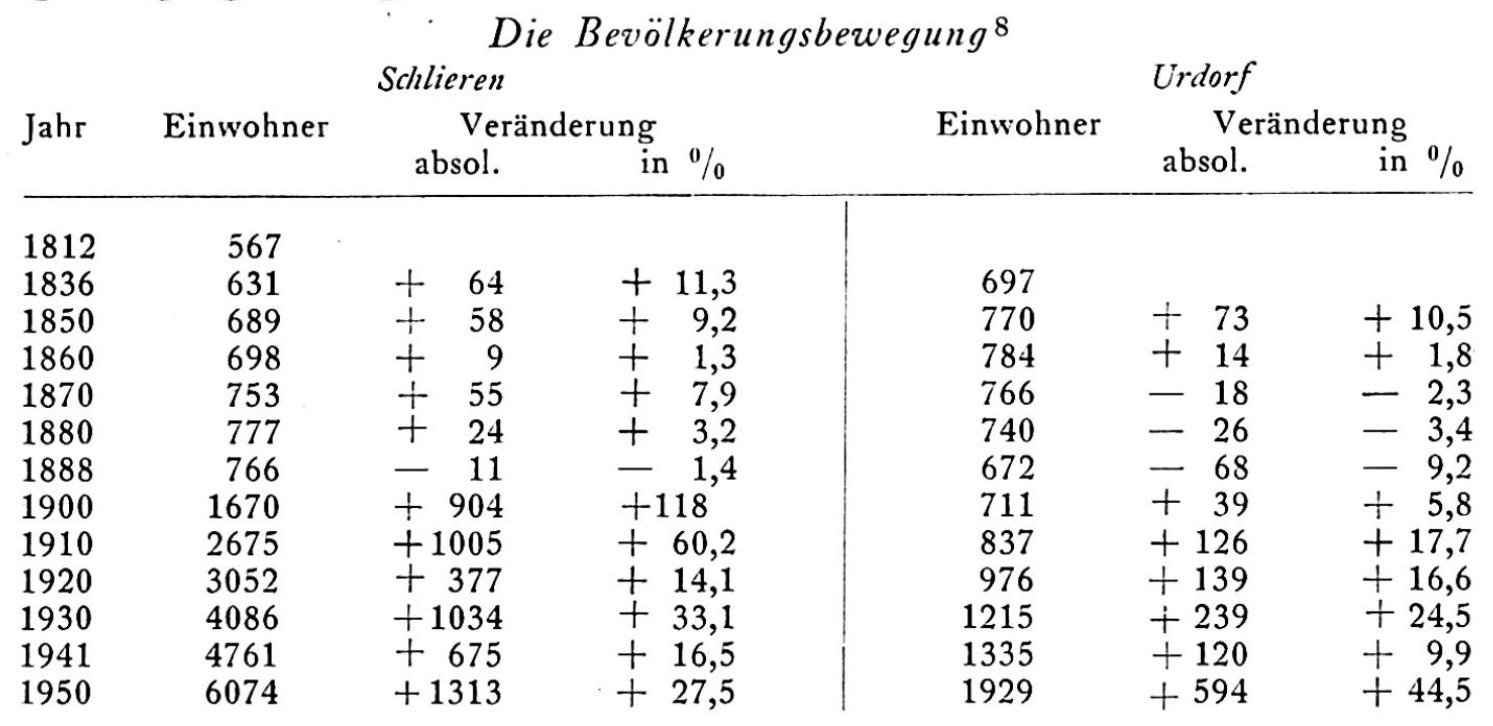

Die zahlenmäßige Entwicklung der Bevölkerung läßt sich in zwei Hauptabschnitte einteilen. Der erste umfaßt das 19. Jahrhundert bis 1888. Die Bevölkerungsbewegung ist in diesem Abschnitt gekennzeichnet durch einen vorerst mäßigen Zuwachs und einen geringen Rückgang im letzten, respektive in den letzten drei Jahrzehnten. Der zweite Abschnitt, die Jahre 1888 bis 1950 umfassend, bringt große Zunahmen.

Der Zuwachs während des ersten Zeitraumes ist wohl zur Hauptsache der allgemeinen Bevölkerungsvermehrung zuzuschreiben, die im Zusammenhang mit der damaligen Verbesserung der wirtschaftlichen und hygienischen Lebensverhältnisse erfolgte. Eine geringfügige Zuwanderung ist in Schlieren als Folge des Eisenbahnbaues und der Ansiedlung einer Leimfabrik nicht ausgeschlossen.

Der Bevölkerungsrückgang wird zweifellos durch Abwanderung verursacht. Direkte Anhaltspunkte für diese Annahme sind allerdings kaum vorhanden; für eine Abwanderung sprechen aber die allgemeinen Verhältnisse. Nach der oben erwähnten Bevölkerungsvermehrung sind die Bauerndörfer um 1860 mehr oder weniger übervölkert. Die Bautätigkeit ist gering, und die Wohngelegenheiten sind restlos ausgenützt. Auf diesen Umstand weisen die verhältnismäßig hohen Behausungsziffern hin ${ }^{9} . \mathrm{Zu}$ dieser Zeit beginnen sich in der Landwirtschaft auch die Verlagerung vom Ackerbau auf einen ausgedehnten Futterbau und der Rückgang des arbeitsintensiven Rebbaues auszuwirken. Diese Wandlung, sowie die Steigerung der Lebensansprüche und der da und dort eintretende Verlust des notwendigen Nebenverdienstes beim Niedergang der zürcherischen Hausindustrie, führen zum Bestreben, die einzelnen Betriebe zu vergrößern ${ }^{10}$. Die überzählige Bevölkerung ist auf neue Berufstätigkeiten angewiesen und beginnt bei der ersten Gelegenheit abzuwandern. Einer Abwanderung steht nicht viel im Wege. Unweit von Schlieren und Urdorf gibt es in der schon kräftig wach-

\footnotetext{
${ }^{8}$ Für 1812 Angaben von J. SPÖRRI (26), für 1836 von MEYer v. KNONAU (20), für 1850-1950 Eidg. Volkszählungen (30).

${ }^{9}$ Nach der Einwohnerzahl und der Zahl der Wohnhäuser sind für Urdorf folgende Behausungsziffern zu errechnen: $1860: 8,8 ; 1888: 6,5$.

10 Vergl. BernhaRd (4).
} 
senden Stadt Zürich und ihrer unmittelbaren Umgebung in zunehmender Zahl neue Beschäftigungsmöglichkeiten. Die Zuwanderung dahin ist denn auch groß, und als Folge steigt zum Beispiel die Einwohnerzahl der damaligen Gemeinde Außersihl zwischen 1860 und 1880 von 2597 auf 14017. Das entspricht einem Zuwachs von 11420 oder $440 \%$ im Laufe von 20 Jahren.

Wenige Jahre vor der Jahrhundertwende werden dann mit der Ansiedlung der beiden noch heute größten Industriebetriebe, der «Schweizerischen Wagons- und Aufzügefabrik» und des städtischen Gaswerkes, in Schlieren selbst neue und vielfältige Arbeitsplätze geschaffen, die natürlich auch dem benachbarten Urdorf zugute kommen. In diesen Jahren wächst die Einwohnerzahl von Schlieren denn auch sprunghaft, wobei sie sich von 1888 bis 1900 mehr als verdoppelt. Mit dieser Entwicklung wird Schlieren mit einem Male aus dem Rahmen der nachbarlichen Gemeinden, denen es bisher in bezug auf Größe und Aussehen etwa gleichzustellen war, herausgehoben.

In Urdorf bleibt eine eigentliche industrielle Entwicklung, wie sie in Schlieren $\mathrm{zu}$ beobachten ist, aus. Hier vergößert sich die Bevölkerung nur allmählich. Einen bearhtlichen Zuwachs erhält sie erst zwischen 1941 und 1950 mit der Zuwanderung von vielen neuen Wohnsiedlern, die in der nahen Stadt oder in Schlieren arbeiten.

Aber nicht nur die Zahl der Einwohner hat sich im Laufe der Zeit stark verändert, sondern auch deren Zusammensetzung. In der ersten Hälfte des 19. Jahrhunderts finden wir in den Dörfern Schlieren, Niederurdorf und Oberurdorf eine ganz und gar bäuerliche Bevölkerung, die nach einem Bericht des damals in Schlieren amtierenden Pfarrers Spörri aus dem Jahre $1812^{26}$ in denkbar einfachen Verhältnissen lebt. «Die 567 Einwohner (von Schlieren) leben fast alle als Bauern und Taglöhner vom Landbau, auch wenige Handwerker und einige Baumwoll- und Seidenspinner treiben nebenher etwas Landbau. Frauen und Mädchen spinnen ihren selbstgepflanzten Flachs. Einfach ist auch die Ernährung. Es gibt ein Erbsen- oder Gerstengericht, oder eine Mehlspeise, oder Erdäpfel, oder dürres Obst und als Beigabe höchstens kalte Milch. Fleisch, auch geräuchertes Schweinefleisch, wird meist nur an Sonntagen gegessen. Wein allerdings wird viel getrunken.»

Von dieser nach Zusammensetzung und Lebensweise einfachen Bevölkerung vollzieht sich eine große Wandlung bis zur differenzierten heutigen Bevölkerung mit Lebensansprüchen, die mit den damaligen kaum zu vergleichen sind. Zunächst werden mit dem Bau der Eisenbahn 1847 in Schlieren und 1863 in Urdorf neue Arbeitsmöglichkeiten als Bahn- und Streckenwärter geschaffen. Heimarbeiter gehen beim Niedergang der Heimindustrie über in die noch bescheidene Fabrikindustrie in Schlieren und Urdorf selbst und in der näheren Umgebung: Engstringen, Altstetten, Zürich, Dietikon und Birmensdorf. Mit dem Beginn der modernen Industrialisierung in Schlieren im letzten Jahrzehnt des 19. Jahrhunderts erhält hier die Beschäftigungsmöglichkeit in der Fabrikindustrie eine bedeutsame Zunahme. Die Zahl der Fabrikarbeiter wächst damit auch sprunghaft, gleichzeitig aber auch die Zahl derer, die in Gewerbe und Handel für die täglichen Bedarfsgüter der zunehmenden Bevölkerung zu sorgen haben.

Die schnelle Entwicklung von Wissenschaft, Technik und Großhandel bringt weitere zahllose Differenzierungen der Berufstätigkeit. Wenn auch viele solcher Spezialisten weder in Schlieren und noch viel weniger in Urdorf eine ihnen entsprechende Tätigkeit finden können, wählen sie doch hier ihren Wohnsitz und fahren täglich in die Stadt an ihren Arbeitsplatz. So hat gerade die Bevölkerung von Urdorf im letzten Jahrzehnt eine Zusammensetzung erhalten, die in keiner Weise dem hier vorhandenen Arbeitsangebot entspricht. Von den im Jahre 1941 in Urdorf wohnenden 561 Berufstätigen (Schlieren 2248) arbeiten 244 (Schlieren 721) außerhalb der Gemeinde, meist in Zürich und Schlieren ${ }^{11}$.

${ }^{11}$ Vergl. Tabelle der Pendelwanderung auf Seite 21. 
Daß diese Wandlungen auf das Leben der Gemeinden in kultureller, sozialer und politischer Hinsicht ebenfalls große Auswirkungen zeitigten, sei hier nur erwähnt und dabei auf die Dissertation von J. Beck «Der Kulturzusammenstoß zwischen der bäuerlichen Gemeinde Witikon und der Stadt Zürich»(28) hingewiesen.

Über die zahlenmäßige Zusammensetzung der Bevölkerung gibt die folgende Tabelle «Berufsstatistik» Auskunft.

\begin{tabular}{|c|c|c|c|c|c|c|c|c|c|}
\hline \multicolumn{10}{|c|}{ Berufsstatistik 12} \\
\hline \multirow[b]{2}{*}{$\mathrm{Jahr}$} & & \multicolumn{4}{|c|}{ Schlieren } & \multicolumn{4}{|c|}{ Urdorf } \\
\hline & & $\begin{array}{l}\text { Ur- } \\
\text { prod. }\end{array}$ & $\begin{array}{l}\text { Handw. } \\
\text { Industrie }\end{array}$ & übrige & Total & $\begin{array}{l}\text { Ur- } \\
\text { prod. }\end{array}$ & $\begin{array}{l}\text { Handw. } \\
\text { Industrie }\end{array}$ & übrige & Total \\
\hline 1850 & $\begin{array}{l}\text { absol. } \\
\text { in } \%\end{array}$ & $\begin{array}{r}180 \\
75\end{array}$ & $\begin{array}{l}48 \\
20\end{array}$ & $\begin{array}{r}12 \\
5\end{array}$ & $\begin{array}{l}240 \\
100\end{array}$ & $\begin{array}{r}156 \\
67\end{array}$ & $\begin{array}{l}58 \\
25\end{array}$ & $\begin{array}{r}18 \\
8\end{array}$ & $\begin{array}{l}232 \\
100\end{array}$ \\
\hline 1870 & $\begin{array}{l}\text { absol. } \\
\text { in } \%\end{array}$ & $\begin{array}{r}159 \\
62\end{array}$ & $\begin{array}{l}54 \\
21\end{array}$ & $\begin{array}{l}45 \\
17\end{array}$ & $\begin{array}{l}258 \\
100\end{array}$ & $\begin{array}{r}145 \\
57\end{array}$ & $\begin{array}{l}75 \\
30\end{array}$ & $\begin{array}{l}34 \\
13\end{array}$ & $\begin{array}{l}254 \\
100\end{array}$ \\
\hline 1910 & $\begin{array}{l}\text { absol. } \\
\text { in } \%\end{array}$ & $\begin{array}{r}135 \\
12\end{array}$ & $\begin{array}{r}737 \\
67\end{array}$ & $\begin{array}{r}236 \\
21\end{array}$ & $\begin{array}{r}1105 \\
100\end{array}$ & $\begin{array}{r}190 \\
49\end{array}$ & $\begin{array}{r}171 \\
44\end{array}$ & $\begin{array}{r}29 \\
7\end{array}$ & $\begin{array}{l}390 \\
100\end{array}$ \\
\hline 1941 & $\begin{array}{l}\text { absol. } \\
\text { in } \%\end{array}$ & $\begin{array}{r}74 \\
3\end{array}$ & $\begin{array}{r}1560 \\
70\end{array}$ & $\begin{array}{r}604 \\
27\end{array}$ & $\begin{array}{r}2248 \\
100\end{array}$ & $\begin{array}{r}118 \\
21\end{array}$ & $\begin{array}{r}282 \\
50\end{array}$ & $\begin{array}{r}161 \\
29\end{array}$ & $\begin{array}{l}561 \\
100\end{array}$ \\
\hline 1950 & $\begin{array}{l}\text { absol. } \\
\text { in } \%\end{array}$ & $\begin{array}{r}58 \\
2\end{array}$ & $\begin{array}{r}2022 \\
70\end{array}$ & $\begin{array}{r}814 \\
28\end{array}$ & $\begin{array}{r}2894 \\
100\end{array}$ & $\begin{array}{r}124 \\
14\end{array}$ & $\begin{array}{r}473 \\
54\end{array}$ & $\begin{array}{r}274 \\
32\end{array}$ & $\begin{array}{l}870 \\
100\end{array}$ \\
\hline
\end{tabular}

3. Die Landwirtschaft

$\mathrm{Zu}$ Beginn des 19. Jahrhunderts ist die Landwirtschaft in Schlieren und Urdorf auf Selbstversorgung eingestellt. Sie hat alles zu liefern, was für die nach dem Bericht jenes Pfarrers Spörri bescheidenen Lebensansprüche der Dorfbevölkerung notwendig ist. Außerdem sind zu jener Zeit ja auch alle Abgaben in Form von Naturalien zu leisten. Der Bauer muß deshalb notwendigerweise eine gewisse Fläche seines Betriebsareals mit Getreide bepflanzen. So besteht nach einem aus dem Jahre 1801 stammenden Katasterverzeichnis in jener Zeit in Urdorf etwas mehr als die Hälfte des Kulturlandes (ohne Wald) aus Ackerland.

\section{Verteilung des Kulturlandes in Urdorf um $180 I^{13}$}

\begin{tabular}{lcr} 
Nutzung & in ha & in \% \\
\hline Ackerbau & 190 & 56 \\
Wiesen & 85,9 & 25 \\
Weideland & 48,2 & 14 \\
Reben & 18,2 & 5 \\
\hline Total & 342,3 & 100
\end{tabular}

Dem System der Dreizelgenwirtschaft entsprechend, ist der größte Teil dieser Ackerfläche auf drei Abschnitte des Gemeindebannes verteilt. Zwei Katasterpläne aus den Jahren 1794 und 1819 lassen diese Flureinteilung in Schlieren deutlich erkennen. In Urdorf zeugen die Bezeichnungen «Bodenzelg», «Gugelwegzelg», «Wagenbachzelg» und «Allmend» ${ }^{14}$ von der Existenz des Dreizelgensystems. Außerdem ist das Ackerland der einzelnen Betriebe auf die ganze Wirtschaftsfläche der Gemeinde verteilt, wie es diesem System entspricht. Auf Grund der im Katasterverzeichnis von 1801 den einzelnen Parzellen beigefügten Flurbezeichnungen kann diese Verteilung einigermaßen rekonstruiert werden. Zwar ist die genaue Abgrenzung der drei Zelgen in Urdorf nicht bekannt, wohl aber deren allgemeine Lage. Da die meisten Betriebe in den drei Abschnitten des Gemeindebannes, in denen die Zelgen liegen, über Ackerland verfügen, kann diese Anordnung als Folge der Dreizelgenwirtschaft gewertet werden, da auch keine andern Ursachen überliefert sind. Als Beispiel sei in der An-

12 Angaben für 1850 von Meyer_v. KNonau (21), die übrigen nach den kantonalen Berufsstatistiken der Volkszählungen.

13 Nach Kataster von 1801 (38).

14 Vergl. Heid" (18). 
merkung die Verteilung des Ackerlandes eines Betriebes in Oberurdorf zahlenmäßig angeführt ${ }^{15}$.

Wie streng die Dreizelgenwirtschaft noch durchgeführt wird, steht nicht fest. Auf jeden Fall aber wird diese nicht mehr in der alten, sondern in einer verbesserten Form betrieben. Nach dem schon früher erwähnten Bericht des Pfarrers Spörri (26) sucht man auch in Schlieren die Bauern zu einer moderneren Wirtschaft anzuhalten. Alle fortschrittlich Gesinnten drängen auf eine Ausdehnung des Futterbaues auf der Brache, als Grundlage einer größeren Viehhaltung. Die Vorurteile des zäh am Herkommen haftenden Bauern sollen aber zahlreich und nur schwer zu überwinden sein. In Urdorf deutet die Aufteilung der Allmend um die Jahrhundertwende auch auf diese Umstellung hin.

Die Gründung von verschiedenen Außenhöfen noch in der ersten Hälfte des 19. Jahrhunderts läßt vermuten, daß man im Begriffe ist, das alte, für alle verbindliche Anbausystem aufzugeben.

Maßnahmen wie der Zehntenloskauf, der um 1832 gesetzlich erleichtert wird, die Förderung von Verkehr und Handel durch den Ausbau des Verkehrsnetzes und der Wegfall von Zollschranken schaffen noch vor 1850 neue Verhältnisse ${ }^{16}$. Brotgetreide kann nun in immer größerem Maße von dorther bezogen werden, wo der Anbau ertragreicher ist. Die Abgaben sind fortan in Bargeld zu entrichten ${ }^{17}$. Damit erhält der Bauer in der Wahl der Nutzungsart freiere Hand. Anderseits benötigt er Bargeld und muß deshalb solche Nutzungsarten wählen, die ihm dieses einbringen. Dazu ist in Schlieren und Urdorf der Grasbau mit Vieh- und Milchwirtschaft besser geeignet als der Getreidebau. Es vollzieht sich denn auch hier ein allmählicher Nutzungswechsel, wobei immer mehr Ackerland in Wiesland übergeht.

Dieser Übergang kann im Zeitraum von 1801 bis 1863 am Beispiel von vier Betrieben in Oberurdorf beobachtet werden.

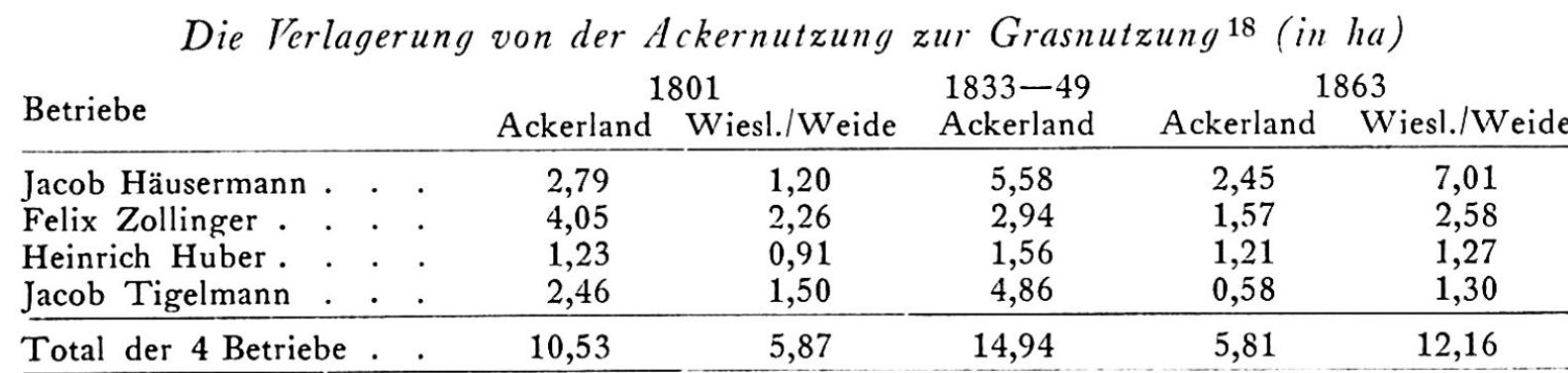

Verhältnis von Ackerland

zu Wiesland..... $100: 56$

$100: 210$

Die einzelnen Betriebe haben in diesem Zeitraum ihre Fläche zum Teil erheblich verändert, was aber der Darstellung des allgemeinen Überganges vom Ackerbau zum Grasbau keinen Abbruch tut. Die Angaben für 1833-1849 stammen aus einer Zusammenstellung der Zehntenloskaufsrechnungen für Oberurdorf. Es ist dort nur das Ackerland aufgeführt. Daß die Betriebe zu jener Zeit noch über verhältnismäßig

15 Auf Grund des Katasters von 1801 umfaßt der Betrieb des Felix Zollinger zu Oberurdorf 34 Parzellen Ackerland, 8 Parzellen Wiesland, 4 Parzellen Rebland, 1 Parzelle Weideland, 1 Parzelle Kraut- und Baumgarten, total 48 Parzellen mit einer Fläche von 6,59 ha, sowie $1^{1 / 8}$ Gerechtigkeit in Holz und Weid. Die 34 Parzellen Ackerland sind wie folgt auf den Gemeindebann verteilt:

11 Parzellen mit 129,5 a im Raum der Bodenzelg $N$ und NE des Dorfes,

$10 " \# 134,97$ a im Raum der Gugelwegzelg E des Dorfes,

$8 \% \quad \%$ 85,72 a im Raum der Wagenbachzelg S des Dorfes,

$5 " \# 52,89$ a an anderem Ort (1 Parzelle) oder mit unbekannter Lage.

16 "Vergl. KohleR (19). 1850 bauen im Kanton Zürich 62 Gemeinden mehr als genug, 46 genügend und $86 \mathrm{zu}$ wenig oder kein Getreide an.

17 Vergl. auch Stat. Mitteilung betr. den Kanton Zürich 1885 (28).

18 Angaben für 1801 laut Kataster (38), für 1833-49 nach Zehntenloskaufsrechnungen für Oberurdorf, 1863 gemäß Hofbeschreibung Oberurdorf 1863 (39). 
große Ackerflächen verfügen, läßt darauf schließen, daß eine wirksame Wandlung der Betriebsform erst mit dem Loskauf des trockenen Zehnten einsetzen kann. Nach einem Zehntenplan von 1819 hätte dieser Loskauf in Schlieren schon früher eingesetzt.

So wandelt sich das Bild der Fluren rings um die Dörfer zusehends. Statt des leuchtenden Gelb der Getreidefelder ist es immer mehr das Grün der Wiesen, das vorzuherrschen beginnt. Der ständig zurückgehende Getreideanbau genügt für den Eigenbedarf bald nicht mehr ${ }^{19}$. Die in Oberurdorf und Schlieren betriebenen Mühlen erhalten immer weniger Arbeit und müssen schließlich gegen das Ende des Jahrhunderts (in Schlieren ca. 1870, in Oberurdorf ca. 1880) stillgelegt werden. Anderseits hat man nun für die Verwertung des größer werdenden Milchertrages zu sor-

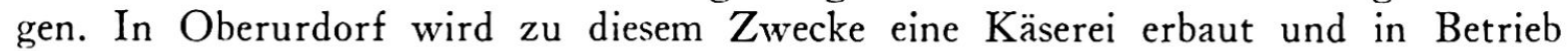
genommen.

Mittlerweile ist die Bevölkerung in der Stadt Zürich und in ihrer Umgebung ständig kräftig gewachsen. Das städtische Gemeinwesen vergrößert mit der ersten Eingemeindung im Jahre 1893 seine Fläche von 169 auf 4499 ha und seine Bevölkerungszahl von 28099 auf 121057 . Die Versorgung der rapid wachsenden Stadt mit täglichen Bedarfsgütern wird immer umfangreicher, eine Gegebenheit, die sich die Landwirtschaft der Umgebung zunutze macht.

Die Umstellung vom Getreidebau auf die Milch-Graswirtschaft lohnt sich immer mehr. Der in Oberurdorf aufgenommene Käsereibetrieb wird schon bald wieder eingestellt (ca. 1896), denn für die Milch ist in Form von Konsummilch genügend Absatzmöglichkeit vorhanden. Diese wird wie bisher in der Sennhütte gesammelt, ein kleiner Teil schon hier an ortsansässige Kunden verkauft, der größte Teil jedoch mit dem Pferdefuhrwerk täglich in die Stadt geführt und an Straßenkundschaft bis hinauf zur Kaserne abgesetzt. Durch die Zunahme der nichtlandwirtschaftlichen Bevölkerung in Schlieren wird hier der ganze Milchertrag im Dorfe selbst gebraucht. Die Bauern verkaufen die Milch im Einzelverkauf «über die Straße». Auf diese Weise kann aber der Bedarf bald nicht mehr gedeckt werden. Von ca. 1910 an übernimmt ein Milchhändler einen Teil der Versorgung mit Milch, die er aus dem Knonaueramt bezieht. Später kommen noch weitere Händler dazu, welche die Milch von Weiningen, Unterengstringen, Schlieren und Urdorf beziehen. In Oberurdorf sorgt heute der Pächter der Sennhütte für die Verteilung und Verwertung der Milch. Der größte Teil wird an Kundschaft in Schlieren und Urdorf ausgeführt und nur noch der Überschuß nach Zürich geliefert. Wegen den günstigen Absatzverhältnissen wird der Ackerbau immer mehr vernachlässigt. Er erreicht um die Mitte der dreißiger Jahre einen Tiefstand. Das Überangebot an Milch führt dagegen zur «Milchschwemme». Nach der kriegswirtschaftlich bedingten neuerlichen Ausdehnung der Ackerfläche ist man heute bestrebt, mehr Ackerland und eine gemischte Betriebsweise beizubehalten. Trotzdem ist der Milchertrag weiterhin angestiegen. Ursache dafür sind eine Intensivierung und Verbesserung der Futterproduktion und die Verwendung von Kraftfutter.

Die Entwicklung der Betriebsverhältnisse mit der starken Verlagerung auf die Milchproduktion äußert sich auch im Bild der landwirtschaftlichen Nutzungsfläche.

\begin{tabular}{|c|c|c|c|c|c|}
\hline Jahr & $\begin{array}{l}\text { teilung } \\
\text { Reben }\end{array}$ & $\begin{array}{l}\text { Yulturl } \\
\text { Acker }\end{array}$ & $\begin{array}{l}\text { in ha } \\
\text { Wiesen }\end{array}$ & $\begin{array}{l}W a \\
\text { Ried }\end{array}$ & Total \\
\hline $\begin{array}{l}\text { in Urdorf : } \\
1884 \\
1939 \\
1945 \\
1950\end{array}$ & 24,4 & $\begin{array}{c}165,2 \\
76 \\
159 \\
122\end{array}$ & $\begin{array}{l}345,4 \\
364 \\
274 \\
316\end{array}$ & 18,6 & $\begin{array}{l}553,6 \\
440 \\
433 \\
438\end{array}$ \\
\hline
\end{tabular}

19 Stat. Mitteilung betr. den Kanton Zürich 1884 (28).

${ }^{20}$ Stat. Mitteilungen betr. den Kanton Zürich 1884 (28), Ergebnisse der Eidg. Betriebszählung 1939 und der Anbauerhebungen 1945 und 1950. 


\begin{tabular}{|c|c|c|c|c|c|}
\hline Jahr & Reben & Acker & Wiesen & Ried & Total \\
\hline in $\mathrm{Scl}$ & & & & & \\
\hline $\begin{array}{l}1884 \\
1939 \\
1945 \\
1950\end{array}$ & 20,3 & $\begin{array}{r}150 \\
47 \\
85 \\
58\end{array}$ & $\begin{array}{l}295 \\
185 \\
134 \\
140\end{array}$ & 13 & $\begin{array}{l}478 \\
232 \\
219 \\
198\end{array}$ \\
\hline
\end{tabular}

Verhältnis Ackerland zu Wiesland:

$\begin{array}{ccc}\text { Jahr } & \begin{array}{c}\text { Crdorf } \\ \text { Ackerland : Wiesland }\end{array} & \begin{array}{c}\text { Schlicren } \\ \text { Ackerland : Wiesland }\end{array} \\ 1884 & 1: 2,1 & 1: 1,97 \\ 1939 & 1: 4,79 & 1: 3,95 \\ 1945 & 1: 1,72 & 1: 1,58 \\ 1950 & 1: 2,59 & 1: 2,4\end{array}$

Nach dem Verschwinden der großen Ackerflächen wird es möglich, den Obstbau zu erweitern. Fast überall auf dem ganzen Gemeindeareal werden Obstbäume gepflanzt. Der Obstbau erfordert viel weniger Arbeitsaufwand als der Rebbau und beginnt diesen allmählich zu ersetzen. Ungefähr von 1920 an ist der Weinbau praktisch bedeutungslos. Dafür wird seither der Obstbau intensiver betrieben. Zahlreiche Bäume minderer Qualität, die eine Bewirtschaftung der Felder mit Maschinen behindern, werden im Zusammenhang mit der Rückkehr zu vermehrtem Ackerbau während des zweiten Weltkrieges entfernt. Die Bäume erhalten gründliche Pflege, und die Qualität der Sorten wird verbessert.

Für Obst und Gemüse finden die Bauern von Schlieren und Urdorf schon frühzeitig Abnehmer in der nahen Stadt. Sie beginnen wahrscheinlich schon in den Achtzigerjahren mit dem mehr oder weniger regelmäßigen Besuch des Wochenmarktes in Zürich. Jedenfalls sind um 1890 die meisten Bauern von Urdorf Marktlieferanten. Von Schlieren sind es nur etwa ein halbes Dutzend bäuerliche Marktfahrer; die übrigen begnügen sich mit dem Verkauf an die zunehmende nichtlandwirtschaftliche Bevölkerung im Dorfe selbst. Infolge der Konkurrenzierung durch die motorisierte Marktlieferung zahlreicher Großgärtnereien nach dem ersten Weltkrieg, geht der bäuerliche Verkauf in der Stadt zurück. Heute gibt es in Schlieren noch einen bäuerlichen Marktlieferanten, in Urdorf deren acht bis zehn. Dafür haben die Bauern immer mehr Gelegenheit, Gemüse und Obst im Dorfe selbst abzusetzen. Diese Funktion wird in Schlieren mehr und mehr von Ladengeschäften übernommen.

Mit der Zunahme der nichtlandwirtschaftlichen Bevölkerung vermehrt sich auch die Zahl der nichtlandwirtschaftlichen Siedlungsbauten. Das von diesen beanspruchte Land ist in Schlieren wie in Urdorf ausschließlich Kulturland, das damit der landwirtschaftlichen Nutzung verloren geht. Von 1884 bis 1950 sind in Schlieren 280 ha, in Urdorf 113 ha - zusammen also fast 400 ha - Kulturland der Landwirtschaft entzogen worden. Davon sind ca. 145 ha, in Schlieren allein etwa 100 ha, als Gebäudeflächen, Hofraum, Anlagen, Bahn, Straßen und Wege zu unproduktivem Land geworden. Die restlichen rund 250 ha sind nun Gärten und Schrebergärten. Der größte Teil dieser Arealverluste fällt auf die Zeit nach 1912.

Der Rückgang des landwirtschaftlichen Bodens hat zwangsläufig eine Verminderung der Zahl der Landwirtschaftsbetriebe zur Folge.

Zahl der Landwirtschaftsbetriebe 21

$\begin{array}{lccccc}\text { Jahr } & 1905 & 1929 & 1939 & 1952 & * \text { * davon } 10, \\ \text { Schlieren } & 65 & 64^{*} & 56^{* *} & 25 & \text { ** davon 12 } \\ \text { Urdorf } & 97 & 89 & 77 & 57 & \text { Kleinpflanzer }\end{array}$

${ }^{21}$ Zahlen von 1905-1939 nach Eidg. Betriebszählungen, 1952 nach eigener Zählung. 
Diese Entwicklung verursacht in formaler und funktionaler Hinsicht erhebliche Veränderungen der alten Bauernsiedlungen.

In Zahlen sind die Verhältnisse folgendermaßen darzustellen:

\begin{tabular}{lrrrrr} 
Jahr & $\begin{array}{c}\text { Landwirtsch. } \\
\text { Gebäude } \\
\text { formal funkt. }\end{array}$ & \multicolumn{2}{c}{$\begin{array}{c}\text { Nichtlandw. } \\
\text { Gebäude }\end{array}$ formal funkt. } & total \\
\hline 1890 & 50 & 44 & 23 & 29 & 72 \\
1913 & 57 & 44 & 64 & 77 & 121 \\
1953 & 46 & 18 & 278 & 306 & 327
\end{tabular}

Als Beispiele formal landwirtschaftlicher aber funktional nichtlandwirtschaftlicher Gebäude sind zu nennen: Wohnhaus und Gewerbe (Schreinerei), Wohnhaus und gewerblicher Lagerraum, Wohnhaus mit Scheune ohne Nutzung.

Der formalen Wandlung der landwirtschaftlichen Bauten geht die funktionale offensichtlich voraus.

$\mathrm{Da}$ in Schlieren die neue Besiedlung im unmittelbaren Bereich des bestehenden Bauerndorfes erfolgt, sind hier die Veränderungen besonders groß. Dazu mag die Lage der Bahnstation in nächster Nähe mit Anlaß gegeben haben. Die Landwirtschaft wird mehr und mehr aus dem Dorfe Schlieren verdrängt, was nicht allein dem Arealverlust zuzuschreiben ist. Viele neue Wohnbauten umgeben die bäuerliche Siedlung und trennen sie vom umliegenden Wirtschaftsareal. Moderne Wohnbauten und Wohn-Geschäftsbauten werden zwischen den Bauernhäusern erstellt. Der moderne Straßenverkehr schränkt die Bauern in ihrer Bewegungsfreiheit noch weiter ein. Die neue Bevölkerung hat oft wenig Verständnis für die Landwirtschaft und ihre Bedürfnisse. Umgekehrt verlocken geregelte Freizeit, früher Feierabend und Barlohn den bäuerlichen Nachwuchs zur Abwanderung in andere Berufe. Der landwirtschaftliche Haus- und Hofraum innerhalb der modernen Siedlung ist schlecht ausgenützter Baugrund und wird oft

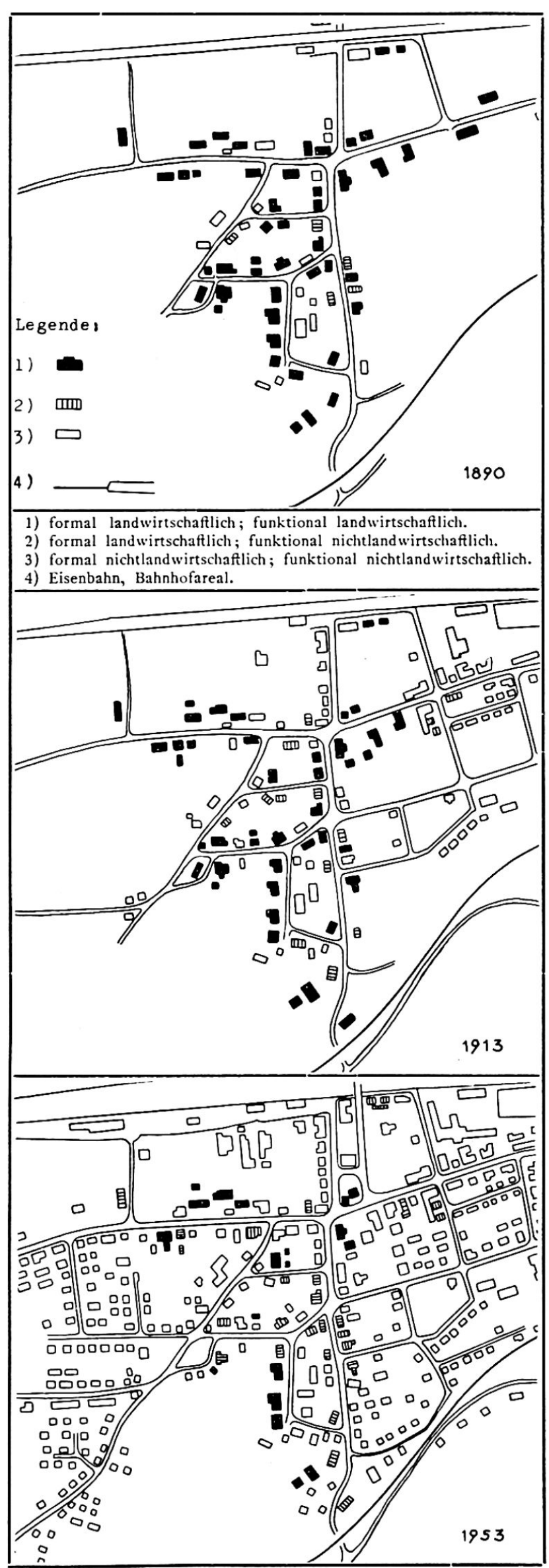

Fig. 1 Formale und funktionale Veränderungen im Bereich der bäuerlichen Dorfsiedlung in Schlieren von 1890 bis 1953 
Spekulationsobjekt, was da und dort den Entschluß zur Aufgabe des Landwirtschaftsbetriebes noch fördern dürfte. In nächster Zeit werden aus diesen Gründen weitere Betriebe, die heute noch von alten Leuten geführt werden, eingehen.

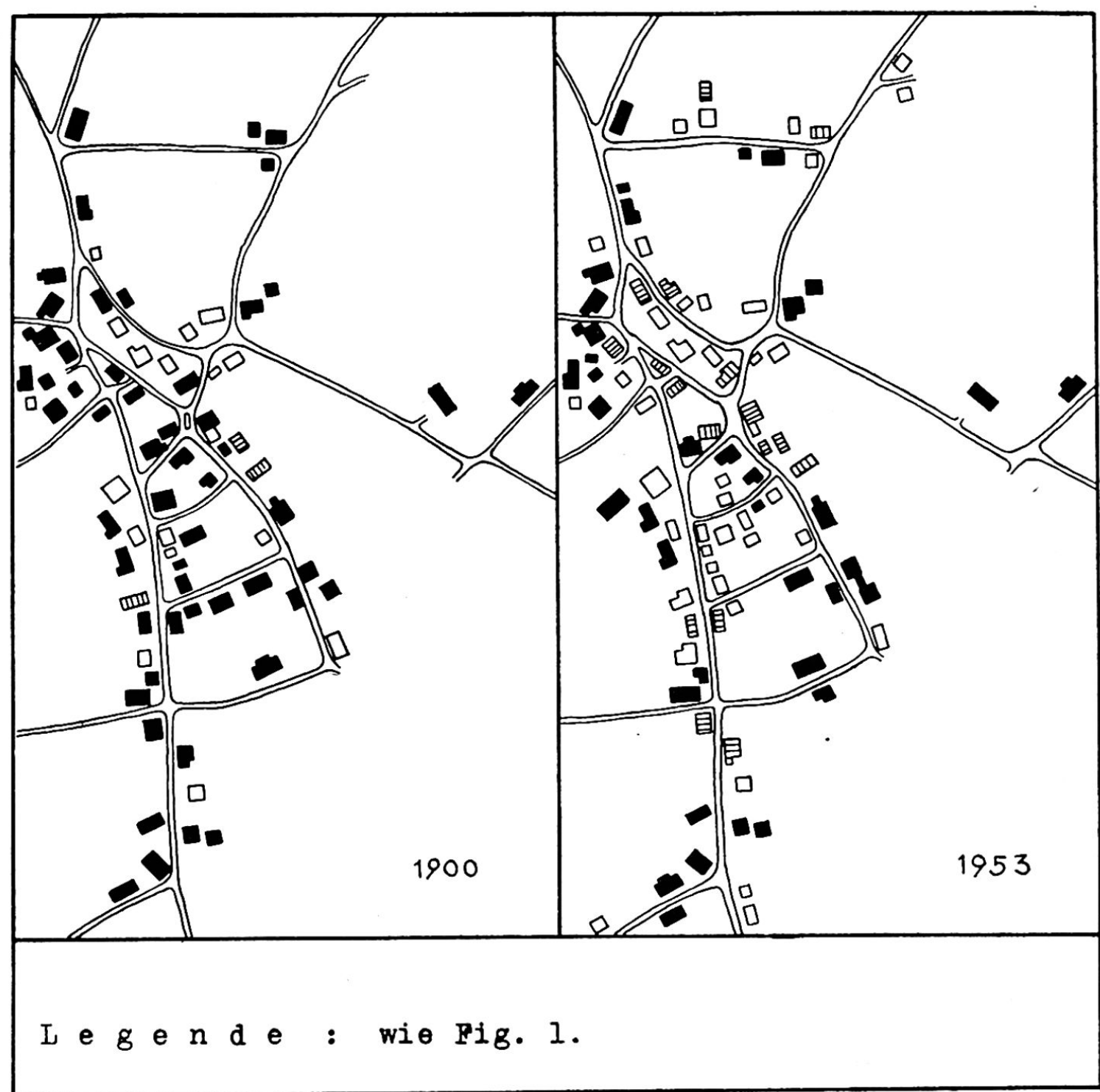

Fig. 2 Formale und funktionale Veränderungen im Bereich der bäuerlichen Dorfsiedlung in Urdorf von 1900 bis 1953

\section{Zahlenmäßige Darstellung von Fig. 2}

\begin{tabular}{|c|c|c|c|c|c|}
\hline Jahr & $\begin{array}{l}\text { Landwirs } \\
\text { formal }\end{array}$ & $\begin{array}{l}\text { 1. Gebäude } \\
\text { funktional }\end{array}$ & $\begin{array}{l}\text { Nichtlar } \\
\text { formal }\end{array}$ & $\begin{array}{l}\text { Gebäude } \\
\text { funktional }\end{array}$ & Gebäude total \\
\hline 170 & 54 & 51 & 17 & 20 & 71 \\
\hline 1953 & 55 & 38 & 40 & 57 & 95 \\
\hline
\end{tabular}

\section{Die zentralen Funktionen}

Es gibt in der Kulturlandschaft organisatorische Gebilde verschiedenster Art. Eine wesentliche Gruppe sind jene, welche nach den zentralörtlichen Prinzipien aufgebaut sind (vergleiche Christaller (12), Carol (7). Ein solches Gebilde steht durch die zentralen Funktionen in innerem Zusammenhang und unterscheidet sich von andern solchen Gebilden (funktionalen Einheiten) durch die oder einen Teil dieser zentralen Funktionen. Ein zentralörtliches Funktional besteht aus einem «zentralen 
Ort» und dem «Ergänzungsgebiet». Das Ergänzungsgebiet wird durch die Reichweite der im zentralen Ort vorhandenen «zentralen Dienste» bestimmt. Diese werden nach ihrer Reichweite, die zentralen Orte nach den dort vorhandenen zentralen Diensten und die zentralörtlichen Funktionale nach der größten Reichweite ihrer zentralen Dienste klassifiziert.

CAROL (9) unterscheidet dabei sieben verschiedene zentralörtliche Stufen oder Ordnungen. Die erste Stufe zentralörtlicher Organisation ist der landwirtschaftliche Betrieb. Dieser ist im vorhergehenden Abschnitt zur Darstellung gelangt. Im Untersuchungsgebiet interessieren vor allem die zweite (dörfliche) Stufe, die dritte (marktörtliche) Stufe und im Zusammenhang mit der Frage nach dem Einfluß der städtischen Entwicklung die vierte (städtische) Stufe.

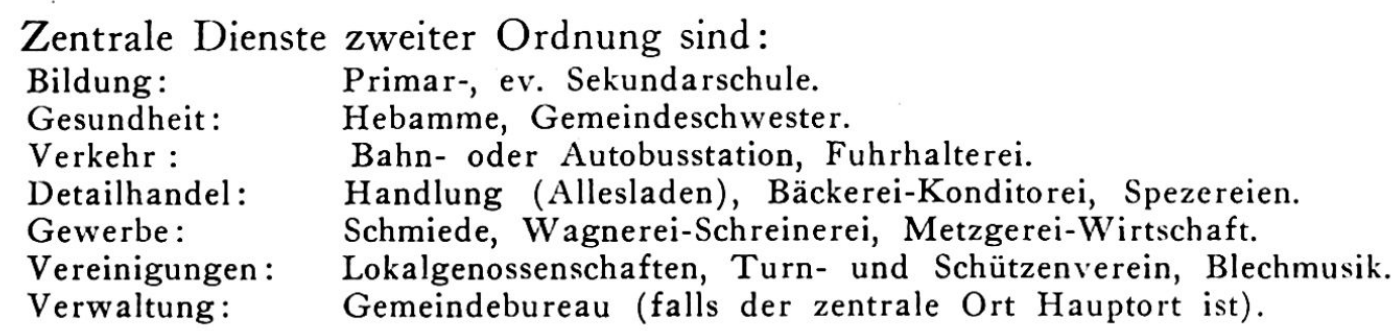

Zentrale Dienste dritter Ordnung sind:

Bildung, Kunst: Sekundarschule, ev. Berufsschule, Laientheater, Kino.

Gesundheit: $\quad$ Ärzte, Zahnärzte, Tierärzte, Apotheke, Krankenhaus.

Verkehr: Bahnstation und Autobuslinien, Garagen, Autotransporte.

Detailhandel: $\quad$ Papeterie-Buchhandlung-Buchbinderei, Tuch-Konfektion, Uhren-OptikBijouterie, landwirtschaftlicher Markt.

Gewerbe: Buchdruckerei, Architekt, Geometer, Lokalbank, Bankfiliale.

Vereinigungen: Filialen kantonaler und nationaler Vereine, Lokalvereine.

Zeitung: Lokalblatt für nähere Umgebung.

Verwaltung: Ev. Bezirksverwaltung.

Zentrale Dienste der vierten Ordnung sind u. a.:

Mittelschule, Museen, Spezialärzte, Verkehrsknotenpunkt, Regionalbanken, Engros-Handel, Treuhand- und Inkassobureaus, Bezirks- und Kantonalverwaltung.

Die Auswahl dieser Dienste erfolgte natürlich auf Grund heute bestehender Verhältnisse und für das Gebiet des schweizerischen Mittellandes. Einige existierten vor hundert Jahren noch gar nicht, so zum Beispiel Bahn, Auto und Kino. Andere haben einen erheblichen Bedeutungswandel erfahren. Sogenannte Tierärzte gab es früher fast in jedem Bauerndorf. Wichtige zentrale dörfliche Einrichtungen wie Ölpresse und Hanfribi sind sogar ganz verschwunden.

Die Bauerndörfer Schlieren und Urdorf der ersten Hälfte des 19. Jahrhunderts weisen erwartungsgemäß eine ganze Anzahl zentraler Dienste der dörflichen Stufe auf. Namentlich das der Landwirtschaft dienende Gewerbe ist umfangreich vertreten. In dem bereits früher erwähnten Katasterverzeichnis aus dem Jahre 1801 (38) von Ober- und Niederurdorf ist zur genaueren Bezeichnung von einzelnen Grundbesitzern neben deren Namen auch der Beruf angegeben. Nach diesem Verzeichnis gibt es in dieser Zeit in Oberurdorf 2 Küfer, 1 Wagner, 1 Schmied, 1 Zimmermann, 1 Schuhmacher, 1 Gerber, 1 Müller, 1 Bäcker und 1 Vieharzt. Diese gleichen Dienste müssen auch in Schlieren vorhanden sein. Nach Zehntenplänen und Urbarien ${ }^{22}$ sind sicher 1 Mühle, 1 Schmiede, 1 Ölpresse, Weinschenken und 1 Schule vorhanden.

1847 wird die Eisenbahnlinie Zürich-Baden dem Verkehr übergeben. Damit erhält Schlieren knapp nördlich des Dorfes eine Bahnhaltestelle. Mit dem Bau der Eisenbahnlinie von Zürich über Altstetten-Birmensdorf-Affoltern a. A. nach Zug im

22 Neujahrsblatt von Schlieren 1954 (25). 
Jahre 1863 erhält auch Urdorf eine Bahnstation, die zwar noch auf dem Boden der Gemeinde Schlieren liegt.

Wesentliche andere zentrale Dienste kommen vorderhand keine neu hinzu. Lediglich die bestehenden dörflichen Dienste werden etwas umfangreicher und differenzierter. $1860^{23}$ gibt es in Schlieren u. a. 2 Bäcker, 2 Ellenwarenhändler, 2 Spezereiwarenhändler, 1 Metzger, 1 Müller, 1 Schmied, 3 Wagner, 2 Küfer, 1 Seiler, 2 Maurermeister, 1 Tierarzt, 1 Schule, 1 Sekundarschule, zu der auch Albisrieden, Altstetten, Urdorf und Dietikon gehören, 1 Postbureau, 1 Gasthaus, 3 Speisewirtschaften und 2 Weinschenken. In Urdorf gibt es außerdem 1 Hafner, 1 Fuhrhalter, 1 Schlosser und 7 Schuster. Ein Metzger erhält hier um 1861 die Bewilligung zur Ausübung seines Gewerbes ${ }^{24}$.

Diese Dienste sind für die Dorfbevölkerung unentbehrlich. Der wertmäßige Umsatz ist aber gering einzuschätzen, ist doch von den beiden Spezereihändlern in Schlieren der eine gleichzeitig auch Lehrer, der andere noch Landwirt, Tierarzt, Schenkwirt und Ellenwarenhändler.

Diese Dienste genügen weitgehend den Bedürfnissen der Dorfbevölkerung jener Zeit. Ob Dienste der dörflichen Stufe auch anderwärts benützt werden, steht nicht fest. Es ist aber anzunehmen, daß dies ausnahmsweise der Fall ist, wenn in Dietikon, Altstetten oder Zürich Dienste höherer Stufen beansprucht werden müssen. Denn Dienste der dritten zentralen Stufe sind um 1860 in Urdorf und Schlieren noch keine vorhanden. In Dietikon findet man beispielsweise einen Glaser, Hafner, Brunnenmacher, Uhrenmacher, Sensenhandel, Geschirrhandel, eine Bierbrauerei und eine Schröpferin, in Altstetten sogar eine Modistin. Auch Ärzte praktizieren an diesen Orten. Die Urdorfer gehören zum Kundenkreis des Dietikoner Arztes (die Protokolle der Gemeinde Oberurdorf von 1863 bis 1884 bezeichnen ihn als «Untersuchungsarzt»). Hingegen gehört Schlieren wahrscheinlich in das Einzugsgebiet der beiden Ärzte in Altstetten.

Dienste der vierten Stufe sind nur in der Stadt Zürich zu finden, wo $1842 \mathrm{Kan}$ tonsspital und Kantonsschule gebaut werden. Hier gibt es auch Spezialgeschäfte und Handelshäuser.

Die noch vor der Jahrhundertwende einsetzende und anhaltende Bevölkerungszunahme erfordert notwendigerweise auch eine Vergrößerung des Umfanges der zentralen Dienste der zweiten Stufe. Mit den neuen Wohnquartieren entstehen neue Ladengeschäfte für Artikel des täglichen Bedarfes. Immer weitere solche Geschäfte, namentlich der Lebensmittelbranche, werden von eigentlichen städtischen Verkaufsorganisationen als Filialen übernommen. Diese dehnen damit ihr Absatzgebiet bis nach Schlieren und in neuester Zeit auch nach Urdorf aus. Auch die Metzger, die früher das Schlachtvieh direkt von den Bauern übernommen haben, beziehen heute das Fleisch wenigstens teilweise aus dem städtischen Schlachthaus. Brot- und Milchprodukte kommen ebenfalls teilweise über die städtischen Filialgeschäfte zum Verkauf. Die wachsende Zahl der täglichen Pendler versorgt sich häufig in der Stadt selbst mit täglichen Bedarfsgütern, die am Wohnort ebenso gut zu haben wären. Urdorf und Schlieren sind auf dem Wege, auf der dörflichen zentralen Stufe ihre ehemalige Selbständigkeit einzubüßen und in das Ergänzungsgebiet der Stadt zu gelangen.

Mit der neuen Entwicklung in Schlieren seit 1890 treten hier auch bald Dienste der dritten zentralen Stufe in Erscheinung. Zu nennen sind: Arzt, Notar und Grundbuchamt, Buchdruckerei, Filiale der Kantonalbank, später Zahnarzt, Architekt, Kleidergeschäft, Fachgeschäft für Schreibmaschinen, Reklameberatung, Kino. In Urdorf ist erst seit 1940 von einer stärkeren Entwicklung zu sprechen. Seither haben sich ein Architekt und ein Arzt hier niedergelassen.

${ }^{23}$ Nach Angaben von Frick (16) zusammengestellt.

24 Gemeinderatsprotokoll von Oberurdorf (36). 

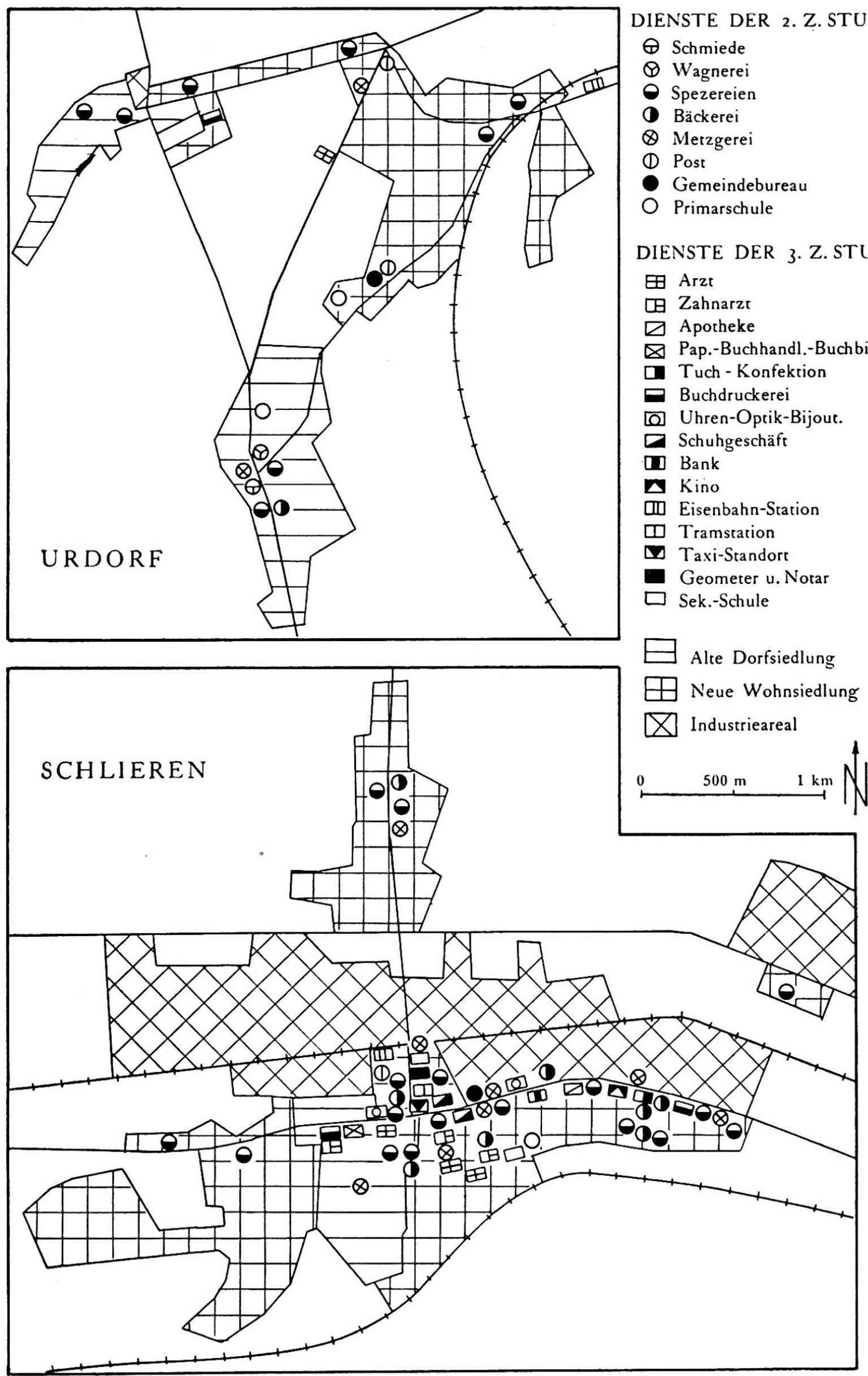

Fig. 3 Standort zentraler Dienste der 2. und 3. Stufe in Schlieren und Urdorf 195t
DIENSTE DER 2. Z. STUFE

$\Theta$ Schmiede

Q Wagnerei

Spezereien

- Bäckerei

$\otimes$ Metzgerei

(1) Post

- Gemeindebureau

O Primarschule

DIENSTE DER 3. Z.STUFE

田 Arzt

IG Zahnarzt

$\square$ Apotheke

$\triangle$ Pap.-Buchhandl.-Buchbind.

- Tuch-Konfektion

- Buchdruckerei

[0] Uhren-Optik-Bijout.

Schuhgeschäft

[i] Bank

ט Kino

인 Eisenbahn-Station

W Tramstation

$\nabla$ Taxi-Standort

- Geometer u. Notar

$\square$ Sek.-Schule

$\boxminus$ Alte Dorfsiedluns

dlung

Industriearea N 
Die Dienste der dritten zentralen Stufe, auch solche die am Ort selbst vorhanden sind, werden fast durchwegs auch in der Stadt benützt. Urdorf gehört zum Teil auch in das Einzugsgebiet von Schlieren (Arzt, Zahnarzt, Bankfiliale, Kino, Fachgeschäfte).

Wie Fig. 3 zeigt, ist in Schlieren ein ausgesprochenes Zentrum entstanden. Dessen Bildung ist offensichtlich durch die besonderen Verkehrsverhältnisse begünstigt worden. Es liegt an der Straße, die von Zürich nach Baden führt. Hier kommen auch die Straßen von Weinigen-Engstringen (von N), von Uitikon a. A. (von S) und von Urdorf (von SW) zusammen. Bis zu diesem Knotenpunkt reicht die städtische Straßenbahn, und von hier aus führen die Autobuslinien nach Engstringen-Weiningen und nach Schönenwerd-Dietikon. Wichtig ist die unmittelbare Nähe der Eisenbahnstation. In diesem Zentrum befinden sich alle Dienste der 3. Stufe. Verstreut sind nur die Ladengeschäfte der Lebensmittelbranche.

In Urdorf, wo es sich hauptsächlich um solche Ladengeschäfte handelt, sind die Dienste dispers verteilt. Die extreme Lage der Eisenbahnstation ist wenig geeignet die Bildung eines Zentrums zu begünstigen. Bei der Planung der zukünftigen Siedlungsgestaltung strebt man jedoch eine solche an und hat mit dem Bau der neuen Schulanlage, dem Gemeindehaus und dem Postbureau den Anfang gemacht.

\section{Die Fabrikindustrie}

Um die Mitte des 19. Jahrhunderts erlebt die Zürcher Seidenfabrikation ihre Blütezeit. Die Betriebe stehen in Zürich und seiner nächsten Umgebung. Es gibt auch zahlreiche andere Betriebe der Textilbranche, so zum Beispiel in Engstringen eine Baumwollspinnerei. In Schlieren und Urdorf jedoch entstehen keine solchen Betriebe. Die Bewohner dieser beiden Dörfer profitieren lediglich durch die Heimarbeit - teilweise bis gegen Ende des 19. Jahrhunderts - von der Textilindustrie.

Im Jahre 1869 wird in Schlieren selbst ein erstes Industrieunternehmen, eine Leimfabrik, in unmittelbarer Nähe der Bahnstation errichtet. Es ist ein Unternehmen, das 1851 gegründet wurde und nun vom Hornbach am Ostende Zürichs nach Schlieren übersiedelt. Der Betrieb, von den Dorfbewohnern «Lymhütte» oder «Lymi» genannt, verarbeitet im Jahre 188085 Wagons Knochen, Knochenschrott und Leimleder 25. Dabei steigt in dieser Zeit die Zahl der Arbeiter von 9 (im Jahre 1870) auf 20 bis 25, soda $\beta$ es theoretisch auf jedes dritte bis vierte Wohnhaus des Dorfes einen Arbeitsplatz trifft.

Erst um die Mitte der neunziger Jahre kommen neue Betriebe hinzu, mit deren Bau die eigentliche umfangreiche Industrialisierung Schlierens eingeleitet wird.

Eine Firma Geißberger, die an der Wiesenstraße 10 in Zürich 8 die Fabrikation von Luxus- und Lastwagen betreibt, wünscht diese auf breitere Basis zu stellen 26 . J. C. Geißberger erwirbt deshalb im Mai 1895 von der Gemeinde Schlieren ein größeres Stück Land östlich des Bahnhofes zwischen Eisenbahnlinie und Badenerstraße und verlegt seinen Betrieb dorthin. Geißberger gilt als der erste Karossier Zürichs, ja der ganzen Nord- und Ostschweiz, und es gehört geradezu zum guten Ton, von ihm beliefert zu werden. Weshalb der Fabrikant Geißberger den neuen Standort seines Unternehmens gerade hier wählt, ist nicht überliefert. Jedenfalls muß aber ausschlaggebend sein, daß hier in geringer Entfernung der mächtig wachsenden Stadt vorzüglich geeignetes Land in unmittelbarer Nähe der Eisenbahn und einer wichtigen Verkehrsstraße zu günstigen Bedingungen erhältlich ist. Das Unternehmen ist in Schlieren vorerst wenig erfolgreich. Erst wie durch den Bau einer größeren Zahl von Schmalspurbahnen und die Umstellung der zürcherischen Straßenbahn auf elektrischen Betrieb der Bedarf an Schienenfahrzeugen beträchtlich zunimmt, eröffnet sich auch für die Firma ein neues Arbeitsgebiet. Sie stellt das gesamte Rollmaterial der Limmattalstraßenbahn her. Später kommt die Fabrikation von Aufzügen, zeitweise

${ }^{25}$ Festschrift Hundert Jahre Ed. Geistlich Söhne AG. (15).

${ }^{26}$ Festschrift 50 Jahre Schweizerische Wagons- und Aufzügefabrik in Schlieren. 
sogar eine Abteilung für Flugzeugbau, hinzu. In diesem Zusammenhang werden die Firma und deren Namen verschiedentlich geändert. Sie heißt heute «Schweizerische Wagons- und Aufzügefabrik Schlieren». Sie beschäftigt gegenwärtig rund $1700 \mathrm{Ar}-$ beiter und Angestellte.

Ein zweites, großes Unternehmen, das in Schlieren in der gleichen Zeit errichtet wird, ist das städtische Gaswerk, welches seinen Betrieb aus der Stadt nach Schlieren verlegt. Dies ist aus hygienischen Gründen und für die Betriebsvergrößerung notwendig. Schon frühzeitig in den neunziger Jahren hat sich die Stadtgemeinde ausgedehnte Landkomplexe in Schlieren gesichert. Der größte Teil des Gemeindeareals nördlich der Eisenbahnlinie und östlich der Straße nach Engstringen ist im Besitze der Stadt. Hier wird von 1896 bis 1898 an der Limmat das Gaswerk gebaut und ein Geleiseanschluß vom Bahnhof Schlieren aus erstellt. Der Betrieb beschäftigt heute 275 Arbeiter und Angestellte.

In der Folge kommen noch zahlreiche weitere Betriebe hinzu, so eine Färberei, ein Aluminiumschweißwerk, eine Kühlschrankfabrik, eine Spiralbohrerfabrik u. a. Die zahlenmäßige Entwicklung zeigt die Fabrikstatistik.

\begin{tabular}{ccc} 
Eidg. Fabrikzählung in & Schlieren (35) \\
Jahr & Betriebe & Fabrikarbeiter \\
\hline 1895 & 2 & 29 \\
1911 & 8 & 711 \\
1923 & 10 & 1478 \\
1929 & 10 & 1891 \\
1937 & 13 & 1354 \\
1944 & 15 & 2120 \\
1947 & 18 & 2104
\end{tabular}

In Urdorf sind die Voraussetzungen für eine industrielle Entwicklung wesentlich ungünstiger als in Schlieren. Einmal fehlt eine genügende Wasserkraft, die in der Zeit des Aufkommens der Textilindustrie für einen Fabrikbetrieb unerläßlich ist. Der kleine Bach genügt wohl für den Betrieb der Mühle und für die Bedürfnisse einiger Gewerbe, zum Beispiel einer Gerberei. Noch vor 1870 entsteht im Herweg bei Niederurdorf eine kleine Eisengießerei und 1880 in Niederurdorf selbst eine aus dem Handwerk hervorgehende kleine mechanische Werkstätte. Die Verkehrsverhältnisse sind aber nicht geeignet, eine eigentliche Industrialisierung zu fördern. Die Eisenbahnlinie von $Z$ ürich nach $Z$ ug führt dem rechtsseitigen Talhang entlang und ist wesentlich höher gelegen als die Talebene. Zudem ist die Bahnstation 1,2 km von den Dörfern Ober- und Niederurdorf entfernt. 1895 gibt es noch keine direkte Straße von Niederurdorf nach der Station. Die Gemeinde bemüht sich aber um deren Bau und begründet die Notwendigkeit u. a. damit, daß die zwei erwähnten Betriebe fast täglich mit Fuhrwerken nach dem Bahnhof zu fahren haben und deshalb genötigt sind, den Umweg über Oberurdorf zu machen oder die Waren nach Schlieren oder Dietikon zu liefern. In der Nähe des Bahnhofes und der Eisenbahnlinie gibt es in Urdorf kein flaches, für die Fabrikindustrie geeignetes Gelände. Solches findet sich wohl auf der ganzen ausgedehnten Ebene des Talbodens nördlich Oberurdorf bis Schönenwerd. Dieses Land ist im Gegensatz zu den Verhältnissen in Schlieren seit jeher in Privatbesitz und bis zur Güterzusammenlegung im Jahre 1930 stark parzelliert. Diese Besitzverhältnisse müssen einen allfälligen Erwerb größerer Landkomplexe durch industrielle Interessenten erschweren oder überhaupt verhindern.

Die Eisengießerei in Niederurdorf beschäftigt in der Zeit von 1900 bis zum ersten Weltkrieg etwa 25 Arbeiter, die meist in Niederurdorf wohnen. In diesem Betrieb werden hauptsächlich Gußdeckel für Kanalisationsschächte hergestellt, die vor allem in Zürich Absatz finden. Auch die Wagonsfabrik in Schlieren und die mechanische Werkstätte in Niederurdorf werden beliefert. 
Veraltete Einrichtungen und unrationelle Betriebsweise behindern allmählich die Konkurrenzfähigkeit und führen schließlich zur Liquidation des Unternehmens um 1935/36. In den heute noch bestehenden Räumlichkeiten richten sich später ein Modellschreiner und ein Sauerkrautfabrikant ein.

Anfangs der neunziger Jahre entsteht an der Straße zwischen Oberurdorf und der Station eine kleine Pulverfabrik mit nur einigen wenigen Beschäftigten, darunter auch Frauen. Im Jahre 1901 geht sie an eine deutsche Firma mit Sitz in Berlin über. Diese steigert in der Folge die Produktion, die etwa in der Zeit von 1910 bis 1912 den Höhepunkt erreicht. Die Zahl der Arbeiter, die fast ausschließlich von Oberurdorf kommen, steigt auf 20 bis 25. Bei Ausbruch des Weltkrieges im Jahre 1914 muß die Fabrikation allerdings eingestellt werden. Die Anlage mit den über einem Dutzend kleinen Gebäuden bleibt aber bestehen und beherbergt nachher allerlei Kleingewerbe, wie Sattler, Velomechaniker, Galvaniseur, Imprägnatefabrikation, zeitweise auch ein Schul- und ein Gemeinderatskanzleiprovisorium. 1949 wird die Fabrikanlage volständig abgebrochen und an ihrer Stelle ein neues Schulhaus gebaut.

Von den drei schon vor 1900 bestehenden Betrieben existiert heute einzig noch die aus der mechanischen Werkstätte hervorgegangene Maschinenfabrik Lips in Niederurdorf. Hier werden zuerst Birnenmühlen und Obstpressen hergestellt, ab 1900 Bäckerei-, seit 1934/35 auch Küchenmaschinen. Die Erzeugnisse der Firma werden in der ganzen Schweiz und auch im Ausland abgesetzt. Der Betrieb zählt 1911 sechs bis sieben, 1937 etwa 20 und 195460 Arbeiter und Angestellte.

In neuester Zeit sind in Oberurdorf und bei der Station einige neue Kleinbetriebe entstanden. So unmittelbar neben dem Bahnhof die Firma Grab \& Wildi AG. für Meßgeräte, Zeichen- und Bureaumaterial, mit Ausstellungs- und Verkaufslokal am Seilergraben in Zürich. Die Fabrikationsabteilung wird 1946 wegen Platzmangel bei der notwendigen Vergrößerung von der Stadt nach Urdorf verlegt. Im weitern sind zu erwähnen: ein Betrieb, in dem Dessins-Filmdruckschablonen hergestellt werden, eine Werkstätte für Aluminiumkonstruktionen und Neonleuchtreklamen, ein Metallspritz- und Schleudergußwerk und eine feinmechanische Werkstätte. Im ganzen eine ziemlich unbedeutende industrielle Entwicklung, die sich in der Fabrikstatistik widerspiegelt.

\begin{tabular}{lcc} 
Eidg. & Fabrikzählung in \\
Jetriebe & $\begin{array}{c}\text { Urdorf (35) } \\
\text { Fabrikarbeiter }\end{array}$ \\
\hline 1895 & 1 & 6 \\
1911 & 3 & 73 \\
1929 & 2 & 18 \\
1937 & 2 & 30 \\
1944 & 2 & 30 \\
1949 & 5 & 52
\end{tabular}

Trotz der wenigen Arbeitsplätze ist die Fabrikindustrie für Urdorf nicht ganz bedeutungslos, vermag sie doch manchen Familien den beim Niedergang der Heimindustrie verloren gegangenen Nebenerwerb zu ersetzen.

\section{Der Verkehr}

Die Entwicklung der Verkehrsverhältnisse steht in engem Zusammenhang und in wechselseitiger Beziehung zur übrigen Entwicklung.

Schlieren liegt im Limmattal an einer schon frühzeitig bedeutsamen Verkehrsachse, die von Zürich nach Basel und Bern und sogar von Süddeutschland nach der Westschweiz und Frankreich führt. Zu Beginn des 19. Jahrhunderts belebt denn auch ein reger Verkehr von Reisekutschen, Postkursen, Boten- und Fuhrdiensten die Straße durch das stille Bauerndorf ${ }^{27}$. Nach dem Bau der «Spanisch Brötli-Bahn»

${ }^{27}$ Neujahrsblatt von Dietikon 1950 (23). 
geht ein großer Teil des Straßenverkehrs auf diese über. In den folgenden Jahrzehn. ten wird der Eisenbahnbau in der Schweiz stark gefördert. Der gute Bahnanschluß in geeignetem Gelände begünstigt in Schlieren die Ansiedlung von Industrieunternehmen (vergl. Abschnitt über die Fabrikindustrie). Daß direkte Geleiseanschlüsse für einzelne Betriebe leicht erstellt werden können, ist bedeutungsvoll und für Unternehmen wie das Gaswerk, das große Mengen Kohlen heranführen muß, lebenswichtig.

Bahnlinie und Station bei Urdorf sind in einem Gelände angelegt, das sich für Industriebauten und direkte Geleiseanschlüsse nicht eignet. Die Bahnverbindung vermag deshalb hier auf die industrielle Entwicklung keinen sichtbaren fördernden Einfluß auszuüben. Sie wird von einigen Abonnenten und von den Bauern, die ihre Marktkörbe nach Zürich führen lassen, benützt. (Freilich ist es bis um 1890 auch nichts Besonderes, mit dem Handkarren zu Fuß den Zürcher Markt zu besuchen.)

Die Industrie und die neuen Bevölkerungsschichten in Schlieren haben ganz andere wirtschaftliche und kulturelle Interessen als die bäuerlichen Einwohner. Das Bedürfnis nach besseren Verbindungen mit der Stadt wächst. So befaßt man sich mit Plänen für eine Limmattalstraßenbahn. Ein erstes Projekt sieht zwei Linien vor, eine von Zürich (Hauptbahnhof) über Weiningen-Würenlos nach Baden und eine vom gleichen Ausgangspunkt über Schlieren-Dietikon nach Bremgarten. Zur Ausführung gelangt schließlich die Strecke Stadtgrenze im Sihlfeld-Schlieren-Dietikon, mit einer Abzweigung von Schlieren nach Weiningen. Die Betriebseröffnung erfolgt in den Jahren 1900/01. Dieses Verkehrsunternehmen, dessen Verwaltung Sitz in Schlieren hat, wird von den beteiligten Gemeinden und von Industrieunternehmern ( $z$. B. Brown-Boveri, Baden und Geistlich, Schlieren) finanziert. Es rentiert aber vorerst nur wenig, da das Bedürfnis offenbar doch noch zu gering ist, und die Bahn zudem als Konkurrenzmaßnahmen verbilligte Fahrten und mehr Kurse einführt. Ende der zwanziger Jahre fehlen die Mittel für dringende Reparaturen. Schließlich werden die meisten Aktien an die Stadt Zürich verkauft, das Unternehmen liquidiert und die Konzession für die Strecke Zürich-Schlieren auf die städtische Straßenbahn übertragen (1930). Die Strecken Schlieren-Dietikon und Schlieren-Weiningen erhalten von nun an einen Autobusbetrieb ${ }^{28}$.

Mit Eisenbahn, Straßenbahn und zwei gut ausgebauten Autostraßen verfügt Schlieren heute über ausgezeichnete Verkehrsverbindungen mit der Stadt. Mit der Bahn beträgt die Fahrzeit bis zum Hauptbahnhof im Zentrum der Stadt 10 bis 12 Minuten. Die gleiche Fahrzeit benötigt man von Urdorf aus. Dank dieser günstigen Voraussetzung sind Schlieren und Urdorf als Wohngebiet für Leute, die in der Stadt arbeiten, geeignet. Die Zahl der Einwohner, die täglich nach Zürich zur Arbeit fahren, nimmt in beiden Gemeinden zu. Über diese Veränderungen gibt die Pendelwanderungsstatistik Auskunft.

\section{Pendelwanderer in Schlieren und Urdorf 29}

\begin{tabular}{lcccc} 
Jahr & $\begin{array}{c}\text { Berufstätige, in der } \\
\text { Gemeinde wohnhaft }\end{array}$ & $\begin{array}{c}\text { Pendel- } \\
\text { abwanderer }\end{array}$ & $\begin{array}{c}\text { Pendel- } \\
\text { zuwanderer }\end{array}$ & $\begin{array}{c}\text { In der Gemeinde } \\
\text { arbeitend }\end{array}$ \\
\hline Schlieren : & & & & \\
1910 & 1076 & 166 & 481 & 1391 \\
1941 & 2248 & 721 & 1444 & 2971 \\
& & & & \\
Urdorf: & 390 & 86 & 22 & 326 \\
1910 & 561 & 244 & 50 & 367 \\
1941 & & & &
\end{tabular}

${ }^{28}$ Neujahrsblatt von Dietikon 1951 (24).

${ }^{29}$ GuTH, H. in Zürcher Wirtschaftsbilder 1945 (17). Die Angaben für 1950 werden demnächst veröffentlicht in Stat. Quellenwerke der Schweiz, Heft 281, Bern 1956. 
Eine entsprechende Veränderung erfährt das Siedlungsbild durch eine intensive Wohnbautätigkeit. Besonders in den letzten zehn Jahren sind zahlreiche neue Wohnbauten entstanden. Sie stehen in Urdorf bezeichnenderweise möglichst nahe der Bahnstation.

\section{Zusammenfassung}

Die wirtschaftlichen, technischen, kulturellen und politischen Wandlungen im 19. Jahrhundert sind von grundlegender Bedeutung für die moderne städtische Entwicklung. Wenn man daher den Veränderungen der Kulturlandschaft nachgehen will, die sich in der Nachbarschaft einer kräftig wachsenden Stadt vollziehen, muß man zwischen Folgen der allgemeinen Wandlungen und solchen der städtischen Entwicklung unterscheiden.

Nach dem Umsturz der alten Eidgenossenschaft im Jahre 1798 mit den nachfolgenden Kriegswirren, Verwüstungen und Plünderungen durch fremde Heere, unter denen auch Zürich und seine Umgebung etliches zu leiden haben, dauert das wechselvolle Ringen um ein moderneres staatliches Leben der Schweiz ein halbes Jahrhundert. Mit der Bundesverfassung von 1848 und der Konstituierung des Bundesstaates an Stelle des früheren Staatenbundes werden u. a. das Recht der freien Niederlassung und Gewerbeausübung endgültig gewährleistet. Die Zollschranken im Innern des Landes fallen, Zoll- und Münzhoheit gehen von den Kaǹtonen an den Bund über, ebenso das Postwesen.

In den gleichen Zeitabschnitt fällt der Beginn einer neuen Industrialisierung. Schon am Ende des 18. Jahrhunderts gilt die Schweiz als ein bedeutendes Industrieland. Die Unternehmen, in der Nord- und Ostschweiz meist solche der Textilindustrie, sind auf dem Verlagssystem aufgebaut und stützen sich auf zahlreiche Heimarbeiter in den Dörfern. Mit der Einführung der mechanischen Spinnerei (1801) in der Schweiz und des mechanischen Webstuhles rund dreißig Jahre später beginnt eine entscheidende Umwandlung der industriellen Struktur und die allmähliche Ablösung des Verlagssystems durch das Fabriksystem. Die Mechanisierung der Textilindustrie ruft neuèn Industriezweigen, namentlich der Maschinenkonstruktion.

Das Aufkommen der Dampfmaschinen in den vierziger Jahren eröffnet für die bisher an die Wasserkraft gebundene Fabrikindustrie neue Möglichkeiten und für die Maschinenindustrie ein neues Arbeitsfeld. Die Eröffnung der ersten Eisenbahnstrecke in der Schweiz von Zürich nach Baden im Jahre 1847 leitet die Epoche des Eisenbahnbaues ein. Bis 1865 entsteht ein schon respektables Netz mit einer Gesamtlänge von $1336 \mathrm{~km}$. Zürich hat Verbindungen nach Basel und der Westschweiz, über Winterthur nach Wil-St. Gallen und Frauenfeld-Romanshorn, nach Glarus und Chur. Der Anschluß an das Ausland ist in Genf und Basel hergestellt und 1882 mit der Eröffnung der Gotthardbahn auch die Verbindung mit Italien. Mit dem Eisenbahnverkehr setzt ein umfangreicher Güteraustausch ein. Die Einfuhr von Rohstoffen gibt der Industrie und der Wirtschaft mächtigen Aufschwung. Zürich wird immer mehr zum Mittelpunkt des wirtschaftlichen und industriellen Lebens der Schweiz und schließlich zum Finanzzentrum von internationaler Bedeutung.

1832 erhält Zürich das erste Staatssteuergesetz; als Folge davon vollzieht sich der für die Landwirtschaft bedeutungsvolle Wandel von der Natural- zur Geldwirtschaft. Das Straßennetz im Kanton wird ausgebaut, Schanzen, Mauern und Tore der Stadtbefestigung fallen: die Stadt kann ihr Wachstum beginnen. Ihre Bevölkerung beginnt sich zusehends zu vermehren: seit langen Jahren nur wenig verändert, zählt die Stadt 179010148 Einwohner. 1836 sind es schon 14243 und 1860 19758. Im Jahre 1893 muß bereits die erste und 1934 die zweite Eingemeindung vollzogen werden. Schließlich zählt das vergrößerte städtische Gemeinwesen Ende 1953409260 Einwohner 30.

${ }^{30}$ Stat. Jahrbücher der Stadt Zürich (29). 
Mit der gründlichen Verbesserung des Volksschulwesens wird 1833 in Zürich auch die Kantonsschule mit Gymnasium und Industrieschule und eine Universität geschaffen. Das Kantonsspital wird erbaut, und 1834 erhält die Stadt ihr erstes ständiges Theater. 1855 folgt die Eröffnung des Eidgenössischen Polytechnikums.

Folgende Veränderungen im Untersuchungsgebiet sind Auswirkungen der oben erwähnten allgemeinen Wandlungen: Umstellung der Landwirtschaft vom Ackerbau auf Milch-Graswirtschaft; Rückgang des Weinbaues zugunsten des Obstbaues; Gründung von Außenhöfen; Umstellung von Selbstversorgung auf Marktwirtschaft; erste Zunahme der Bevölkerung bis 1860 und nachfolgende Abwanderung; Schaffung von Verkehrsverbindungen durch den Bau der Eisenbahn; Rückgang der Heimarbeit und Beginn erster Fabrikarbeit; Differenzierung des Gewerbes im 19. Jahrhundert; Beginn beruflicher Spezialisierung und Steigerung der Lebensansprüche.

Direkt auf die Entwicklung der Stadt sind zurückzuführen:

Ansiedlung der ersten Industriebetriebe in Schlieren (Leimfabrik, Gaswerk und Wagonsfabrik); Beginn der Lieferung landwirtschaftlicher Produkte (Milch, Gemüse, Obst) an die Stadtbevölkerung und damit im Zusammenhang Intensivierung der Milchproduktion und spezialisierter Gemüsebau in Gärtnereien; Verlust von privatem und von Gemeindeboden durch Verkauf an die Stadt und städtische Interessenten; Veränderung der Bevölkerungsstruktur durch Ansiedlung einer in der Stadt arbeitenden Bevölkerung (Pendler) und damit Bau zahlreicher Wohnsiedlungen.

$\mathrm{Da}$ in Urdorf erst mit der Zuwanderung der Pendler in den letzten zehn Jahren eine nennenswerte Entwicklung einsetzt, ist diese direkt und allein auf den Einflu $\beta$ der wachsenden Stadt zurückzuführen.

Viele Veränderungen können nicht ohne weiteres eindeutig und als direkte Folge der allgemeinen oder der Stadtentwicklung zugeschrieben werden; manche sind erst indirekte Folgen. Beispielsweise leitet die Industrialisierung in Schlieren, zu der die städtische Entwicklung Zürichs zwar den Anstoß gegeben hat, eine Eigenentwicklung cin. Zu dieser gehören : Zunahme der nichtlandwirtschaftlichen Bevölkerung, der nichtlandwirtschaftlichen Bauten; Verlust landwirtschaftlichen Areals und Rückgang der Landwirtschaftsbetriebe; weitere Zunahme der Industrie und der zentralen Dienste.

Neben dieser Eigenentwicklung beginnt sich in den letzten Jahren mit der $\mathrm{Zu}$ wanderung städtischer Pendler erneut eine direkte Einflußnahme der Stadt abzuzeichnen. Eine solche macht sich auch dadurch geltend, indem Schlieren wie auch Urdorf auf der dörflichen zentralen Stufe in das Ergänzungsgebiet der Stadt einbezogen werden.

Die im Untersuchungsgebiet seit fünfzig bis sechzig Jahren sichtbar werdende Entwicklung hat die Kulturlandschaft dahin verändert, daß die ursprüngliche ländliche Kulturlandschaft in großen Teilen einer städtisch anmutenden Kulturlandschaft Platz gemacht hat.

\section{Teil}

\section{Die formale Struktur des Überganges vom Zentrum der Stadt Zürich in die ländliche Umgebung im Sektor des Limmattales}

Nach der detaillierten Aufnahme eines kleinen Raumes im I. Teil, soll sich nun hier die Untersuchung nur auf eine Feldkartierung stützen, dafür aber einen größeren Ausschnitt berücksichtigen.

\section{A. GRUNDLAGEN}

\section{Abgrenzung und Fläche des Untersuchungsgebietes}

Der für die Untersuchung gewählte sektorförmige Ausschnitt umfaßt im großen und ganzen den Talraum des Limmattales vom Seende bis hinunter nach WeiningenUrdorf. Die breite Talebene bot sozusagen die einzige Gelegenheit für ein ungehin- 
dertes räumliches Wachsen der Stadt. Auf allen andern Seiten haben natürliche Hindernisse wie der Uetliberg, der Zürichberg, der Käferberg und der Zürichsee dieses Wachstum eingeschränkt oder doch modifiziert. Gegen das Limmattal hin ist denn auch die erste modernere räumliche Ausdehnung der Stadt erfolgt, als die Ebenen außerhalb der Sihl dicht überbaut wurden. Viele Industriebetriebe begünstigten die Ansiedlung neuer Bewohner, deren Zahl in Außersihl, den heutigen Kreisen 4 und 5, von 1860 an sprunghaft in die Höhe stieg. Schon nach vier Jahrzehnten wohnten hier mehr Leute als in der alten Stadt (Kreis 1).

Die genaue Begrenzung des Untersuchungsgebietes ist nach Stadtplan und Karte $1: 25000$ wie folgt zu bezeichnen: Bürkliplatz- Limmat bis Kornhausbrücke-Hönggerstraße-Bellikersteig-Waldrand Waid-Waldränder auf der Höhe der rechten Talflanke bis westlich Weiningen (Haslern)-Hardwald-Einmündung des Schäflibaches in die Limmat-Waldränder des Hohnert westlich Urdorf bis Egg-Aspwald-Waldränder östlich von Urdorf bis Station Urdorf-Waldränder an der linken Talflanke des Limmattales bis Triemli-Birmensdorferstraße bis Bahnhof Wiedikon-Schimmelstraße-Brandschenkestraße-Schanzengraben-Bürkliplatz. Das Untersuchungsgebiet umfaßt eine Fläche von rund 3500 ha.

Die periphere Begrenzung wurde so weit außen gewählt, damit der ganze Übergang vom unzweifelhaft städtischen Gebiet des Zentrums mit der City bis hinaus in die tatsächlich ländliche Umgebung etwa südlich Urdorf und im Reppischtal beobachtet werden konnte.

\section{Die formalen Elemente}

An der Konstituierung der Kulturlandschaft sind die in Abschnitt 2 des I. Teiles erwähnten formalen Elemente beteiligt.

Der Untergrund wird durch obere Süßwassermolasse und auf ihr liegenden Schotter- und Moränenschuttmassen gebildet ${ }^{31}$. Die Molasse selbst ist nur zu einem kleinen Teil direkter Untergrund, so auf den Höhen nördlich der Limmat (Sonderi, Gubrist, Haslern), in einem Streifen am Abhang südlich Schlieren, der auch in das Urdorfertal hineinzieht, längs des Hohnertwald und im Reppischtal. Den Talgrund des Limmattales und des Urdorfer Seitentales bedecken Schotter der niederen Terrassen, im Dreieck Unterengstringen-Geroldswil-Hardwald sind es Schotter der mittleren Terrassen. Die übrigen Teile, also im wesentlichen die Talhänge, sind mit Moränenschutt überdeckt, der teilweise auch Schotter der hohen Terrassen überkleistert. Im Raum südöstlich Albisrieden bestehen alluviale Aufschüttungen in Form von Rutschungen und Gehängeschutt.

Die Böden, mittel- bis tiefgründige Braunerdeböden, sind im Bereiche der Schotter trocken und durchlässig, im Molasse- und Moränengebiet eher lehmig und gelegentlich etwas naß. Wo der Grundwasserspiegel hoch steht, können auch die Böden auf den Schotterflächen sumpfig sein.

Das Relief ist durch drei Eintalungen gekennzeichnet: das in allgemein WSWRichtung verlaufende Limmattal, das in dieses von Süden einmündende Urdorfertal und das Reppischtal. Die Ebene des Limmattales ist im ausgewählten Abschnitt 1,5 bis 2,5 km breit. Die Talhänge sind im allgemeinen mäßig steil. Einzelheiten sind auf der Böschungskarte (Kartenbeilage I) ${ }^{32}$ ersichtlich. Nach der Böschungskarte, die ein etwas größeres als das eingangs erwähnte Untersuchungsgebiet umfaßt, verteilen sich die verschieden geneigten Flächen wie folgt:

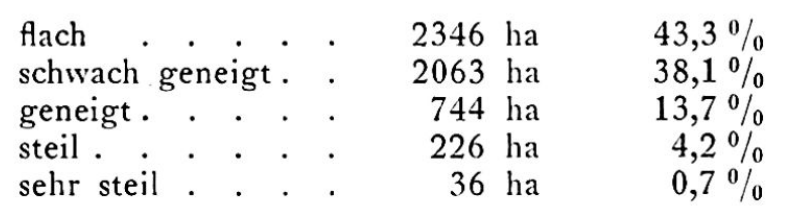

31 SUTER (27).

sehr steil . . . 36 ha $0,7 \%$

32 Nach Darstellungsmethode von Carol. (6). 
Der entscheidende Faktor für eine Differenzierung der klimatischen Verhältnisse ist die Exposition. Der ganze rechtsseitige Talhang des Limmattales ist nach SSW exponiert, der linksseitige nach NNW. Die sich daraus ergebenden klimatischen Unterschiede und ihre Auswirkungen auf die Kulturvegetation sind schon im ersten Teil für das Gebiet von Schlieren und Weiningen erwähnt worden. Sie haben für die ganze Ausdehnung des Limmattales Gültigkeit. Während in Weiningen große Rebberge existieren, sind die umfangreichen Rebpflanzungen bei Engstringen und Höngg wie auf der gegenüberliegenden 'Talseite verschwunden. An diesem sonnigen Talhang machen sich dafür Wohnsiedler die klimatischen Vorzüge zu Nutzen. Wohnbauten sind allerdings auch auf dem jenseitigen Talhang bei Altstetten und Albisrieden nicht ausgeblieben. Infolge Industrialisierung und Stadtnähe sind dort Bedürfnis und Interesse für jegliches Wohnsiedlungsgelände so stark gewachsen, daß allfällige klimatische Nachteile keine Rolle spielten. Ähnlich verhält es sich bei Schlieren.

Auf mikroklimatische Verschiedenheiten, namentlich als Folge der Ansammlung vieler Bauten, sei in diesem Zusammenhang nur hingewiesen.

Gegenüber der Kulturvegetation tritt die Naturvegetation ganz in den Hintergrund, weshalb wir sie hier vernachlässigen können. Im offenen Kulturland, im allgemeinen westlich von Höngg und Altstetten, herrscht die landwirtschaftliche Kulturvegetation vor: Graswuchs, Futterpflanzen, Getreide, Hackfrüchte, Reben und Obstbäume. Die verschiedenen Kulturen, namentlich Graswuchs und Ackerkulturen, sind bei starker Parzellierung gemischt. Die Obstbäume konzentrieren sich um die Dörfer Urdorf, Weiningen, Unter- und Oberengstringen und Schlieren, sind aber auch fast überall auf den Feldfluren dazwischen zu finden. Nennenswerte Rebberge gibt es wie schon erwähnt nur bei Weiningen.

Im dichter besiedelten Gebiet werden in Gärtnereien, Schrebergärten und Hausgärten, Gemüse, Hackfrüchte, Obstbäume und Blumen gepflanzt, in Ziergärten und Anlagen Zierrasen, Zierbüsche, Bäume und Blumen.

Die Bauten erscheinen in mannigfachen Formen und wechselnder Verbreitung. Der Variationsbereich etwa der Wohnbauten vom modernen elfstöckigen Hochhaus über die Mietskasernen bis zum einfachen Einfamilienhaus ist groß. Beachtliche Unterschiede gibt es auch bei den Industriebauten in bezug auf Größe und Form. Die Betriebe des Untersuchungsgebietes gehören vor allem zur Metall-, zur holzverarbeitenden und zur chemischen Industrie. Daneben gibt es noch viele Arten von Bauten verschiedenster Formen: Geschäfts-, Bahnhof-, öffentliche und Kulturbauten, Bauten für Verkehr, Sport und Landwirtschaft.

\section{Die Feldkartierung ${ }^{33}$}

Die Feldkartierung wurde im Jahre 1953 ausgeführt. Alle Aufzeichnungen beruhen auf persönlicher Beobachtung im Felde.

Die Originalkartierung wurde in verschiedenen Maßstäben durchgeführt. Für die offeneren Gebiete genügte der Maßstab 1:10 000, für die dicht besiedelten Teile, namentlich gegen das Zentrum der Stadt, war mit einem Maßstab 1:5000 noch zweckmäßig zu arbeiten. Als Kartengrundlagen dienten deshalb der Topographische Atlas 1:25000 in der Vergrößerung 1:10 000, die Übersichtspläne des Vermessungsamtes der Stadt Zürich im Maßstab 1:5000 und die Katasterpläne einzelner Gemeinden.

Auf Grund dieser Originalkartierungen wurde die Karte im Maßstab 1:10000 gezeichnet und hernach auf den Maßstab 1:25000 verkleinert. Aus Rücksicht auf die Übersichtlichkeit und die Form der Darstellung mußte eine gewisse Generalisierung vorgenommen werden. Die kleinste noch zur Darstellung gelangte Fläche mißt $30 \times 50 \mathrm{~m}$. Kleinere Flächen wurden zur Umgebung gerechnet. Einzelne Siedlungen,

\footnotetext{
${ }^{33}$ Vergleiche Kartenbeilage II. Die Landnutzung im oberen Limmattal.
} 
die das Mindestmaß 3 nicht erreichen, sind durch Signaturen dargestellt: im freien Gelände stehende Einzelsiedlungen, nichtlandwirtschaftliche Bauten innerhalb landwirtschaftlicher Siedlung und landwirtschaftliche Bauten innerhalb nichtlandwirtschaftlicher Siedlung.

Die Feldkartierung beschränkt sich auf die beiden Elemente Kulturvegetation und Bauten. Bei beiden Elementen sind zwei Gruppen von Merkmalen zu unterscheiden. Die eine trägt zur Konstituierung der ländlichen, die andere zur städtischen Kulturlandschaft bei. Folgende Merkmale gehören zu den beiden Gruppen:

Ländliche Kulturlandschaft

Städtische Kulturlandschaft

\section{Merkmale der Bauten}

Bauernhäuser (Mehrzweckhäuser)

Bäuerliche Wohnhäuser

Ökonomiegebäude

Herrschaftshäuser bei Gutsbetrieben

Geschäftshäuser
Wohnbauten
Industriebauten
Sportbauten

Merkmale der Kulturvegetation

Graswuchs
Futterpflanzen
Getreide
Hackfrüchte
Reben
Obstbäume
Gemüse
Blumen
Zierrasen
Zierbüsche
Bäume

Gewerbliche, öffentliche, Kult- und Verkehrsbauten können nicht ohne weiteres einer der beiden Gruppen zugeordnet werden. Zum Beispiel gehören Kirche und Schulhaus sowohl zur ländlichen als auch zur städtischen Kulturlandschaft.

Von den übrigen Elementen ist das Relief am stärksten an der Gestaltung des Kulturlandschaftsbildes beteiligt. Es ist aus diesem Grunde in der Böschungskarte dargestellt worden.

Da uns hier in erster Linie das aktive Hinauswachsen der Stadt in die ländliche Umgebung interessiert, richtet sich unser Augenmerk vor allem auf die Merkmale der städtischen Kulturlandschaft. Das kommt darin zum Ausdruck, daß bei der Auswahl der Legende die Merkmale der ländlichen Kulturlandschaft nur in ihrer Gesamtheit berücksichtigt werden, während diejenigen der städtischen Kulturlandschaft differenziert dargestellt sind.

Diskussion der Legende:

Zur Siedlung werden Gebäude, Hofraum, Hausgarten und angrenzende Straßenfläche gerechnet.

a) Geschäftsbauten

Es handelt sich hier um reine Geschäftshäuser ohne Wohnungen. Sie sind gekennzeichnet durch große gleichmäßig ausgebildete Fassaden mit regelmäßiger Anordnung der Fenster. Hier befinden sich Bureauräumlichkeiten, Zeichensäle und Ateliers. Verkaufslokale, meist im Erdgeschoß oder im ersten Stock, sind an den großen Schaufenstern und Auslagen, ihren Firmen- und Reklametafeln gut erkennbar. Neuere Geschäftshäuser sind leicht zu bestimmen, im Gegensatz zu solchen älteren Baustils, wie sie im Raume zwischen Hauptbahnhof und Bürkliplatz vorhanden sind. Diese weisen oft keine größeren regelmäßigen Fassaden auf und gleichen in den obern Stockwerken der Bauart städtischer Bürgerhäuser. Eine Anzahl solcher Bauten ist deshalb nicht zu den Geschäftshäusern zu rechnen, obwohl sie funktional dazu gehören.

b) Wohn-Geschäftssiedlung

Gebäude mit nach außen erkennbaren Geschäftsräumen im Erdgeschoß und eventuell ersten Stockwerk und Wohnungen darüber. Die Geschäftsräume dienen meist als Verkaufslokale, Gastwirtschaften, Werkstätten mit Auslagen und Bureaus.

c) Wohnsiedlungen

Mehrfamilienhäuser, geschlossene Bauweise:

Da die Wohnungseinteilung in der Gestaltung der Fassade zum Ausdruck kommt, kann man sie gut als Wohnhäuser erkennen. Die Fassaden sind in kürzere Einheiten eingeteilt, zu denen ein Eingang, verschiedenartige Fenster für Treppenhaus, Küche und 
Wohnräume und eventuell ein Balkon gehören. Als Mehrfamilienhäuser werden Wohnhäuser mit mindestens zwei Stockwerken und wenigstens zwei Wohnungen pro Stockwerk bezeichnet.

Geschlossene Bauweise kennzeichnen: Häuserblocks in einem Straßenviereck mit offenen oder überbauten Innenhöfen, geschlossene Häuserflucht beiderseits der Straße auf eine Länge von mindestens $100 \mathrm{~m}$, geschlossene Häuserflucht nur auf einer Straßenseite auf eine Strecke von mindestens $200 \mathrm{~m}$, in allen drei Fällen auch mit Lücken, wenn diese nicht größer sind als die Fassadenhöhe der benachbarten Gebäude.

Mehrfamilienhäuser, offene Bauweise:

Merkmale der Gebäude wie bei Mehrfamilienhäusern geschlossener Bauweise; aber im allgemeinen kleinere Baueinheiten. Bei offener Bauweise stehen die Häuser meist nicht parallel zur Straße. Bei Zeilenbau längs der Straße sind die Abstände zwischen den Häusern größer als ihre Fassadenhöhen. Stets ist Umgelände (Rasen, Gärten) vorhanden.

1-2-Familienhäuser :

Ein- bis mehrstöckige Häuser mit höchstens einer Wohnung pro Stockwerk, oder einstöckige Häuser mit ein bis zwei Wohnungen (Doppeleinfamilienhäuser). Immer Umgelände als Haus- oder Ziergarten oder Park.

d) Industrie

Fabrik- und Werkstattbauten, Lagerbauten, Lagerplätze von Industrie-, Handels- und Bauunternehmungen.

e) Landwirtschaftliche Siedlung

Bauernhäuser (Wohn- und Ökonomiegebäude zusammengebaut oder getrennt), Scheunen, Remisen.

f) Kirchen und Schulen

Gebäude mit dazugehörender Umgebung. Kirche mit Kirchhof, Schulhaus mit Turnund Pausenplatz.

g) Eisenbahnanlagen

Bahnhofanlagen mit Bahnhofgebäude, Güterschuppen, Ausweich-, Abstell- und Rangiergeleise, Lokomotivschuppen.

Große Verkehrsbauten von Straßenbahn und Straßenverkehr.

h) Anlagen

Grünanlagen, Friedhöfe, auch als Anlagen gestaltete Freibäder, z. B. Letzigraben.

i) Gärtnereien

Große einheitliche Flächen mit Gemüseanbau oder kleinere Flächen mit Blumen, Baumschulen, Treibkästen und Treibhäuser, Wasserverteilungsanlagen.

k) Schrebergärten

Kleinste Parzellen mit vielfältig gemischtem Anbau von Gemüse, Blumen, Beeren; Bäume, Sträucher; kleine Gartenhäuschen.

1) Sportanlagen

Fußballplätze mit kurz geschnittenem Rasen, Toren, Aschenbahnen, Tribünen, Garderoben; Tennisplätze.

m) Landwirtschaftliches Areal

Wiesen, Äcker, Streuland, landwirtschaftlicher Gemüsebau, Reben.

Für die weiteren kartierten Merkmale sei auf die Legende der Karte verwiesen.

\section{B. DIE STRUKTUR DER LANDNUTZUNG}

\section{Die Feinstruktur}

Die Feinstruktur ist, wie das Bild der Kartierung zeigt, außerordentlich vielfältig, was flächenmäßigen Umfang und Form und die Verteilung der verschiedenen Merkmale betrifft.

Die Flächen mit Bauten sind meistens, entsprechend der Anlage von Straßen und der Parzellenform des Baugrundes, gradlinig begrenzt. Das gilt aber auch für die Mehrzahl der Vegetationsflächen, namentlich wo sie an überbaute Flächen stoßen, aber auch wegen der üblichen geraden Grenzziehung bei der Einteilung der Parzellen und der häufig künstlich geradlinig geführten Waldränder. Die Flächen haben eine ein- 
fache, regelmäßige Form, etwa quadratisch oder rechteckig; zahlreich sind auch die unregelmäßigen Vielecke verschiedenster Art.

Ein Vergleich mit der Böschungskarte zeigt, daß alle größeren Flächen der Bauten auf dem Talboden liegen und Industrieareal sind, das ebenen Baugrund voraussetzt. Damit ist ein differenzierender Einfluß des Elementes Relief festzustellen, der in einer andern Erscheinung noch deutlicher zum Ausdruck kommt. Viele Flächen der Überbauung sind von langgestreckter Form, da sie sich den Straßen entlang ziehen. Am Abhang, wo diese fast ausschließlich parallel zum Hang verlaufen, wie in Höngg auf der rechten Talseite, häufen sich die schmalen und länglichen Formen, deren einheitliche Richtung auffällt. Eine ähnliche Tendenz ist auch weiter talabwärts auf der gleichen Seite bei Ober- und Unterengstringen festzustellen, nicht aber am gegenüberliegenden Talhang bei Altstetten, wo die Hangneigung geringer ist und Straßen in der Fallinie möglich sind.

$\mathrm{Da}$ und dort konzentrieren sich einzelne Merkmale, so z. B. die Geschäftsbauten im innersten Winkel des Sektors. Von hier aus bis rund fünf Kilometer talabwärts sind die Flächen mit Merkmalen der Vegetation überall vollständig von Bauten umschlossen. Noch weiter talauswärts dagegen sind die überbauten Flächen ganz von freiem Umgelände umgeben.

Die unregelmäßige Verteilung überbauter und nichtüberbauter Flächen sowie die Konzentration einzelner Merkmale lassen verschiedene Abschnitte unterscheiden.

\section{Die Nutzungseinheiten}

( Vergleiche dazu die Kartenbeilage III, Deckblatt zu Karte II.)

Da die Kartierung nur die Nutzung durch Bauten und Vegetation umfaßt und alle übrigen Elemente nicht berücksichtigt werden, handelt es sich bei den Abschnitten um formale Nutzungseinheiten. Jede Nutzungseinheit unterscheidet sich von ihrer Umgebung durch eine bestimmte Auswahl oder Häufung oder eine besondere Anordnung der in ihr vorhandenen Merkmale. Jede ist relativ, im Vergleich mit ihrer Umgebung, einheitlich. Die Grenze einer Nutzungseinheit liegt dort, wo sich eines oder mehrere ihrer Merkmale wesentlich verändern.

So sind 28 verschiedene Nutzungseinheiten zu unterscheiden, die als N 1-28 bezeichnet werden. Die Tabelle auf S. 29 enthält eine Zusammenstellung über den Inhalt der einzelnen Nutzungseinheiten, als Ergebnis einer planimetrischen Ausmessung der Karte II im Maßstab 1:10 000.

Die Nutzungseinheiten unterscheiden sich durch folgende Merkmale von ihrer Nachbarschaft :

N 1 Geschäftsbauten flächenmäßig;

N 2 Wohn-Geschäftsbauten flächenmäßig, Geschäftsbauten vereinzelt;

N 3 Wohnsiedlung flächenmäßig, geschlossene Bauweise;

$\mathrm{N} 4$ Industrieareal in großer Fläche;

N 5 Große Freiflächen, dazwischen in breiter, bandförmiger Anordnung Wohnsiedlung und Industrieareal;

N 6 Größere Flächen Industrieareal, gemischt mit mittleren Flächen Wohnsiedlung;

N 7 Wohnsiedlungen (Ein- und Mehrfamilienhäuser offener Bauweise), angeordnet um eine kleine Fläche Wohn-Geschäftsbauten und mit eingeschlossenen mittleren und kleinen Freiflächen;

N 8 wie $\mathrm{N} 7$;

N 9 Industrieareal in mittleren Flächen, durchsetzt von kleinen Flächen Wohnsiedlung und kleinen und mittleren Freiflächen;

N 10 Große Freiflächen (Schrebergärten, Gärtnereien), durchsetzt von kleinen Flächen Wohnsiedlung und Industrie; 
Inhalt der Nutzungseinheiten in ha:

\begin{tabular}{|c|c|c|c|c|c|c|c|c|c|c|c|c|c|c|c|c|c|}
\hline \multicolumn{11}{|c|}{ Bauten } & \multicolumn{6}{|c|}{ Vegetation } & \multirow[b]{2}{*}{$\begin{array}{l}\vec{\pi} \\
\stackrel{0}{0} \\
\stackrel{H}{*}\end{array}$} \\
\hline 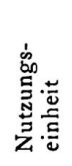 & 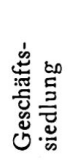 & 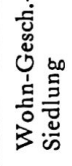 & 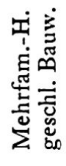 & 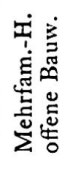 & 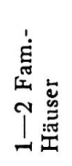 & 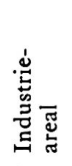 & 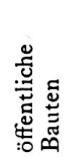 & 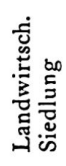 & 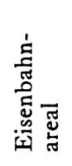 & $\stackrel{\bar{\Xi}}{\circ}$ & 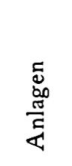 & 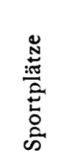 & 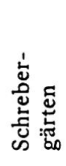 & 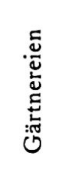 & 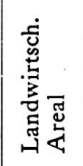 & $\stackrel{\text { ङू }}{\stackrel{0}{\circ}}$ & \\
\hline$N_{1}$ & 27,7 & 23,3 & 1,4 & - & 0,5 & - & 0,2 & -. & 3,2 & 56,3 & 5,4 & - & - & - & - & 5,4 & 61,7 \\
\hline N 2 & 7,6 & 77,9 & $\begin{array}{l}7,2 \\
7,2\end{array}$ & - & 2,8 & 23,6 & 23,2 & - & 23,4 & 165,7 & 4,6 & - & - & - & - & 4,6 & 170,3 \\
\hline N 3 & 0,1 & 12,8 & 56,1 & 1,1 & - & 12,3 & 7,1 & - & 24,9 & 114,4 & 5,2 & - & 2,3 & - & - & 7,5 & 121,9 \\
\hline N 4 & - & 1,2 & 1,0 & 0,9 & 0,4 & 73,6 & - & - & 14,6 & 91,7 & - & - & 0,3 & - & - & 0,3 & 92,0 \\
\hline N 5 & - & 2,0 & 8,9 & 26,4 & 1,8 & 27,3 & 3,2 & - & 15,2 & 84,8 & 26,5 & 16,7 & 63,8 & 37,7 & 34,3 & 149,0 & 233,8 \\
\hline N 6 & 1,1 & - & 3,5 & 5,3 & 9,8 & 53,3 & - & - & 3,6 & 76,6 & 0,2 & 1,2 & 7,1 & - & 10,4 & 18,9 & 95,5 \\
\hline N 7 & - & 1,1 & - & 46,7 & 44,2 & 7,6 & 3,2 & 4,3 & $\sqrt{3}$, & 107,1 & 0,7 & 1,2 & 3,9 & 7,1 & 21,0 & 33,9 & 141,0 \\
\hline N 8 & - & 7,6 & - & 52,3 & 42,2 & 5,3 & 7,9 & 2,5 & 0,2 & 118,0 & - & - & 10,2 & 9,6 & 19,7 & 39,5 & 157,5 \\
\hline N 9 & - & - & - & 1,9 & 4,4 & 33,6 & - & - & 7,4 & 47,3 & - & - & 20,0 & 9,4 & 3,9 & 33,3 & 80,6 \\
\hline N10 & - & - & - & 0,9 & 3,2 & 7,7 & - & 1,5 & - & 40,7 & - & 17,0 & 48,0 & 22,8 & 58,3 & 146,1 & 186,8 \\
\hline N11 & - & 3,6 & - & 43,6 & 65,6 & 3,1 & 4,7 & 2,8 & - & 123,2 & 5,2 & - & 6,5 & 2,2 & 37,9 & 51,8 & 175,0 \\
\hline N12 & - & - & - & 0,6 & 1,5 & 0,3 & - & 1,0 & - & 3,4 & - & 1,3 & 2,2 & -2 & 106,0 & 109,5 & 112,9 \\
\hline N13 & - & - & - & - & 3,2 & - & - & 3,7 & - & 6,9 & - & - & 2,4 & 2,5 & 123,2 & 125,7 & 132,6 \\
\hline N14 & -. & - & - & 2,2 & 3,4 & 1,9 & - & 1,2 & - & 8,7 & - & - & 6,3 & 1,0 & 50,9 & 58,2 & 66,9 \\
\hline N15 & - & - & - & - & 5,1 & - & - & -2 & - & 5,1 & 1,8 & - & 3,6 & 10,4 & 60,7 & 76,5 & 81,6 \\
\hline N16 & - & - & - & - & 0,3 & - & - & 1,0 & - & 1,3 & - & - & 0,5 & - & 73,4 & 73,9 & 75,2 \\
\hline N17 & 0,3 & 7,2 & - & 9,5 & 30,4 & 1,9 & 1,7 & 5,7 & - & 56,7 & 2,1 & - & 5,3 & 1,6 & 21,3 & 30,3 & 87,0 \\
\hline N18 & - & - & - & - & 7,0 & 56,6 & - & 0,1 & 7,2 & 63,7 & - & 1,7 & 9,1 & 3,7 & 26,4 & 48,1 & 111,8 \\
\hline N19 & - & - & - & 2,8 & 9,4 & 0,3 & - & 0,7 & -2 & 13,2 & - & - & 13,2 & 2,6 & 32,1 & 47,9 & 61,1 \\
\hline $\mathrm{N} 20$ & - & 1,2 & - & 5,7 & 30,4 & 1,2 & 3,3 & 7,9 & $\ldots$ & 49,7 & - & - & 0,6 & 25,6 & 97,9 & 124,1 & 173,8 \\
\hline N21 & - & -2 & - & - & 6,2 & - & - & 1,4 & - & 7,6 & - & - & - & - & 98,8 & 98,8 & 106,4 \\
\hline N22 & - & - & - & - & 2,4 & - & 0,6 & 13,8 & - & 16,8 & - & - & - & $\ldots$ & 7,5 & 7,5 & 24,3 \\
\hline $\mathrm{N} 23$ & - & - & - & - & 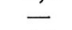 & - & - & 0,7 & - & 0,7 & - & - & - & - & 249,1 & 249,1 & 249,8 \\
\hline N24 & - & - & - & - & 0,1 & 7,7 & - & - & - & 7,8 & - & - & 0,5 & - & 58,6 & 59,1 & 66,9 \\
\hline $\begin{array}{l}\mathrm{N} 24 \\
\mathrm{~N} 25\end{array}$ & - & - & - & - & - & - & - & 0,1 & - & 0,1 & - & - & - & - & 57,8 & 57,8 & 57,9 \\
\hline N26 & - & 0,3 & - & 6,0 & 33,6 & 2,4 & 1,9 & 3,2 & 0,7 & 47,4 & - & - & 2,2 & 13,9 & 70,8 & 87,6 & 135,0 \\
\hline N27 & - & - & - & - & 2,2 & 0,4 & 0,3 & 6,8 & - & 9,7 & 0,2 & - & 0,2 & - & 7,2 & 7,6 & 17,3 \\
\hline N28 & - & - & - & - & 0,4 & - & - & 2,7 & - & 3,1 & - & - & - & 0,9 & 379,9 & 380,8 & 383,9 \\
\hline
\end{tabular}


$\mathrm{N} 11$ wie $\mathrm{N} 7$;

N 12 Große landwirtschaftliche Fläche mit vereinzelten landwirtschaftlichen Bauten, Wohnbauten und Industrieareal;

N 13 Große landwirtschaftliche Fläche mit kleinen Flächen Gärtnereien, Wohnsiedlung und landwirtschaftlicher Siedlung;

N 14 Landwirtschaftliche Fläche mit kleinen Flächen von Schrebergarten und Gärtnereien, durchschnitten von einem Band Wohnsiedlung und Industrieareal;

N 15 Landwirtschaftliche Fläche mit kleinen Flächen Schrebergarten, Gärtnereien und Wohnsiedlung;

N 16 Landwirtschaftliche Fläche mit vereinzelten landwirtschaftlichen und Wohnsiedlungen;

N 17 Wohnsiedlungen (Einfamilien- u. Mehrfamilienbauten), angeordnet um eine kleine Fläche Wohn-Geschäftsbauten, aufgelockert durch eingeschobene, teilweise eingeschlossene Freiflächen und mit vereinzelten und kleinen Flächen landwirtschaftlicher Siedlung;

$\mathrm{N} 18$ wie $\mathrm{N} 9$;

N 19 Wohnsiedlung in bandförmiger Anordnung, landwirtschaftliches Areal, Schrebergärten und Gärtnereien;

N 20 Offene Freiflächen (landw. Areal und Gärtnereien), vermischt mit kleinen und mittleren Flächen Wohnsiedlung und vereinzelten kleinen Flächen landwirtschaftlicher Siedlung;

N 21 Landwirtschaftliche Flächen mit einzelnen kleinen Flächen Wohnsiedlung;

N 22 Zusammenhängende Flächen landwirtschaftlicher Siedlung mit vereinzelten Wohnbauten;

N 23 Nur landwirtschaftliches Areal;

N 24 Landwirtschaftliches Areal mit kleinen Flächen Industrieareal in bandförmiger Anordnung;

N 25 Nur landwirtschaftliches Areal;

N 26 wie $\mathrm{N} 20$;

N 27 Zusammenhängende Flächen landwirtschaftlicher Siedlung mit vereinzelten und kleinen Flächen Wohnsiedlung;

N 28 Landwirtschaftliches Areal mit vereinzelten landwirtschaftlichen und Wohnbauten.

Die Ähnlichkeit einzelner Einheiten (z. B. N 20 und N 26) geht besonders auch aus der Tabelle (S. 29) hervor. In der nachfolgenden allgemeinen Beschreibung sollen deshalb nicht alle 28 Nutzungseinheiten berücksichtigt werden.

N 1 umfaßt den größten Teil des zwischen Limmat, Sihl und Schanzengraben gelegenen Gebietes mit der Geschäftscity zwischen Hauptbahnhof, Bürkliplatz und Sihlporte und Teilen der alten städtischen Siedlung zwischen Lindenhof, Rennweg und Fraumünster. Fünf- bis sechs- und mehrstöckig erheben sich die geschlossenen Häusermauern beidseits der belebten Straßen und Gassen. Mächtige Fassaden, wie etwa die der nüchternen Amtshäuser beim Werdmühleplatz, der alten Bankbauten am Paradeplatz, der modern gestalteten Geschäftshäuser bei der Sihlporte und der Warenhäuser wechseln mit Fassaden vom bescheidenen Ausmaß eines städtischen Bürgerhauses und andern verschiedenartigster Gestaltung. Aber überall wird das Erdgeschoß von Ladenlokalen eingenommen, die mit ihren Auslagen und den zahlreichen Firmen- und Reklametafeln das Bild beleben und die Aufmerksamkeit auf sich ziehen. Die Bahnhofstraße ist in dieser Hinsicht zu mehr als nur zu lokaler Berühmtheit gelangt. Trotz sozusagen lückenloser Überbauung dieses Gebietes ist der Verstädte- 
rungsprozeß auch hier noch nicht abgeschlossen: Alte, kleinere Gebäude, die oft früher als Wohnbauten gedient haben, werden abgebrochen und durch große, den städtischen Funktionen besser dienende Geschäftsbauten ersetzt.

N 2 ist ein flaches Gelände und liegt westwärts der Sihl. Hier ist das dichte Straßennetz zum größten Teil geplant rechtwinklig angelegt. Geschlossene oder nur wenig durchbrochene Häuserzeilen umschließen Innenhöfe, in die man nur schwer Einblick erhält und in denen vielfach Gewerbe- und Kleinindustriebauten ihren Platz haben. Im Erdgeschoß sind überall Ladenlokale, auch Bureau- und Schalterräume, Gaststätten und gewerbliche Räume eingerichtet. Abgesehen von den Hauptverkehrsadern sind die Straßen weniger belebt und die Auslagen und Firmenschilder meist von bescheidenerem Aussehen. Einige größere Schulanlagen und die Kaserne mit dem Kasernenplatz tragen zur Auflockerung der dicht überbauten Fläche bei.

N 3. Auch hier erheben sich wie in N 2 unmittelbar beidseits der Straßen die Mauern der Häuser in geschlossener Zeile. Innenhöfe sind gelegentlich grün bepflanzt. Ladenlokale - es handelt sich meistens um solche der Lebensmittelbranche - gibt es fast nur in Eckhäusern an Straßenkreuzungen.

N 5 ist eine ebene, sich quer über das Tal breitende Fläche, die nur im südlichsten Teil leicht ansteigt. Sie ist der Überrest des einstmals vor dem Stadtrand gelegenen offenen Geländes und wird auf der Ostseite durch die dicht überbaute Fläche N 3 und auf der Westseite durch die von Altstetten (N 6 und N 8) her sich ausbreitenden Industrie- und Wohnbauflächen begrenzt. Namhafte Teile der noch freien Flächen sind noch für die Überbauung vorgesehen ${ }^{34}$.

N 6 ist eine auf der Talebene liegende Industriefläche, die teilweise von Wohnsiedlungen durchsetzt ist. Die Betriebe gehören meistens der Holz und Eisen verarbeitenden Branche an. Ein Geleiseanschluß führt bis zum südlichen Zipfel, wo die Lagerhallen des Zollfreilagers stehen. Lagerplätze und Freiflächen lockern die Überbauung auf.

N 8. Die Wohnsiedlungsflächen von Altstetten liegen im SW-Teil auch auf dem schwach geneigten Hang. An Stelle eines alten Dorfteiles ist an der Ausfallstraße nach Baden ein ausgesprochenes Zentrum entstanden. Die alten Gebäude wurden und werden zum Teil heute noch abgebrochen und durch moderne Wohn-Geschäftsbauten ersetzt. Durch dieses Zentrum führt die städtische Straßenbahnlinie nach Schlieren. $400 \mathrm{~m}$ nördlich davon liegt die SBB-Station an der Linie Zürich-Baden mit der Abzweigung nach Affoltern a. A.-Zug. Die offene Überbauung mit Ein- und Mehrfamilienhäusern läßt überall Durchblicke frei und genügend Platz für Gärten und Rasen.

N9 ist ein Industriegelände zwischen Eisenbahnlinie und Überlandstraße. Die Industrieflächen sind durch Schrebergärten und Gärtnereien durchbrochen. Man gewinnt deshalb auch nicht den Eindruck einer intensiven industriellen Überbauung wie etwa in $\mathrm{N}$ 4. Im östlichen Teil handelt es sich nur um Lagerplätze mit einfachen, niedrigen Holzbauten (z. B. Abbruchunternehmen), im westlichen Teil sind es gröBere Unternehmen (Apparate-, Metall- und chemische Branche).

N 10, auf dem flachen Talboden zwischen Limmat und Überlandstraße gelegen, ist eine größtenteils offene Fläche, aber weit davon entfernt, den Eindruck ländlicher Verhältnisse $\mathrm{zu}$ erwecken. Das vorhandene landwirtschaftliche Areal ist nur bedingt als solches bebaubar, da hier Grundwasser gefaßt wird und deshalb die Oberfläche geschont werden muß. Die Sportplätze sind Rasenplätze mit kurz geschnittenen Rasen und weiß gestrichenen Fußballtoren. Daneben gibt es auch Tennisplätze. Bezeichnend ist aber die große Fläche der Schrebergärten. Mit ihren Weglein, Gartenhägen, Sträuchern und Büschen und den zahlreichen Gartenhäuschen bilden sie oft ein

${ }^{3+}$ Vergl. Zonenplan zur Bauordnung der Stadt Zürich (42). 
mannshohes und für das Auge undurchdringliches Dickicht. Einige eingestreute Fabrikanlagen und Mietshäuser, gleichförmige Flächen von Gemüsegärtnereien und wenige armselige und einsame landwirtschaftliche Ökonomiegebäude vervollständigen das Bild dieses Geländes, wo man den Eindruck hat, weder auf dem Land noch in der Stadt zu sein.

N 14 ist eine fast ausschließlich offene Fläche zwischen Altstetten und Schlieren, die nur längs der Zürcherstraße von einer schmalen bandförmigen Überbauung mit Wohnsiedlung durchbrochen wird. Diese zieht sich dem Fuß des linksseitigen Talhanges entlang, den an einigen steilen Stellen Büsche und Schrebergärten (von N 15), sonst aber Wiesen und Obstbaumgärten bedecken. Davor breitet sich die offene Talebene mit Wiesen und Äckern und Streifen von Schrebergärten und Gärtnereien. Sie wird durchschnitten vom doppelspurigen Geleise der Eisenbahn, der Überlandstraße und einer Pappelreihe. Auf Grund des Bauzonenplanes der Gemeinde Schlieren ist zu erwarten, daß in nächster Zeit noch namhafte Teile des Geländestreifens zwischen Bahnlinie und Zürcherstraße von Industrie besetzt werden.

N 15 nimmt den zwischen den Siedlungsflächen von Altstetten (N 8) und dem Waldrand der Landwirtschaft reservierten Geländestreifen ein und zieht sich von hier nordwärts bis fast zur Talebene hinunter. Das landwirtschaftliche Areal wird meistens von den noch in Altstetten bestehenden Bauernbetrieben aus bewirtschaftet. In der Nutzungseinheit selbst gibt es keine Landwirtschaftsbetriebe, dafür eine Anzahl Gärtnereien und Wohnbauten. Der ländliche Aspekt ist überhaupt gering, da zudem der Blick auch auf große Teile des Häusermeeres der Stadt fällt, deren scheinbar lückenlose Überbauung sichtbar bis in die unmittelbare Nähe reicht.

N 17 umfaßt die Hauptwohnsiedlungsfläche von Schlieren und ist mit N 8 (Altstetten) zu vergleichen. Das Zentrum, das von der städtischen Straßenbahn erreicht wird, hält den Vergleich am ehesten aus. Sonst ist alles etwa um eine Stufe «ländlicher». Hier stehen noch mehr Bauernhäuser unmittelbar neben modernen Wohnund Wohn-Geschäftsbauten. Die bäuerliche Dorfsiedlung ist umfangreicher erhalten, die Wohnsiedlungsflächen sind kleiner, es fehlt die große Häufung der Mehrfamilienhäuser und das offene Umgelände reicht viel näher bis ans Zentrum heran.

N 20 In Ober- und Unterengstringen auf dem rechtsseitigen Talhang sind die beiden kleinen ursprünglichen Bauerndörfer noch deutlich zu erkennen. Viele Bauernhäuser beherbergen noch Bauernbetriebe, was an den frischen Miststöcken leicht zu erkennen ist. Eine ganze Anzahl jedoch - namentlich in Oberengstringen - ist ihrem Zweck entfremdet: Die Mistgrube ist trocken, die landwirtschaftlichen Geräte sind entfernt, vielleicht hängen noch einzelne verrostet und verstaubt unter dem Vordach, manchmal ist das Tor der Tenne abgeändert, die Tenne eine Garage oder ein Lagerraum, im Stall eine kleine Werkstatt eingerichtet. $Z$ wischen die alten Bauernhäuser hinein drängen sich moderne Wohnbauten. Auf dem bäuerlichen Wirtschaftsareal in der näheren und weiteren Umgebung der alten Dörfer gruppieren sich Wohnbauten, nicht gerade in großen Flächen, da und dort, vor allem längs der rechtsseitigen Limmattalstraße. Es sind Einfamilienhäuser und moderne Mehrfamilienhäuser. Überall liegen dazwischen offene Flächen mit Äckern, Wiesen und Gärtnereien.

N 22 ist das Bauerndorf Weiningen. Die wenigen nichtlandwirtschaftlichen Bauten, einzelne Wohnhäuser innerhalb des Dorfes und an dessen Nordrand, vermögen den ganz und gar bäuerlichen Charakter der Siedlung nicht zu beeinträchtigen.

N 23 Die südlich von Weiningen sich ausbreitende Fläche mit Äckern, Wiesen und Obstbäumen liegt etwas höher als der eigentliche Talboden. Sie ist zum größten Teil durch einen von Unterengstringen nach dem Hardwald ziehenden Moränenwall gegen die überbauten Flächen bei Schlieren abgeschlossen. Das Bild der ländlichen Kulturlandschaft ist hier ungeschmälert erhalten. 
N 27. Oberurdorf ist wohl räumlich von den neuen Siedlungsflächen getrennt, auch der weitaus größte Teil seines Ungeländes ist davon frei, aber innerhalb des Dorfes selbst gibt es eine ganze Anzahl nichtlandwirtschaftlicher Bauten. Einige sind umgebaute alte Gebäude, andere aber neuere Wohnhäuser, eines sogar ein modernes Mehrfamilienhaus, das schlecht hierher paßt. In der Gesamtheit sind diese Bauten im Begriff, das bäuerliche Dorfbild zu verwischen.

Bemerkenswert sind noch Form und Anordnung der Nutzungseinheiten. Die meisten sind länglich, was dem Einfluß der in Talrichtung verlaufenden Hauptverkehrsachsen auf die Besiedlung zuzuschreiben ist. N2, 3 und 5 liegen dagegen ausgesprochen quer zur Talachse infolge mehr oder weniger konzentrischen Wachstums um das Hauptzentrum.

Der Unterschied zwischen den einzelnen Nutzungseinheiten ist mehr oder weniger groß. Einige haben ausgesprochen gleichen Inhalt, wie z. B. N 20 und N 26; N 12, 13, 15; N 16, 23, 25, 28. Andere haben teilweise gleichen Inhalt und unterscheiden sich durch wenige Merkmale, wieder andere haben keine Ähnlichkeit. Fassen wir die Nutzungseinheiten mit gleichem und ähnlichem Inhalt zusammen, ergeben sich sieben Gruppen. Eine Gruppe entspricht einer Nutzungseinheit auf der nächst höheren Stufe; wir wollen sie aber nicht als solche bezeichnen, weil in einzelnen Gruppen die räumliche Einheit fehlt.

Gruppen, zu ihnen gehörende Nutzungseinheiten und Merkmale, durch die sich eine Gruppe von den andern unterscheidet:

Gruppe I N 1, 2, 3, 4

Flächenmäßig zusammenhängende Überbauung, geschlossene Bauweise, wenige kleine umschlossene Freiflächen.

Gruppe II N 5, 6, 7, 8, 9 (11), (17, 18)

Flächenmäßig zusammenhängende Überbauung, offene Bauweise, zahlreiche kleine bis große umschlossene Freiflächen.

Gruppe III N 19, 20 (26)

Nur lose oder nicht zusammenhängende Siedlungsflächen, keine umschlossenen Freiflächen.

Gruppe IV N 10

Nichtlandwirtschaftliches Areal mit einzelnen kleinen Siedlungsflächen.

Gruppe V N (12), (13), 14, 15 (21), (24)

Landwirtschaftliches Areal mit einzelnen verstreuten kleinen nichtlandwirtschaftlichen Siedlungs- und Vegetationsflächen.

Gruppe VI N22(27)

Geschlossene landwirtschaftliche Siedlungsfläche mit einzelnen nichtlandwirtschaftlichen Bauten.

Gruppe VII N 16 (23), (25), (28)

Landwirtschaftliches Areal mit einzelnen landwirtschaftlichen Bauten.

( ) bedeutet: von den andern $\mathrm{N}$ räumlich getrennt.

Vergleiche zu dieser Gruppierung auch Kartenbeilage III.

$\mathrm{Zu}$ beachten ist die auf der Karte und im Gelände deutlich sichtbare Grenze zwischen den Gruppen I und II. Sie unterscheiden sich im wesentlichen durch die Art der Bauweise ihrer Siedlungen (geschlossen und offen). Dieser Unterschied ist aber zum großen Teil eine Folge der Wandlung städtebaulicher Prinzipien.

$\mathrm{Da}$ auch die sieben Gruppen gemeinsame Merkmale haben, ist eine noch größere Zusammenfassung möglich. Die Zahl der entscheidenden Merkmale beschränkt sich dann auf einige wenige. Auf diese Weise sind noch drei Hauptgruppen zu unterscheiden (vergleiche Karte III). 
Hauptgruppe A Gruppen I und II

Flächenmäßig zusammenhängende städt. Besiedlung mit umschlossenen Freiflächen.

Hauptgruppe B Gruppen III, IV und V

Flächenmäßig nicht zusammenhängende städtische Besiedlung und offene Freiflächen.

Hauptgruppe C Gruppen VI und VII

Landwirtschaftliches Areal und landwirtschaftliche Siedlungen.

Noch kürzer gesagt: In Hauptgruppe A sind die dicht besiedelten Flächen, in Hauptgruppe B die locker besiedelten und in Hauptgruppe $\mathrm{C}$ die agrarischen Flächen zusammengefaßt.

\section{Die Intensität der stälttischen Merkmale}

Es ist offensichtlich, daß nicht alle Merkmale der städtischen Kulturlandschaft in gleichem Maße Ausdruck städtischer Eigenart sind. Beispielsweise ist eine Fläche mit Geschäftsbauten samt dem sichtbaren geschäftigen Treiben der Menschen - wie etwa an der Bahnhofstraße - als weit «städtischer» zu bezeichnen als eine mit Mehrfamilienhäusern. Bei dieser Beurteilung spielen meistens auch die hinter den Formen stehenden Funktionen mit. Die zentralen Funktionen in den Geschäftsbauten der City gelten als entscheidende Merkmale der Stadt ${ }^{35}$. Auch die Wohnsiedlungen, die in Zusammenhang mit der Stadtbildung und damit der Zentralisation, der Spezialisierung der Arbeit, der Trennung von Arbeits- und Wohnplatz und städtischem Leben, stehen, müssen als städtische Merkmale betrachtet werden. Ihre Funktion ist aber für die Stadtwerdung nicht so bedeutend, was auch durch den formalen Unterschied zu den Geschäftsbauten zum Ausdruck kommt.

Wir wollen nun versuchen, die Merkmale nach der Intensität ihrer stadtbildenden Eigenschaften zu ordnen ${ }^{36}$. Nach ihrer Beurteilung im oben erwähnten Sinn und begonnen mit der größten Intensität könnte etwa folgende Reihenfolge aufgestellt werden: Geschäfts-Siedlung; Wohn-Geschäfts-Siedlung; Mehrfamilienhäuser geschlossener Bauweise; Mehrfamilienhäuser offener Bauweise; Ein- bis Zweifamilienhäuser. Schulen und Kultbauten sind nicht ohne weiteres einzuordnen, da sie von groBer formaler Verschiedenheit sein können. Ohne an ihre zentrale Bedeutung zu denken, sind sie nach der Wirkung ihrer baulichen Erscheinung etwa gleich zu werten wie Mehrfamilienhäuser offener Bauweise. Die Industrie braucht im Sinne der zentralen Funktionen nicht unbedingt stadtbildende Eigenschaft zu haben. Die mit ihr verbundene Spezialisierung der Arbeit und Konzentration der Produktion hat aber Auswirkungen vor allem formaler Natur, deren Charakter durchaus städtisch ist. Das Industrieareal kann deshalb ebenfalls in die Reihe aufgenommen werden.

Die Vegetationsflächen sind nun allerdings schwieriger zu beurteilen. Kann ihnen überhaupt stadtbildende Eigenschaft zugeschrieben werden? Auf jeden Fall vermögen sie das Bild der reinen ländlichen Kulturlandschaft zu beeinträchtigen, und zwar wenn sich nur ländliche und städtische Kulturlandschaft gegenüberstehen - im Sinne der stadtbildenden Faktoren. Die Anlagen sind die einzigen Vegetationsflächen, welche auch im Zentrum vorhanden sind. Von diesen erhalten sie deshalb den höchsten Intensitätswert. Dann folgen Sportplätze, Schrebergärten und Gärtnereien.

Um die Intensitätswerte der verschiedenen Merkmale miteinander vergleichen zu können, wären $Z$ ahlenwerte zweckmäßig. Solche Zahlenwerte, denen freilich nur relative Bedeutung zukommt, liefern uns die Assekuranzwerte der Bauten. Ein Vergleich mit den Merkmalen der Vegetation ist damit nicht ohne weiteres möglich.

35 Christaller (12), Meer (22).

36 Der Begriff der "städtischen Intensität » ist von ARNhold (1) in ähnlichem Sinne verwendet, aber auf ganz andere Faktoren bezogen worden (Dichte der Wohnhäuser, Bevölkerungsdichte, Bevölkerungsbewegung, Anteil der landw. Bevölkerung). 
Ein geeigneteres Zahlenverhältnis, in dem auch die Vegetationsflächen eingeschlossen wären, könnten die Werte der Investitionen pro Flächeneinheit ergeben. Diese umfassen den Grundstückpreis, Gebäudewert, die Umgebungsarbeiten und Inneneinrichtungen, Bodenverbesserungen und Anpflanzungen und könnten die Unterschiede differenzierter zum Ausdruck bringen. Da keine statistischen Unterlagen dafür vorhanden sind, ist eine Verwendung dieser Werte ausgeschlossen. Es können aber auch die Assekuranzwerte brauchbare Vergleichswerte liefern, da die Bauten schließlich die wesentlichen stadtbildenden formalen Merkmale sind. Im Assekuranzwert pro Flächeneinheit der besetzten Fläche (= Baugrundstück = Gebäudegrundfläche, Hofraum und Garten) berechnet, kommt sowohl die Dichte der Überbauung als auch die Größe und Gestaltung der Bauten zum Ausdruck.

Als Unterlagen dienten die Angaben des Statistischen Amtes der Stadt Zürich über die Assekuranzwerte der Neubauten von 1924 bis 1953 (29). Daß dabei die alten Bauten nicht berücksichtigt werden, spielt keine Rolle; wir interessieren uns ja nur für die relativen Werte.

\section{Assekuranzwerte der Neubauten der Stadt Zürich}

(Durchschnitt 1924-1953)

Assekuranzwert in Fr. Entsprechende Nomenklatur der pro $\mathrm{m}^{2}$ besied. Fläche Legende auf Karte II

Gebäude für Handel, Industrie, Gewerbe, Geschäftshäuser, Hotels Andere größere Gebäude Wohnhaus mit Geschäftslokalen

1204

213

419

239

94

238
Geschäftssiedlung

Industrieareal

Wohn-Geschäftssiedlung

Mehrfam.-H. geschl. Bauweise

Mehrfam.-H. offene Bauweise

1 - 2 Fam. Häuser

Schulen, Kirchen

Einfamilienhäuser
Gebäude f. Schule, Kultus, öff. Verwaltung

Da bei den Mehrfamilienhäusern nicht zwischen offener und geschlossener Bauweise unterschieden ist, müssen wir die entsprechenden Werte schätzen und setzen Fr. 300.- für geschlossene und Fr. 200.- für offene Bauweise fest. Sportplätze und Schrebergärten weisen ebenfalls vielfach Gebäulichkeiten auf. Deshalb konnten für diese Merkmale Werte berechnet werden, die den in der Tabelle aufgeführten Werten der baulichen Merkmale entsprechen. Für eine nur kleine Zahl von Sportplätzen mit überdurchschnittlich vielen Gebäulichkeiten wurde ein Wert von rund 3 Fr., für Schrebergärten von etwas mehr als $1 \mathrm{Fr}$. berechnet. Wir haben so einen Anhaltspunkt für die Größenordnung der Intensitätswerte der Vegetationsmerkmale. Auf Grund der früheren Beurteilung setzen wir für Anlagen 3, für Sportplätze 2 und für Schrebergärten und Gärtnereien 1 ein.

Damit haben wir eine reelle Grundlage für die relativen Werte der Intensitäten. Den für die Flächeneinheit 1 ha gesetzten Intensitätswert eines Merkmals wollen wir kurz «Merkmalswert» nennen. Daß wir dabei den Intensitätswert auf die Flächeneinheit 1 ha beziehen und nicht mehr auf $\mathrm{m}^{2}$ geschieht der Einfachheit halber und hat auf die späteren Resultate ja keinen Einfluß.

Die Merkmalswerte:

Geschäftssiedlung . . . . . . . . . 1200

Wohn-Geschäftssiedlung. . . . . . . . . . 400

Mehrfamilien-Haus, geschlossene Bauweise . . . 300

Mehrfamilien-Haus, offene Bauweise . . . . 200

Schulen und Kirchen . . . . . . . . . 250

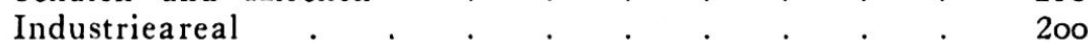

1-2 Familien-Häuser . . . . . . . . . . . . 100

Anlagen

Sportplätze

3

Schrebergärten, Gärtnereien . 
Mit diesen Werten ist es uns nun möglich, unsere früheren Nutzungseinheiten nochmals auf andere Art vergleichend zu betrachten.

Wir berechnen dazu in jeder Nutzungseinheit und für jedes Merkmal die Teilintensität (Fläche des Merkmals $\times$ Merkmalswert). Die Summe aller Teilintensitäten ergibt die Gesamtintensität der Nutzungseinheit. Die durchschnittliche Größe dieses Wertes pro Hektare entspricht dem durchschnittlichen Intensitätswert der Nutzungseinheit. Als Grundlage dienen die Flächenangaben in der Tabelle Seite 29.

Es konnten folgende durchschnittliche Intensitätswerte für die 28 Nutzungseinheiten ermittelt werden:

\begin{tabular}{|c|c|c|c|}
\hline $\begin{array}{c}\text { Nutzungs- } \\
\text { einheit }\end{array}$ & $\begin{array}{l}\text { Fläche } \\
\text { in ha }\end{array}$ & $\begin{array}{l}\text { Gesamtintensität } \\
\text { der Nutzungseinheit }\end{array}$ & $\begin{array}{l}\text { Durchschnittl. Intensität } \\
\text { der Nutzungseinheiten/ha }\end{array}$ \\
\hline N 1 & 61,7 & 43736 & 709 \\
\hline $\mathrm{N} 2$ & 170,3 & 57934 & 340 \\
\hline $\mathrm{N} 3$ & 121,9 & 31523 & 259 \\
\hline $\mathrm{N} 4$ & 92,0 & 18640 & 203 \\
\hline N 5 & 233,8 & 18444 & 79 \\
\hline N 6 & 95,5 & 15794 & 165 \\
\hline N 7 & 141,0 & 16535 & 117 \\
\hline N 8 & 157,5 & 20815 & 132 \\
\hline N 9 & 80,6 & 9049 & 112 \\
\hline N 10 & 186,8 & 2145 & 11 \\
\hline N 11 & 175,0 & 18520 & 106 \\
\hline N 12 & 112,9 & 335 & 3 \\
\hline N 13 & 132,6 & 323 & 2 \\
\hline N 14 & 66,9 & 1167 & 17 \\
\hline N 15 & 81,6 & 529 & 6 \\
\hline N 16 & 75,2 & 31 & 0,4 \\
\hline N 17 & 87,0 & 8998 & 103 \\
\hline N 18 & 111,8 & 13476 & 120 \\
\hline N 19 & 61,1 & 1576 & 26 \\
\hline N 20 & 173,8 & 5752 & 33 \\
\hline N 21 & 106,4 & 620 & 6 \\
\hline N 22 & 24,3 & 390 & 16 \\
\hline N 2.3 & 249,8 & 0 & 0 \\
\hline N 24 & 66,9 & 1551 & 23 \\
\hline N 25 & 57,9 & 0 & 0 \\
\hline N 26 & 135,0 & 5791 & 45 \\
\hline N 27 & 17,3 & 376 & 21 \\
\hline N 28 & 383,9 & 41 & 0,1 \\
\hline
\end{tabular}

N 1 hat weitaus den höchsten Wert, was durchaus der Bedeutung dieses Abschnittes als der City entspricht. Im übrigen erweist sich die früher vorgenommene Zusammenfassung der Nutzungseinheiten zu Gruppen auch in bezug auf die Intensitätswerte als gerechtfertigt. Jenen Gruppen entsprechen folgende Intensitätswertbereiche:

$\begin{array}{lcl}\text { Gruppe I } & 709-203 & \text { Hauptgruppe A } \\ \text { Gruppe II } & 165-103,79 & \\ \text { Gruppe III } & 45-26 & \text { Hauptgruppe B } \\ \text { Gruppe IV } & 11-2 & \\ \text { Gruppe V } & 23-21,16 & \text { Hauptgruppe C } \\ \text { Gruppe VI } & 21,0 & \\ \text { Gruppe VII } & 0,4-0\end{array}$

Besonders erwähnt werden müssen N 5, N 22 und 27.

N 5 (I. Wert 79) nimmt gewissermaßen eine Zwischenstellung zwischen den Gruppen II und III ein. Ihr Wert liegt unter dem Hauptbereich der Gruppe II, aber auch deutlich über dem von Gruppe III. Da die Siedlungsflächen, die sich um die ursprünglichen Dörfer Albisrieden (N 7) und Altstetten (N 8) herum immer mehr ausdehnen und sich mit den direkt um das Zentrum der Stadt herum gewach- 
senen Flächen zunehmend verbinden, werden die dazwischen liegenden offenen Flächen von N 5 immer häufiger von Siedlungsflächen durchschnitten und enger umschlossen.

N 22 und N 27 sind die landwirtschaftlichen Siedlungen Weiningen und Oberurdorf. Bei den verhältnismäßig kleinen Flächen dieser Einheiten ergeben auch nur geringe Flächen städtischer Merkmale einen hohen Durchschnittswert. Innerhalb dieser Siedlungen kommen aber die einzelnen städtischen Bauten viel weniger zur Geltung als auf offenem Gelände, da die benachbarten Bauernhäuser sie weitgehend dem Blick entziehen. Man hat sich deshalb zu fragen, bei welchem Umfang der städtischen Merkmale eine landwirtschaftliche Siedlung nicht mehr als solche bezeichnet werden kann. Schätzungsweise dürfte das etwa dann der Fall sein, wenn jedes dritte ein nichtlandwirtschaftliches Gebäude ist, oder der Flächenanteil der städtischen Merkmale ein Drittel der ganzen Siedlungsfläche beträgt. Das ist weder bei N 22 noch bei N 27 zutreffend, bei letzterer fehlt allerdings nicht mehr viel. Bei der Gruppierung der Nutzungseinheiten sind deshalb beide als landwirtschaftliche Siedlungen bewertet.

Ferner ist darauf hinzuweisen, daß zwischen einzelnen Nutzungseinheiten der Hauptgruppe $\mathrm{B}$ und der Hauptgruppe $\mathrm{C}$ mit geringer Besiedlung nur kleine Unterschiede bestehen, was auch aus der Größe der entsprechenden Intensitätswerte hervorgeht. Es scheint deshalb nicht sofort eindeutig, zu welcher Gruppe etwa die Nutzungseinheiten 12 und $13 \mathrm{zu}$ rechnen sind. Bis $\mathrm{zu}$ einem gewissen Grad ist es Ermessenssache, sie der Gruppe $V$ und der Hauptgruppe B zuzuteilen. In ihnen treten die nichtlandwirtschaftlichen Siedlungen in eigentlichen Parzellen auf, wobei in einer Parzelle mehrere Bauten stehen. Diese Erscheinung haben sie mit allen andern Nutzungseinheiten der Hauptgruppe B gemeinsam und unterscheiden sich gerade dadurch von den Nutzungseinheiten der Hauptgruppe $C$, in denen nichtlandwirtschaftliche Bauten nur einzeln anzutreffen sind. Somit ist immerhin ihre vorgenommene Zuteilung gerechtfertigt.

\section{GLIEDERUNG UND CHARA:KTERISIERUNG.DES ÜBERGANGES}

Städtische und ländliche Kulturlandschaft sind eng und ungleichmäßig ineinander verzahnt, weshalb der unmittelbare Übergang von der einen zur andern nicht ohne weiteres $\mathrm{zu}$ erkennen ist. Von topographischen und guten Verkehrsverhältnissen begünstigt, dringen städtische Elemente bis weit in die umgebende ländliche Kulturlandschaft hinaus, während diese an andern Stellen in eigentlicher Stadtnähe sozusagen unberührt geblieben ist. So gelangt man vom Zentrum der Stadt in gewissen Richtungen bald und fast unvermittelt an Wälder, Wiesen und Felder. In andern Richtungen, z. B. über Altstetten, Schlieren und Urdorf, erreicht man diese erst über zahlreiche Stufen von wechselndem und allgemein abnehmendem städtischen Charakter. Aus dieser teilweise feinen Differenzierung des Überganges heben sich drei Hauptstufen deutlich hervor: die dicht, die nur locker städtisch besiedelten und die ländlichen Flächen. Die erste Stufe ist ausschließlich durch formale Manifestationen städtischer Kulturlandschaft bestimmt, in der zweiten gibt es daneben auch viele Formen der ländlichen Kulturlandschaft, in der dritten nur solche der ländlichen Kulturlandschaft.

Dichte und lockere städtische Besiedlung sind demnach formale Erscheinungen städtischer Kulturlandschaft. Wo diese Flächen (Flächen im Sinne der Nutzungseinheiten) räumlich zusammenhängen und an das Zentrum der Stadt Zürich anschließen, bilden sie zusammen den formalen Bereich dieser städtischen Kulturlandschaft. Das entspricht etwa dem, was allgemein als städtische Agglomeration bezeichnet wird. Nicht die ganze Agglomeration kann aber als eigentliche Stadt oder als urbanes Gebiet bezeichnet werden. Als solche können nur die dicht besiedelten Flächen gelten, die untereinander zusammenhängen und rings um das Zentrum anschließen. Die iso- 
lierten Flächen N 17 und 18 (Schlieren) sind nicht zur städtischen oder « urbanen Zone»Zürichs zu rechnen. Sie sind, wie wir früher gesehen haben, zum größten Teil die Folge selbständiger Entwicklung und stehen auch deshalb in keinem Zusammenhang mit der eigentlichen Stadtfläche. Die an die urbane Zone anschließende lockere Besiedlung ist das Gebiet, in dem der Einfluß der sich ausbreitenden städtischen Kulturlandschaft zu erheblichen Formveränderungen führt. Es ist das gerade außerhalb der Stadt liegende Wachstumsgebiet, die «suburbane Zone». Zu ihr gehören alle Nutzungseinheiten der Hauptgruppe B und die darin liegenden N 17 und 18. Sie vermittelt den ganzen Übergang von der Stadt zur ländlichen Umgebung oder der «nichturbanen Zone».

An keiner Stelle der suburbanen Zone, weder bei Engstringen noch bei Urdorf, wo es immerhin zahlreiche moderne Wohnsiedlungen und auch Wohn-Geschäftsbauten gibt, hat man den ungeschmälerten Eindruck städtischer Besiedlung. Bauernhäuser, Wiesen, Äcker, pflügende und erntende Bauersleute und bäuerliche Fahrzeuge, die in der Nachbarschaft zu sehen sind, vermögen dem städtischen Eindruck erheblich Abbruch zu tun. Das ist bis zu einem gewissen Grad auch in Schlieren (N 17 und 18) der Fall. Umgekehrt verwischen auch überall städtische Merkmale den bäuerlichen Charakter und zwar auch in den landwirtschaftlichen Siedlungen, wo moderne nichtlandwirtschaftliche Bauten neben den Bauernhäusern stehen (Ober- und Unterengstringen, Schlieren). Vergleiche dazu auch die Schilderungen der Nutzungseinheiten im II. Teil.

\section{Teil}

\section{Die städtische Agglomeration von Zürich}

Auf Grund der Ergebnisse des II. Teiles wird in diesem Teil die Ausbreitung der urbanen und der suburbanen Zone der ganzen Stadt festgelegt. Dies soll aus arbeitstechnischen Gründen nicht mit Hilfe einer Feldkartierung, sondern durch Auswertung von Luftbildern erfolgen.

\section{A. DIE ARBEITSGRUNDLAGEN}

\section{Theoretische Voraussetzungen}

Die Ergebnisse des II. Teiles bilden die praktischen Voraussetzungen für eine Bestimmung der Ausdehnung der städtischen Agglomeration von Zürich und der suburbanen Zone im besondern. Wir haben festgestellt, daß die suburbane Zone im Limmattal als Mischungszone zwischen städtischer und ländlicher Nutzung deutlich zu unterscheiden ist von der urbanen Zone einerseits und der nichturbanen Zone anderseits. Die suburbane Zone beginnt - vom Kern der Stadt ausgehend - dort, wo die Siedlungsflächen die offenen Flächen nicht mehr umschließen, sondern umgekehrt von diesen umschlossen werden. Sie endet, wo die städtischen Merkmale verschwinden oder nur noch in ungenügender Dichte auftreten. Die Begrenzung gegen die urbane Zone fällt mit dem Rand jener Siedlungsflächen zusammen, die offene Flächen umschließen. Sie ist leicht zu erkennen. Die Begrenzung gegen die nichturbane Zone kann erst bestimmt werden, wenn ein Grenzwert bekannt ist.

Es handelt sich also darum, jene Dichte der städtischen Merkmale als Grenzwert festzulegen, bei der die Bezugsfläche gerade noch zur suburbanen Zone zu rechnen ist. Von den zehn in diese fallenden Nutzungseinheiten sind $N$ 12, 13, 15 und 21 am schwächsten von städtischen Merkmalen durchsetzt und deshalb geeignet, diesen Grenzwert zu liefern. (Wie schon früher erwähnt, ist es bis zu einem gewissen Grad Ermessenssache, einen Teil dieser Flächen überhaupt zur suburbanen Zone zu rechnen.)

Berücksichtigen wir zunächst nur dię Merkmale der Bauten, die wir ohne Differenzierung nur in ihrer Gesamtheit als städtische Merkmale betrachten wollen. Dabei bezeichnen wir jede zusammenhängende Fläche städtischer Bauten als städtische Sied- 


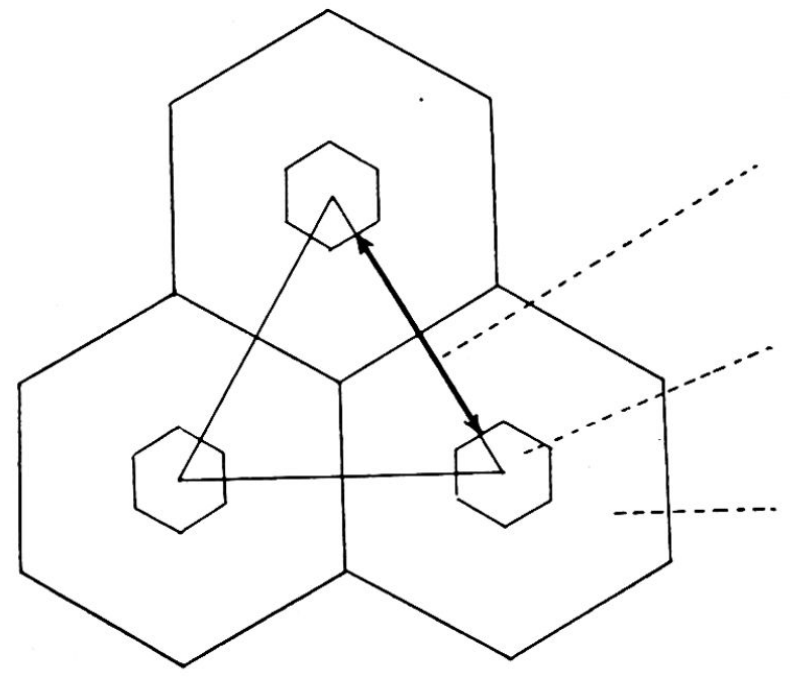

Fig. 4 Theoretische gleichmäßige Verteilung der Siedlungsparzellen

Abstand der Siedlungsparzellen

Siedlungsparzelle

Bezugsfläche pro Siedlungsparzelle

lungsparzelle. Diese Siedlungsparzellen sind weder gleichmäßig auf die Nutzungseinheiten verstreut, noch ist ihr flächenmäßiger Umfang gleich. Die durchschnittliche Dichte ist aber ein theoretischer Wert, mit dem die Vorstellung verknüpft werden kann, daß alle Siedlungsparzellen gleiche Größe haben und gleichmäßig auf die Bezugsfläche (Nutzungseinheit) verteilt sind. Bei der theoretischen Annahme der gleichmäßigen Verteilung liegt eine Siedlungsparzelle auf jedem Eckpunkt eines Netzes gleichseitiger Dreiecke. Jeder Eckpunkt liegt im Zentrum einer Teilfläche in der Form eines regulären Sechseckes. Der Abstand zwischen den Parzellen gibt ein Maß für die Dichte. Werden die Parzellen punktförmig angenommen, was dann möglich ist, wenn nur ihre Anzahl, nicht aber ihre Flächen eine Rolle spielen, dann entspricht ihr Abstand der Seitenlänge der Dreiecke. Da aber natürlich auch die Größe der Parzellen von Bedeutung ist, müssen deren Flächen mitberücksichtigt werden. Der Abstand wird dann um die Breite dieser Flächen reduziert. Vergleiche Fig. 4.

Der durchschnittliche Abstand der Siedlungsparzellen ist in den vier ausgewählten Nutzungseinheiten aus folgenden Zahlen errechnet worden:

\begin{tabular}{cccccc} 
N & $\begin{array}{c}\text { Fläche von N } \\
\text { (Bezugsfläche) } \\
\text { ha }\end{array}$ & $\begin{array}{c}\text { Fläche } \\
\text { ha }\end{array}$ & $\begin{array}{r}\text { Siedlungs-Parzellen } \\
\text { Anzahl }\end{array}$ & $\begin{array}{r}\text { Größe d. Bezugsfläche } \\
\text { Größe ha }\end{array}$ & $\begin{array}{r}\text { pro Siedlungsparzelle } \\
\text { ha }\end{array}$ \\
\hline N12 & 112,9 & 2,4 & 7 & 0,34 & 16,13 \\
N13 & 132,6 & 3,2 & 12 & 0,27 & 11,05 \\
N15 & 81,6 & 5,1 & 9 & 0,57 & 9,07 \\
N21 & 106,4 & 6,2 & 12 & 0,52 & 8,87 \\
\hline N12, 13, 15,21 & 433,5 & 16,9 & 40 & 0,40 & 10,84
\end{tabular}

Durchschnittlicher Abstand der Siedlungsparzellen: $334 \mathrm{~m}$. Dieser läßt sich aus der Größe der Bezugsflächen und der Parzellenflächen berechnen.

Nun sollen aber die Merkmale der Vegetation, die ja zum städtischen Charakter der Kulturlandschaft auch beitragen, ebenfalls berücksichtigt werden. Es ist nicht gleichgültig, ob zwischen den Siedlungsparzellen nur landwirtschaftliches Areal oder städtische Vegetationsparzellen liegen. Wir bestimmen daher noch den durchschnitt- lichen Abstand zwischen den städtischen Siedlungs- und Vegetationsparzellen.

\begin{tabular}{cccccc} 
N & $\begin{array}{c}\text { Fläche von N } \\
\text { (Bezugfläche) } \\
\text { ha }\end{array}$ & $\begin{array}{c}\text { Siedlung- und Vegetations-Parzellen } \\
\text { Fläche } \\
\text { ha }\end{array}$ & Anzahl & $\begin{array}{c}\text { Größe d. Bezugsfläche } \\
\text { Größe ha }\end{array}$ & $\begin{array}{c}\text { pro Parzelle } \\
\text { ha }\end{array}$ \\
\hline N12 & 112,9 & 5,9 & 10 & 0,59 & 11,29 \\
N13 & 132,6 & 5,7 & 15 & 0,38 & 8,84 \\
N15 & 81,6 & 20,9 & 22 & 0,95 & 3,71 \\
N21 & 106,4 & 6,2 & 12 & 0,52 & 8,87 \\
\hline N12,13,15,21 & 433,5 & 38,7 & 59 & 0,66 & 7,34
\end{tabular}


Durchschnittlicher Abstand von Siedlungs- und Vegetationsparzellen: $264 \mathrm{~m}$.

Auf Grund dieser Berechnung wählen wir folgende Grenzwerte:

$350 \mathrm{~m}$ Abstand zwischen städtischen Siedlungsparzellen

$250 \mathrm{~m}$ Abstand zwischen städtischen Siedlungs- und Vegetationsparzellen

$200 \mathrm{~m}$ Abstand zwischen städtischen Vegetationsparzellen allein.

Der dritte Wert wurde wegen der geringeren Intensität der Vegetationsmerkmale gegenüber denen der Bauten niedriger angesetzt als $250 \mathrm{~m}$.

Mit Hilfe dieser Grenzwerte sind wir nun in der Lage, die Flächen mit lockerer städtischer Besiedlung festzulegen. Als solche gelten Flächen, die mit einem Netz von Dreiecken überzogen werden können, deren Seiten nicht länger als $350 \mathrm{~m}$ sind und deren Ecken innerhalb von städtischen Siedlungsparzellen liegen. Ferner auch Flächen mit einem Netz von Dreiecken mit maximaler Seitenlänge von $250 \mathrm{~m}$, deren Ecken innerhalb von städtischen Siedlungs- und Vegetationsparzellen liegen; und schließlich auch Flächen mit einem Dreiecksnetz mit Seitenlängen von höchstens $200 \mathrm{~m}$, dessen Eckpunkte innerhalb von städtischen Vegetationsparzellen liegen.

Auf Grund der Ausführungen über die Beeinträchtigung des bäuerlichen Siedlungsbildes durch städtische Merkmale (Seite 37) gelten im Bereich landwirtschaftlicher Siedlungen folgende Voraussetzungen: Fallen drei oder mehr landwirtschaftliche Gebäude innerhalb die kleinste mögliche Dreieckfläche, dann gehört diese nicht zur Fläche der lockeren Besiedlung.

Zur suburbanen Zone gehören jene Flächen lockerer städtischer Besiedlung, die an die urbane Zone anschließen.

\section{Hilfsmittel}

Um die Verbreitung der dicht und locker besiedelten Flächen bestimmen zu können, müssen die Parzellen mit städtischen Merkmalen zuerst kartiert werden. Die Möglichkeit der Auswertung von Flugphotographien gestattet hier eine zweckmäßige Arbeitstechnik.

Als Grundlage wurden die Blätter 42, 43, 155, 158, 159, 160, 161, 174, 175, 177, 210 und 228 des Topographischen Atlas der Schweiz im Maßstab 1:25000 verwendet.

An Flugphotographien wurden die entsprechenden Aufnahmen, insgesamt 282 Bilder ausgewertet ${ }^{37}$. Für die Kartenblätter 210 und 212 stammen die Bilder $(13 \times 13$ $\mathrm{cm}$ ) aus den Jahren 1943/44. Für alle übrigen sind die Aufnahmen in den Jahren 1951 bis 1954 erstellt worden. Ihr Ausmaß beträgt $18 \times 18 \mathrm{~cm}$, der Maßstab rund 1:20 000, ihre Aufnahmehöhe ca. $4000 \mathrm{~m}$ über Grund. Sie sind stereoskopisch auswertbar. Aufnahmezeit: Mai bis August.

Die aus den Jahren 1943/44 stammenden Aufnahmen sind nur bedingt mit den neueren zusammen zu verwenden, da sich seither im Kulturlandschaftsbild des näheren und weiteren Bereiches der Stadt vieles geändert hat. Es handelt sich aber nur um eine kleine Zahl von Bildern, die trotzdem ausgewertet wurden und die zudem Gegenden darstellen, die teilweise wenige Veränderungen erfahren haben. Sonst wäre eine bedauerliche Lücke entstanden. An kritischen Stellen, wie zwischen Männedorf und Stäfa, wurden die Verhältnisse im Gelände nachgeprüft.

Um mit den Flugaufnahmen arbeiten zu können, mußten wir sie zuerst eichen, uns darüber Rechenschaft geben, was man auf ihnen in bezug auf unsere Legende (gemäß Kartenbeilage II) zu erkennen vermag.

Eichen der Flugbilder:

Nachfolgend werden die Formen und Besonderheiten aufgeführt, an denen im allgemeinen die einzelnen Merkmale des Untersuchungsgebietes auf den Flugbildern

${ }^{37}$ Alle Aufnahmen von der Eidg. Landestopographie in Bern. 
zu erkennen sind. Die Angaben in Klammern beziehen sich auf die Koordinatenfelder der Bilder I und II (Beilage IV), in denen entsprechende Beispiele vorhanden sind.

Geschäftssiedlung;

Wohn-Geschäftssiedlung;

Wohnsiedlung, Mehrfamilien-Häuser, geschlossene Bauweise:

Können im einzelnen nicht unterschieden werden; als Gesamtheit der geschlossenen Überbauung sichtbar. Mehr oder weniger geschlossen umbaute Parzellen in Straßenvierecken mit Innenhöfen, die häufig ebenfalls überbaut sind. (I. O-S/12-18.)

Wohnsiedlung, Mehrfamilien-Häuser, offene Bauweise:

Längliche Gebäude mit Umgelände, Garten oder Rasen, Weglein als Zugang zu den Hauseingängen. Einzelne vorhandene Wohn-Geschäftsbauten als Ladenlokale nicht ohne weiteres zu erkennen, nur bei Häusern mit gepflästertem Vorplatz an Straßenkreuzungen zu vermuten. (I. $\mathrm{K} / 2 ; \mathrm{II} . \mathrm{K} / 16$.)

Wohnsiedlung, 1-2 Familienhäuser:

Kleiner Grundri $B$ in meist annähernd quadratischer Form, Garten rings um das Haus mit regelmäßiger Abgrenzung, bei Flächensiedlung als Baugrundstücke gut erkennbar; Weglein zum Hauseingang. Häufig gleichförmige Anordnung in Reihen und Flächen von gleichartigen Gebäuden. (I. E/5; II. E/6-7; II. H/12-13.)

Industrieareal:

Sehr große Gebäudeformen in Länge und Breite, dazwischen auch kleine und kleinste Bauten, ineinandergeschachtelte Gebäudekomplexe, Gebäude auf Längsseite zusammengebaut, Dächer mit besonderen Formen der Belichtungs- und Entlüftungseinrichtungen. Zwischen und neben den Gebäuden Röhrenleitungen, Tanks, Stapel- und Lagerplätze von Holz und Kohle u. a., Straßen- und Geleiseanschluß, Zu- und Wegfahrten, Silobauten und Gaskessel.

(I. $\mathrm{H}-\mathrm{K} / 12-14$; II. $\mathrm{H}-\mathrm{N} / 10-13$; II o/3.)

Landwirtschaftliche Siedlung:

Große Gebäude ebenso lang wie Mehrfamilien-Häuser, aber breiter. Daneben oder angebaut auch kleine Gebäude, Schuppen, Waschküchen, Trotten, Schweineställe u. a. Sind Wohnhaus und Scheune zusammengebaut, ist das Dach meist nicht auf der ganzen Länge gleich breit. Keine scharfe Abgrenzung des Hofes gegen die Umgebung, Übergang in den Baumgarten, Wegzufahrt zu den Gebäuden, bei Einzelhöfen Flurwege von diesen ausgehend. Bei dörflicher Siedlung große Unregelmäßigkeit in Größe und Anlage der Gebäude. (II. E/16; II. C-D/1; II. R/10.)

Kirchen, Schulen:

Meist größere Gebäude, Kirchturm, Kirchhof, Friedhơ an der regelmäßigen Gräbereinteilung erkennbar; Schulhaus, oft Gebäudegruppe, Turn- und Pausenplatz, Turnanlagen. (I. $\mathrm{K} / 3$ II. $\mathrm{Q} / 7$; II. $\mathrm{Q} / 5$.)

Anlagen:

Weganlagen, Baum- und Buschgruppen. (I. P/16; I. K-L/16.)

Sportanlagen :

Feldeinteilung und abgenutzte Rasenstellen vor den Toren der Fußballfelder, Oval der Aschenbahnen. Tennisplätze sind nicht mit Sicherheit zu erkennen. (I. M/8.)

Schrebergärten :

Kleinparzellierte Flächen mit Weglein, crscheinen im Grundton hell, darauf unregelmäBig verstreut als dunkle Punkte Büsche und Bäumchen. Die Gartenhäuschen erscheinen als kleine viereckige Punkte in mehr oder weniger regelmäßiger Anordnung. (I. H/9-11; II. $\mathrm{N}-\mathrm{O} / 16$.

Gärtnereien :

Die Parzellen sind mit denen des Ackerlandes zu vergleichen, weisen aber im Gegensatz zu jenen eine charakteristische Querstruktur auf, was von den verschiedenen Pflanzungen herrührt. Häufig sind mehrere Parzellen zu einem ganzen Komplex zusammengefaßt und sogar ineinander verschachtelt. Gebäulichkeiten innerhalb dieser Flächen oder am Rand. Treibhäuser und Treibbeete sind kaum zu erkennen. (II. G/11-12; II. H/9-10.)

Landwirtschaftliches Areal:

Wiesen als dunklere Flächen, darauf verstreut Bäume als noch dunklere kleine Flecken erscheinend. Äcker als helle Flächen in langen schmalen Parzellen, gelegentlich feine Längsstruktur; je nach Anbau auch als dunkle Flächen erscheinend, dann aber in gleichmäßigerer Färbung als die Dauerwiesen. Rebland als kurze Parzellen zwischen parallel am Hang verlaufenden Wegen. (II. E-G/1-3; II. B/2-3, Reben.) 
Da wir die Dichte der städtischen Merkmale als maßgebend für die Unterscheidung von suburbanem und nichturbanem Gebiet nehmen wollen, kommt es bei der Flugbildauswertung im wesentlichen darauf an, daß wir die ländlichen von den städtischen Merkmalen unterscheiden können. Bei den Vegetationsmerkmalen ist dies ohne Mühe möglich. Etwas mehr Schwierigkeiten bietet die Unterscheidung von landwirtschaftlichen und nichtlandwirtschaftlichen Siedlungen und Einzelbauten. An zwei Beispielen, die im Gelände nicht bekannt waren, wurde die Zuverlässigkeit der Auswertung geprüft. Von insgesamt 125 bewerteten Gebäuden (ungefähr zur Hälfte landwirtschaftliche und zur Hälfte nichtlandwirtschaftliche Bauten) konnten 7 nicht richtig identifiziert werden. Das entspricht einem Fehler von 5,6\%. Diese Fehlermöglichkeit fällt nicht stark ins Gewicht, wenn noch berücksichtigt wird, daß einige der nicht richtig erkannten Gebäude auch im Gelände nicht eindeutig zu beurteilen waren, da es sich um umgebaute ehemalige Bauernhäuser handelte. Jedenfalls kann die Flugbildauswertung in Verbindung mit Feldaufnahmen in einem Ausschnitt des Untersuchungsgebietes hier genügende Resultate liefern.

\section{Arbeitstechnisches}

Bei der praktischen Ausführung mußten zuerst die dicht besiedelten Flächen festgelegt werden. Vom Zentrum der Stadt oder von einem Nebenzentrum ausgehend, wurden die von Siedlungsflächen ganz umschlossenen Freiflächen auf den Flugbildern aufgesucht und auf den Kartenblättern eingezeichnet. Hierauf konnte der Außenrand der umschließenden Siedlungsflächen als Abgrenzung der dichten Besiedlung ermittelt werden. Von hier aus waren zunächst die Standorte städtischer Merkmale der Bauten auf die Karte zu übertragen. Dabei mußten nur solche Punkte eingezeichnet werden, welche die Konstruktion eines Netzes möglichst groBer Dreiecke, jedoch mit maximaler Seitenlänge von $350 \mathrm{~m}$, zuließen. Dieses Netz war sodann am Rand oder in Lücken unter Berücksichtigung städtischer Vegetationsparzellen durch ein solches mit maximaler Maschenweite von $250 \mathrm{~m}$, bzw. $200 \mathrm{~m}$, zu ergänzen. Diese Netzflächen ergaben die Bereiche lockerer städtischer Besiedlung.

Die Zusammenfassung der Ergebnisse auf den einzelnen Kartenblättern erfolgte im Maßstab $1: 75$ ooo.

\section{B. DIE RESULTATE}

Die Resultate dieses Teils sind in der Karte «Die städtische Agglomeration von Zürich» (Kartenbeilage V) dargestellt. Das Kartenbild und dessen Nachprüfungen im Gelände zeigen, daß der im Untersuchungsgebiet des Limmattales ermittelte Grenzwert für die Dichte städtischer Besiedlung durchaus den Realitäten entspricht. Wesentlich andere Verhältnisse, die es notwendig gemacht hätten, einen neuen Grenzwert $\mathrm{zu}$ bestimmen, wurden nicht angetroffen. In den locker besiedelten Flächen kommen tatsächlich jene Gebiete mit der notwendigen räumlichen Differenzierung zur Darstellung, die Merkmale der städtischen Kulturlandschaft in solcher Dichte aufweisen, daß sie ohne $Z$ weifel nicht mehr als ländlich bezeichnet werden können. Sozusagen bei allen Ortschaften, die an Verkehrsachsen liegen, aber auch bei vielen andern, gibt es solche Flächen. Dies dürfte sogar bei den meisten Siedlungen des ganzen schweizerischen Mittellandes der Fall sein, da nicht ohne Grund allgemein von dessen zunehmender «Verstädterung 》 gesprochen wird.

In verschiedenen größeren Orten kommt es aber auch zur Ausbildung dicht besiedelter Flächen, wie in der Stadt selbst. Diese scheinen ausgesprochen an den Standort der Eisenbahnstationen gebunden zu sein. Das Wachstum dieser Orte ist meist mit einer wirtschaftlichen und industriellen Entwicklung verknüpft, die von der Stadt veranlaßt oder begünstigt worden ist. Beispiele dafür sind Schlieren, Dietikon, Adliswil, Thalwil, Dübendorf und Wallisellen.

Wir definieren: Die städtische Agglomeration ist der formale Bereich der städtischen Kulturlandschaft; zu ihr gehören alle jene dicht und locker städtisch besiedelten Flächen, die mit den Siedlungsflächen des Stadtkernes eine räumliche Einheit bilden.

Die Agglomeration reicht somit im Limmattal bis unterhalb Dietikon, im Sihltal bis Langnau-Gattikon, am Zürichsee bis oberhalb Horgen und oberhalb Männe- 
dorf, im Glattal bis Dübendorf-Wangen-Dietlikon-Wallisellen-Glattbrugg und umschließt im Furttal Affoltern. Das entspricht, vom Hauptbahnhof aus in Luftlinie gemessen, folgenden Ausdehnungen: im Limmattal $12 \mathrm{~km}$, am rechten Zürichseeufer $19 \mathrm{~km}$, im Glattal $9 \mathrm{~km}$ (Wangen) und $7 \mathrm{~km}$ (Glattbrugg).

Die räumliche Entwicklung der städtischen Besiedlung ist stark durch die topographischen Gegebenheiten beeinflußt. Sie hält sich zum größten Teil an die ebenen Flächen im Limmattal, an den beiden Ufern des Zürichsees und im Glattal. Aber auch namhafte Gebiete des günstig exponierten rechten Talhanges im Limmattal und beidseits des Zürichsees sind vor allem in das Wohnsiedlungsgebiet einbezogen. Im übrigen verhindern die bewaldeten $H$ öhen des Albis und Zimmerberges gegen SW, des Pfannenstiels-Zürichberges gegen $\mathrm{E}$ und des Käferberges-Altberges gegen $\mathrm{N}$ eine uneingeschränkte Ausbreitung der Agglomeration. Sie reicht dafür in oft nur schmalen Bändern entlang den Tal- und Verkehrsachsen weit in die Umgebung der Stadt hinaus, immer neue bestehende Siedlungen einbeziehend. Wo Siedlungsflächen so zusammenwachsen, bestehen gelegentlich erst schmale Verbindungen, wie z. B. zwischen Herrliberg und Meilen oder Meilen und Männedorf am rechten Zürichseeufer. Freilich sind es nicht die bewaldeten Höhen allein, die der Besiedlung Schranken setzen, sondern das entspricht auch dem Willen der Menschen. Zweifellos wären die Wälder am Zürichberg und Käferberg längst der Bautätigkeit zum Opfer gefallen, wenn ihr Fortbestand im Interesse der Allgemeinheit nicht sichergestellt worden wäre. Damit sind diese Wälder aber in die unmittelbare Nähe der Stadtsiedlung geraten und haben gewisse Veränderungen erfahren, die sie von Wäldern in ländlichem Bereich immerhin unterscheiden. Die zahlreichen ausgebauten Spazierwege und der Strom der Spaziergänger, der sich an schönen Tagen darüber ergießt, die vielen Ruhebänke und die künstliche Beleuchtung sind formale Merkmale dafür, daß der Wald nicht mehr nur forstwirtschaftlicher Nutzung dient, sondern eine bedeutende Funktion als Erholungsstätte für die Stadtbewohner erfüllt.

Innerhalb der Agglomeration reicht die urbane Zone vom Zentrum bis unterhalb Höngg und Altstetten, bis Wollishofen, Tiefenbrunnen, Schwamendingen, Seebach und Neu-Affoltern. Es gehören alle dicht städtisch besiedelten Flächen dazu, die mit dem Zentrum in räumlichem Zusammenhang stehen. Alle außerhalb anschließenden Flächen der Agglomeration gehören zur suburbanen Zone. Vergleiche dazu die Nebenkarte auf Kartenbeilage V. Die planimetrische Ausmessung auf den Kartenblättern 1:25000 hat folgende Flächen ergeben:

\begin{tabular}{llrl}
$\begin{array}{l}\text { Urbane Zone } \\
\text { Suburbane Zone }\end{array}$ & $\begin{array}{l}\text { dichte Besiedlung } \\
\text { dichte Besiedlung } \\
\text { lockere Besiedlung }\end{array}$ & $\begin{array}{l}1162 \\
5247\end{array}$ ha & 3529 ha \\
& & 9909 ha \\
\hline Agglomeration total & & 9938 ha
\end{tabular}

\section{Z USAMMENFASSUNG}

Im Gebiet, das im Laufe der Entwicklung in den Bereich städtischer Besiedlung hineingeraten ist, sind zahlreiche Veränderungen eingetreten, die auf den direkten Einfluß der zunehmenden Stadtwerdung Zürichs zurückzuführen sind. Besonders hervorzuheben sind: das zunehmende Interesse an den in der Stadt angebotenen zentralen Diensten, die beginnende Abhängigkeit von der Stadt auf der bisher selbständigen dörflichen Stufe der zentralen Dienste, starke Bevölkerungszunahmen mit Wandlungen der Berufsstruktur, zunehmende Trennung von Arbeitsort und Wohnort, Übersiedlung aus der Stadt verdrängter Industriebetriebe, Veränderung der Siedlungsstruktur durch neue Industrie- und Wohnsiedlungsbauten, Rückgang des landwirtschaftlichen Areals und der landwirtschaftlichen Betriebe, Umstellung der bäuerlichen Marktwirtschaft auf die Bedürfnisse der Stadt und später auf die am Wohnort selbst zunehmende Kundschaft. 
Der Übergang vom Zentrum der Stadt bis in die ländliche Umgebung erfolgt über mehr oder weniger zahlreiche und differenzierte Stufen. Als Hauptstufen treten dabei die dicht und die locker städtisch besiedelten Flächen und die ländlichen Flächen hervor. Die dicht besiedelten und mit dem Stadtkern räumlich zusammenhängenden Flächen bilden in formaler Hinsicht das eigentliche Stadtgebiet oder die urbane Zone. Die an diese anschließenden locker besiedelten Flächen und einzelne eingestreute dicht besiedelte Flächen lokaler Zentren sind in formaler Hinsicht das Stadtrandgebiet, die Mischzone städtischer und ländlicher Merkmale, die städtische Wachstums- oder die suburbane Zone.

Suburbane und urbane Zone sind durch eine gewisse Häufung von Merkmalen der städtischen Kulturlandschaft gekennzeichnet. Sie bilden zusammen den ganzen formalen Bereich der städtischen Kulturlandschaft, oder die städtische Agglomeration. Die suburbane Zone ist deutlich von der urbanen Zone zu unterscheiden und stellt eine manchmal breite, gelegentlich aber sehr schmale Stufe des Überganges von dieser zur nichturbanen Umgebung dar. Hier sind die städtischen Merkmale in geringerer Dichte zu finden, und es wechseln in buntem Durcheinander Formen der ländlichen und der städtischen Kulturlandschaft. Zahlreich sind die Einzelformen, und überall treffen Gegensätze aufeinander. Neben dem neuen mehrstöckigen Wohn-Geschäftshaus steht ein bäuerliches Ökonomiegebäude; neben der Wohnsiedlung mit Mehrfamilienhäusern, Zierrasen und Plattenwegen pflügt der Bauer seinen Acker; in nächster Nachbarschaft der bäuerlichen Häusergruppe gibt es Zeilen von nichtlandwirtschaftlichen Wohnhäusern; neben der alten dörflichen Siedlung moderne Wohnsiedlungen und Industriebauten. Bald sind die Häusergruppen klein, bald groß, einmal liegen die Siedlungsparzellen eng beieinander, dann wieder weit auseinander. Die geteerte Quartierstraße endet in einem holprigen Feldweg; Wiesen und Äcker wechseln mit Schrebergärten und Gärtnereien.

Die suburbane Zone von Zürich reicht, entsprechend der topographischen Gestaltung in diesem Raum, in drei Richtungen weit in die Umgebung der Stadt hinaus: längs des Zürichsees, im Limmattal und im Glattal. Am rechten Zürichseeufer, wo sie sich in einem schmalen Band bis oberhalb Männedorf hinaufzieht, erreicht sie - von der Grenze der urbanen Zone bei 'Tiefenbrunnen aus gerechnet - eine Ausdehnung von $16 \frac{1}{2} \mathrm{~km}$. Die entsprechende Ausdehnung im Limmattal mißt von unterhalb Altstetten bis unterhalb Dietikon rund $7 \mathrm{~km}$, im Glattal von Schwamendingen bis Wangen rund $5 \mathrm{~km}$. Auf der Südwestseite gegen den Uetliberg und auf der Ostseite gegen den Zürichberg ist ihre Ausdehnung völlig unbedeutend. Teilweise stößt dort sogar die urbane Zone unvermittelt auf die nichturbane Umgebung. Die ganze Fläche der suburbanen Zone umfaßt rund $64 \mathrm{~km}^{2}$. Die urbane Zone selbst ist mit rund $35 \mathrm{~km}^{2}$ etwas mehr als halb so groß. Die ganze städtische Agglomeration von Zürich hat somit heute eine Ausdehnung von rund $100 \mathrm{~km}$. 1950 wurden in diesem Bereich 495000 Einwohner gezählt, davon 370000 in der urbanen und 125000 in der subburbanen Zone.

\section{LITERATURVER ZEICHNIS}

1 ARnhold, H.: Die Abgrenzung der Stadtlandschaft. Ein Beitrag zur Stadtgeographie und Raumplanung. In Wissenschaftliche Veröffentlichungen des Deutschen Institutes für Länderkunde. Leipzig 1953.

2 Bonnoure, P.: Etudes sur les éléments de l'organisme urbain. I La Banlieue. Les Etudes Rhodaniennes. Revue de Géographie de Lyon. 1950.

3 Beck, H.: Der Kulturzusammenstoß zwischen der bäuerlichen Gemeinde Witikon und der Stadt Zürich. Diss. Zürich 1952.

4 Bernhard, H.: Die Veränderungen in den Areal- und Grundbesitzverhältnissen des Kantons Zürich im Laufe des 19. Jahrhunderts. 1914.

5 Boesch, H.: Die Wirtschaftslandschaften der Erde. Zürich 1947.

6 Carol, H.: Die Böschungskarte. Eine exakte und anschauliche Darstellung des Reliefs. Plan, 4. Jahrg. 1947. 
7 Carol, H.: Das agrargeographische Betrachtungssystem. Ein Beitrag zur landschaftskundlichen Methodik, dargelegt am Beispiel der Karru in Südafrika. Bern 1952.

8 Carol, H.: Zur Diskussion um Landschaft und Geographie. Manuskript; erscheint demnächst.

9 Carol, H. und Werner, M,: Städte wie wir sie wünschen. Ein Vorschlag zur Gestaltung schweizerischer Großstadt-Gebiete, dargestellt am Beispiel von Stadt und Kanton Zürich. Zürich 1949.

10 Chatelin, A.: Les notions démographiques de zones urbaines: de la "cité» à la "banlieue". In Les Etudes Rhodaniennes. Revue de Géographie régionale. 1946.

11 Chatelin, A.: Les banlieues et les transports automobiles. Revue de Géographie de Lyon. 1951.

12 Christaller, W.: Die zentralen Orte in Süddeutschland. Eine ökonomisch-geographische Untersuchung über die Gesetzmäßigkeit der Verteilung und Entwicklung der Siedlungen mit städtischen Funktionen. Jena 1933.

13 Clozier, R.: La Gare du Nord. Paris 1940.

14 Dickinson, R.: City, Region and Regionalism, a geographical contribution to human ecology. London 1947.

15 Festschrift "Hundert Jahre Ed. Geistlich Söhne AG. für chemische Industrie." 1951.

16 FrICK, J.: Gemeindebuch des Limmattales. Zürich 1863.

17 Guth, H.: Die Pendelwanderung im Kanton Zürich 1941. Zürcher Wirtschaftsbilder, Nr.5/6 1945.

18 Heid, K.: Chronik von Urdorf. 1949. Gemeindearchiv.

18a Martin, R.: Beiträge zur Stadtgeographie von Luzern. Diss. Zürich 1951.

19 Kohler, J. M.: Landwirtschaftliche Beschreibung der Gemeinden Dettenried, Höngg, ThalwilOberrieden, Uitikon, Wangen, Weyach. Zürich 1852.

20 Meyer von Knonau, G.: Der Kanton Zürich. Historisch-geographisch-statistisch geschildert von den ältesten Zeiten bis auf die Gegenwart. 1844.

21 Meyer von Knonau, G.: Die Volkszählung im Kanton Zürich vom 18. bis 23. März 1850.

22 MeEr, Th.: Wandlungen des Stadtbegriffes. Diss. Zürich 1951.

23 Neujahrsblatt von Dietikon 1950: Die öffentlichen Verkehrsbetriebe von Dietikon, I. Teil. Post, Telegraph, Telephon und Zoll. Bearbeitet von K. HeID; herausgegeben von der Kommission für Heimatkunde Dietikon.

24 Neujahrsblatt von Dietikon 1950: Die öffentlichen Verkehrsbetriebe von Dietiken, II. Teil. Die Limmattal-Straßenbahn. Dietikon 1951.

25 Neujahrsblatt von Schlieren 1954: Die Orts- und Flurnamen der Gemeinde Schlieren. Bearbeitet von G. FAUSCH; herausgegeben von der Vereinigung für Heimatkunde Schlieren.

26 SpÖRri, J. J.: Vortrag über die Gemeinde Schlieren vor der Ascetischen Gesellschaft des Kantons Zürich 1813. Erhalten in den Handschriften des Vereins. Zentralbibliothek Zürich.

27 Suter, H.: Geologie von Zürich einschließlich seines Exkursionsgebietes. Zürich 1939.

\section{STATISTIKEN UND PROTOKOLLE}

28 Statistische Mitteilungen betr. den Kanton Zürich. Statistisches Bureau des Kantons Zürich. Jahrg. 1884 und 1885 .

29 Statistische Jahrbücher der Stadt Zürich. Statistisches Amt der Stadt Zürich. Jahrg. 1924-1953.

30 Eidg. Volkszählung 1950. Eidg. Statistisches Amt. Bern 1951.

31 BenZ, J.: Übersicht des Flächeninhaltes des Kantons Zürich. Nach topographischen Aufnahmen von 1846-1851. Statistisches Bureau des Kantons Zürich.

32 Arealstatistik der Schweiz. Jahre 1912 und 1952. Eidg. Statistisches Amt.

33 Zürcher Wirtschaftsbilder, bearbeitet vom Statistischen Bureau des Kantons Zürich, Jahrg. 6, 1950. Die Anbauflächen in den Gemeinden seit 1939.

34 Eidg. Betriebzählung 1952. Eidg. Statistisches Amt.

35 Eidg. Fabrikstatistik 1855, 1895, 1911, 1929, 1937, 1944, 1949. Eidg. Statistisches Amt.

36 Gemeinderatsprotokolle der Gemeinde Oberurdorf 1854-1884. Gemeindearchiv.

37 Gemeinderatsprotokolle der Gemeinde Niederurdorf 1873-1905. Gemeindearchiv.

38 Kataster der Liegenschaften der Gemeinde Ober- und Niederurdorf, Distrikt Mettmenstetten. 1801. Staatsarchiv Zürìch.

39 Hofbeschreibung Ober-Urdorf 1863. Grundbuchamt Schlieren.

\section{PLÄNE.}

40 Generalplan des Schlierer Zehndens von I. Martin Dæniker 1794.

41 "Plan über alle dem loblichen Spittalamt Zürich zehendbar gewesenen Güter in der Gemeind Schlieren, zum Behuf des Zehenden-Loskaufs geometrisch aufgenommen durch Rudolf Diezinger von Wädenswil, im August und September 1819." Gemeindearchiv Schlieren.

42 Zonenplan zur Bauordnung der Stadt Zürich. Beschluß des Gemeinderates vom 4.9.1946 und Abänderungsbeschlüsse vom 20.10.1948 und 28.1.1953. 
The present study is an investigation of the structure and the extent of the suburban zone of the town of Zuerich. For the treatment of this subject, the assumption is made that cultural landscape, as the most complex form of landscape, must not be interpreted from one point of view only, but on the basis of several and completely different principles (Hettner). In this case it is above all formal (morphological) characteristics which have been taken into account.

Part I of this study deals with that area which in the course of time has come under the influence of the spreading town. The investigated area is confined to two communes; the changes on them directly due to the urban development are determined. The most important of these are found to be the following: the settling of industries crowded out of the city; the sale of agricultural produce in the town and, in connection with this, an intensified production of milk and the specialization on vegetable crops; the loss of private and common land as a result of its being sold to interested parties from the town, both private and municipal; changes in the structure of the population due to the influx into the new residential areas of people working in town.

In part II, a cross-section, extending from the centre of the town into the rural surroundings, is being investigated on formal principles only. This investigation is founded on cartographical field-work. On the basis of the existing features, it is possible to distinguish various land use units (Nutzungseinheiten). A comparison of these units according to their kind and frequency together with a general description of their characteristics leads up to the formation of certain groups of identical or similar land use units. An attempt at a numerical comparison of these units confirms this valuation and grouping. Certain "rates of urban intensity" per square unit ("Städtische Intensitätswerte") are attributed to the urban characteristics, mainly buildings, the insurance values of which form an accessible and serviceable basis for comparison. By adding this "rate of urban intensity" to the area of the land use units, the "medium rate of urban intensity" is ascertained. As a result of this grouping, there eventually emerge three categories: 1. Urban Zone with a continuous area of urban settlement and enclosed open spaces. 2. Suburban Zone with discontinuous areas of urban settlement and unenclosed open spaces. 3. Non-urban Zone with agricultural land and agricultural settlements.

The results of part II are being made use of in part III, where the extent of the whole suburban zone is ascertained. The essential criteria for its delimitation are the following : the suburban zone is immediately adjacent to the urban zone with the densely populated built-up areas and the small enclosed open spaces. Moreover, it contains all areas with the plots of urban buildings being no further apart than $350 \mathrm{~m}$. Similarly, the urban green plots are taken into account. In order to establish the distribution of urban plots, open and built-up, aerial photographs are used instead of field-work maps. In this way, an area of approx. $100 \mathrm{sq} . \mathrm{km}$. is arrived at for the whole urban agglomeration, including the urban and the suburban zones. In 1950,495000 people lived in this area, 370000 of them in the urban zone with $36 \mathrm{sq.} \mathrm{km}$., and 125000 in the suburban zone with 64 sq. $\mathrm{km}$.

\title{
TALGESCHICHTLICHE PROBLEME IM AARGAUISCHEN REUSSTAL
}

\author{
Mit 1 Karte und 3 Abbildungen
}

\section{HeINRICH JäCKLI}

Talgeschichte im schweizerischen Mittelland kann von Quartärgeologie und Morphologie nicht getrennt werden. Am Beispiel des aargauischen Reußtales, zwischen subalpiner Molasse im Süden und Kettenjura im Norden, seien einige talgeschichtliche Probleme des schweizerischen Mittellandes, so wie sie sich heute, rund ein halbes Jahrhundert nach den grundlegenden Arbeiten von Fritz Mühlberg, Jakob Hug und RoMAN Frei darbieten, in genetischem Zusammenhang dargestellt.

\section{Pliozän}

\section{ZEITLICHE ABFOLGE}

Die Geschichte der Täler des schweizerischen Mittellandes beginnt im jüngsten 'Tertiär, im Pliozän, mit dem Ende der Molasse-Sedimentation. Die Senkungstendenz kam damals aus endogenen Gründen zum Stillstand und wurde durch eine Hebung 


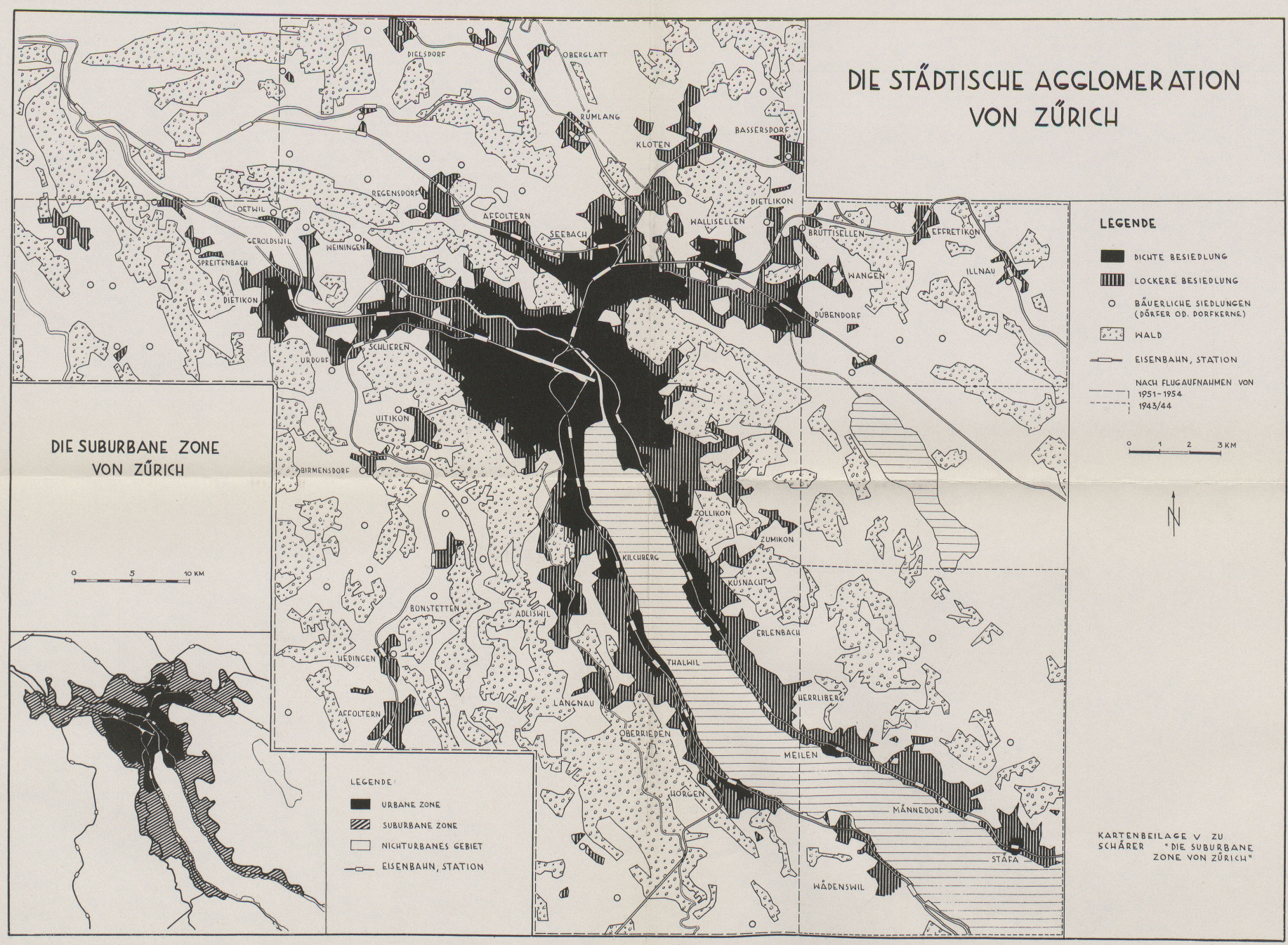




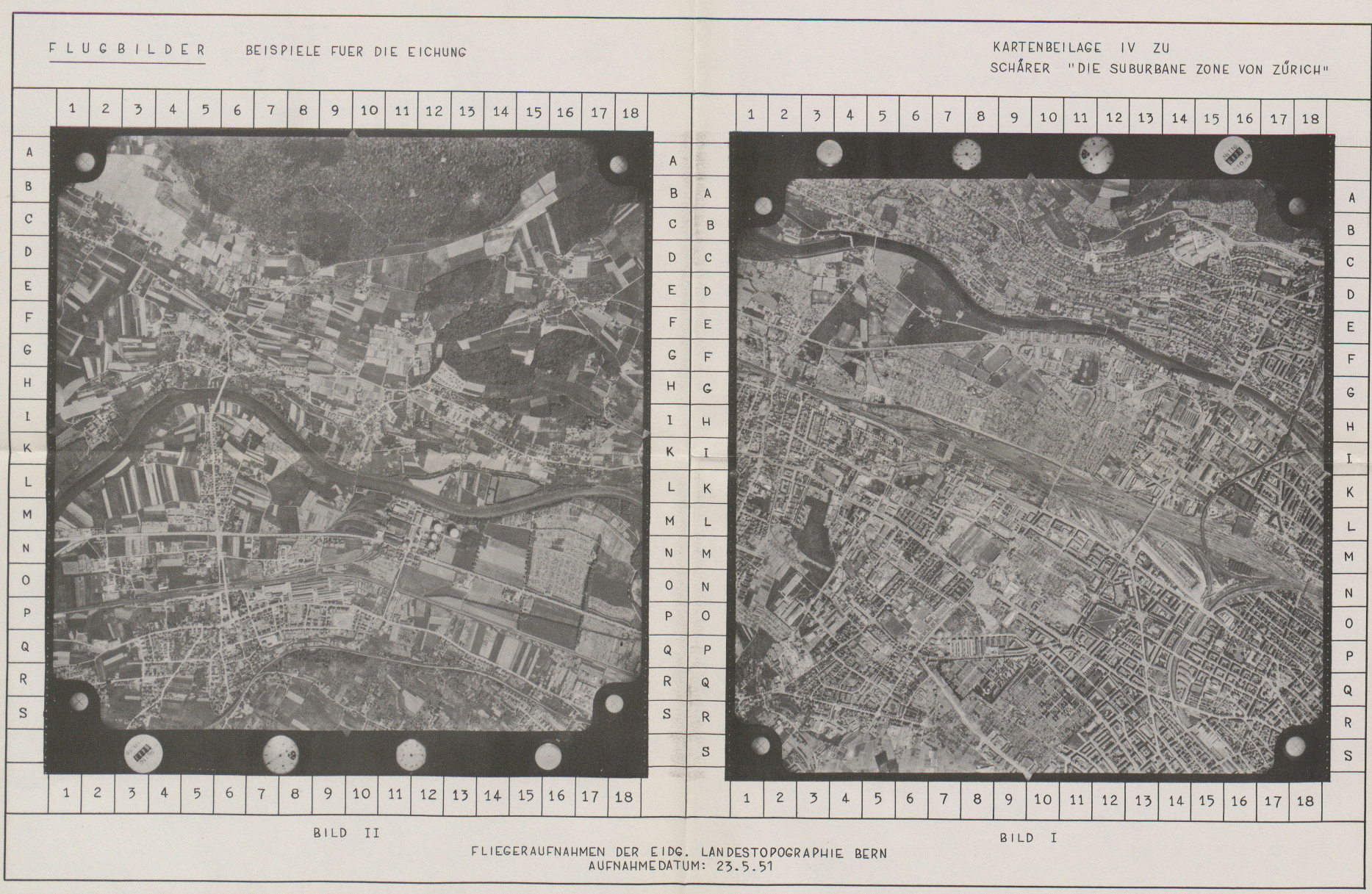




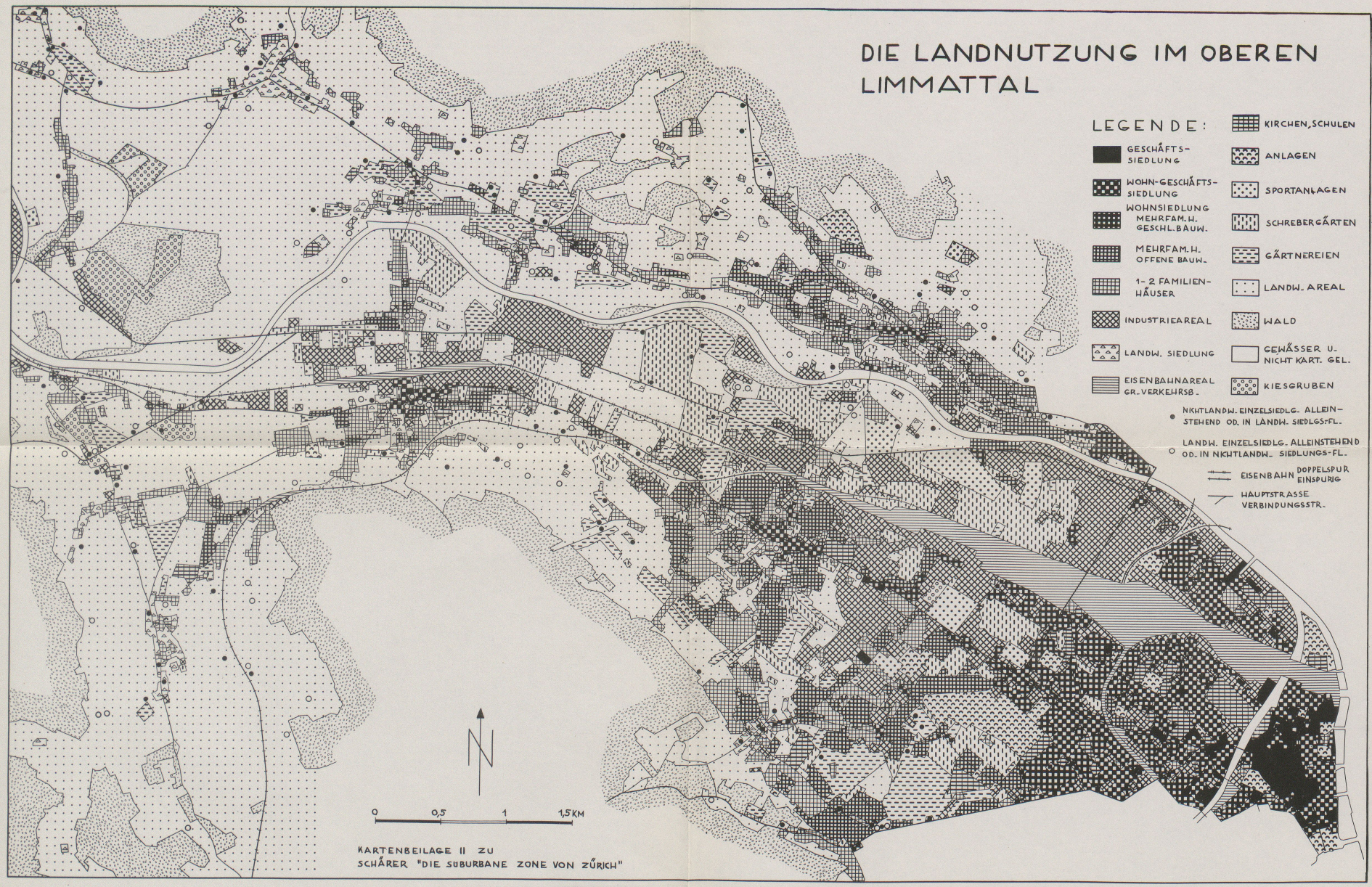




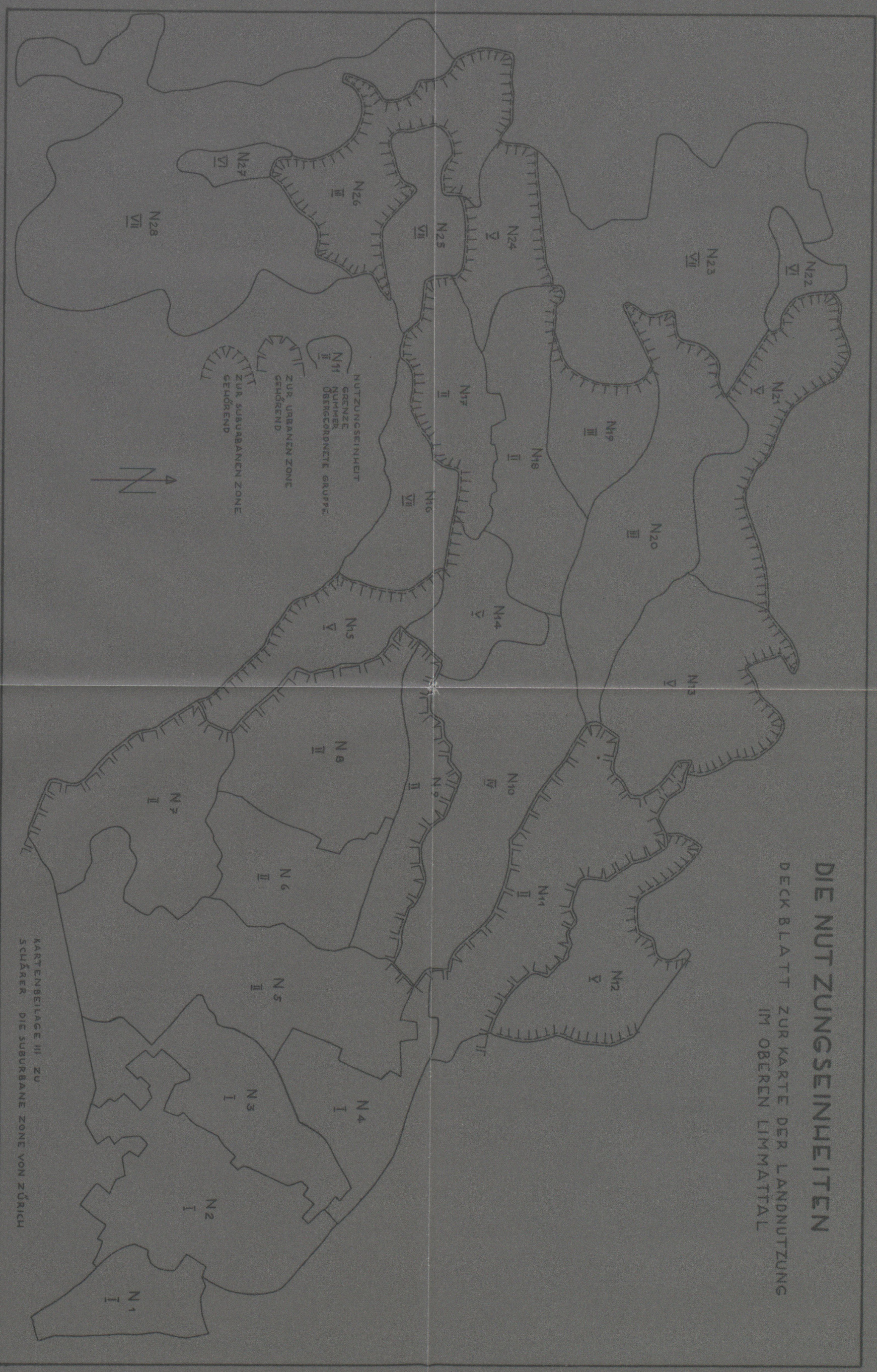




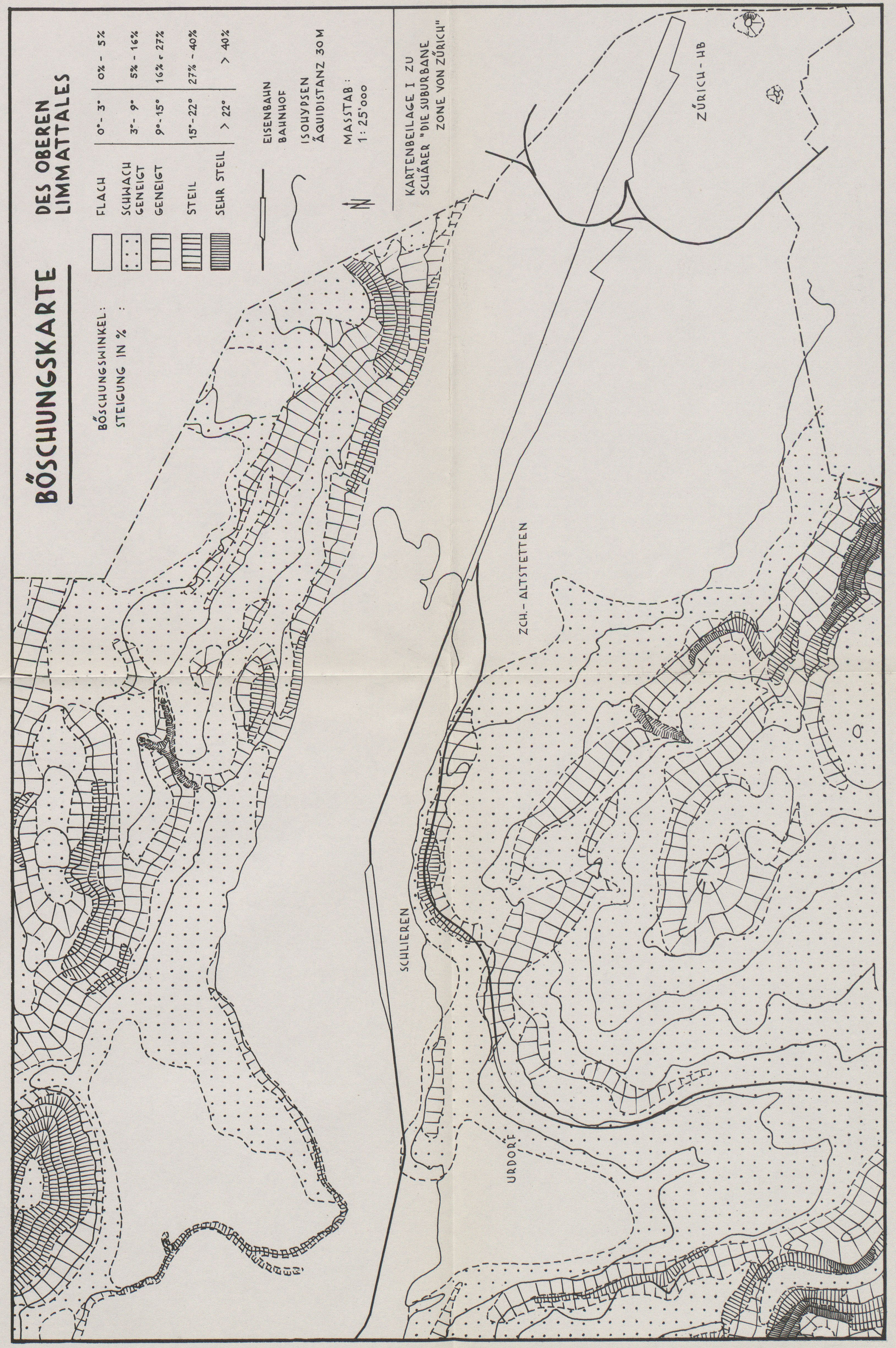

